\title{
ESSAYS IN \\ SCIENTIFIC SYNTHESIS
}

\section{EUGANO RIGNANO}



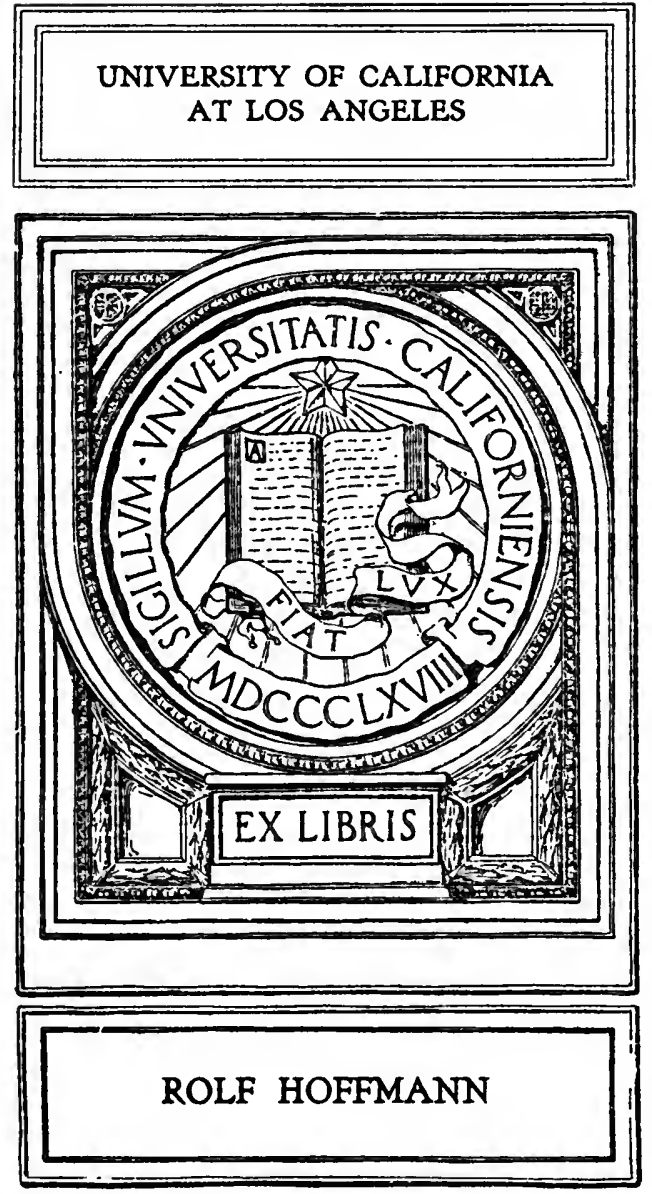


\section{UNIVERSITY of CALIFORIIA}

AT

LOS ANGELES

LIBRARY 
Digitized by the Internet Archive in 2007 with funding from Microsoft Corporation

http://www.archive.org/details/scientificsynth00 rigniala 


\section{ESSAYS IN SCIENTIFIC SYNTHESIS}





\section{ESS A Y S}

IN

\section{SCIENTIFIC SYNTHESIS}

BY

EUGENIO RIGNANO

EDITOR OF " SCIENTIA," THE INTERNATIONAL REVIEW OF SCIENTIFIC SYNTHESIS

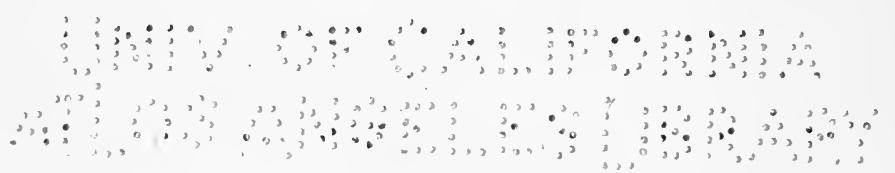

THE OPEN COURT PUBLISHING COMPANY CHICAGO

1918 


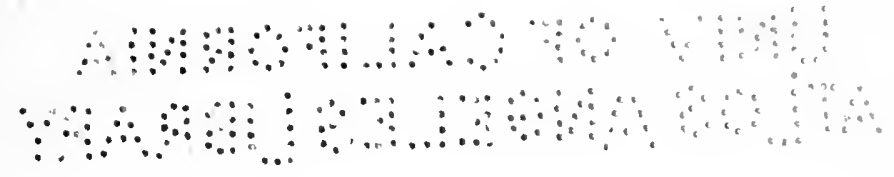

(All rights reserved) 


\section{$P B$
3636
$R 4 E 7$}

\section{PREFACE TO THE ENGLISH EDITION}

THE essays composing this volume have already appeared in various periodicals, such as Scientia, $L a$ Revue Philosophique, La Revue du Mois, the Monist, and also (before the war) in the Archiv für die gesammte Psychologie and the Annalen der Naturphilosophie. They were revised and published in a French edition in I9I2 (Félix Alcan, Paris). Although each of these essays is a study complete in itself, they are connected by one and the same synthetic spirit, and are animated by one and the same object: that of demonstrating the utility in the biological, psychological, and sociological fields of the theorist, who, without having specialized in any particular branch or subdivision of science, may nevertheless bring into those spheres that synthetic and unifying vision which is brought by the theorist-mathematician, with so much success, into the physico-chemical field of science.

It is often said and often repeated that the English are not attracted by broad generalizations, which are too far above reality, and that they cannot, or do not care to, leave the safe ground of facts. Well! it is true that in these essays an attempt is made to reach generalizations of the loftiest scope, and that, too, in those fields in which the need of such generalizations 
is most felt, and in which the attempt is fraught with the greatest risk. But in spite of that I venture to hope that they will be as warmly received in the AngloSaxon world as elsewhere, because each generalization, vast as it may be, is not only based upon the solid ground of facts, but is even, if I may say so, constituted by those countless facts themselves, arranged in such a way that the generalization in question spontaneously springs to light. In this, too, I have done nothing more than follow the example which has been given to us by some of the most famous English writers.

If, then, the very warm reception awarded to these essays in France may be traced to their theoretical and synthetic character, I may venture to hope that they will be received with an equal warmth in Britain and America, when the solidity and magnitude of their empirical basis is realized. And if, in the eyes also of that Anglo-Saxon public, this book succeeds in demonstrating the aforesaid utility of theoretical investigation even in these fields which are of so purely experimental a character, my efforts will be amply rewarded.

Meanwhile, one agreeable duty remains to be discharged : to tender my best thanks to Mr. Philip E. B. Jourdain, to whose suggestion an English edition is due, and to Mr. W. J. Greenstreet, to whom I am indebted for the English translation.

E. R.

Milan, July 1917. 


\section{CONTENTS}

Preface to the English Edition . $\quad{ }^{\text {Pagx }}$

I. The Rôle of the Theorist in the Sciences

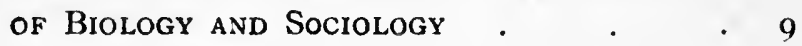

II. The Synthetic Value of the Evolvtion THEORY .

III. Biological Memory in Energetics • . 54

IV. ON the Mnemic Origin and Nature of the Affective Tendencies . . $\quad$. 90

V. What is Conscrousness? . . . . 133

VI. The Religrous Phenomenon . . . I5I

VII. Historic Materialism . . . . . . I88

VIII. SOCIALISM . $\quad . \quad$. $\quad . \quad$. $\quad .216$

Index of Authors Cited. $\quad$. $25 \mathrm{I}$

INDEX OF SUbjects. $\quad$. $\quad . \quad 253$ 



\title{
ESSAYS IN SCIENTIFIC SYNTHESIS
}

\author{
I
}

THE RÔLE OF THE THEORIST IN

THE SCIENCES OF BIOLOGY AND SOCIOLOGY

SUPPOSE a mathematician were to examine all available records of experimental research in physics, and to make himself master of the results reported and described in the literature of the subject. And suppose that he then shut himself up in his study and proceeded to a general consideration of the bearing of those results, in the course of which he modified current conceptions and accepted theories, and broached new theories of his own. Let us further suppose that it were now discovered that this "theorist" had never made an experiment in his life, or that he had never seen, even from a distance, a scientific instrument. The discovery would awaken no comment. Such a carefully finished theory as the mathematician has worked out is made by means of analyses and comparisons, of generalizations and hypotheses, tested and verified by the correspondence of the facts with the results of reasoning. None can question the value and the need of such work, if we are to have a progressive systematization, and are 
to approach an ever-closer synthesis of the confused mass of facts which in a continuous flood are poured forth by research upon the scientific market. Nor will adverse comment be aroused if the physico-mathematician, instead of devoting the whole of his life to one given line of research, turns, on the contrary, from one branch of physics to another with which it seems to have little or nothing in common-from celestial mechanics to the elasticity of bodies, from hydrodynamics to thermodynamics, from electricity to optics. Most will agree that it is just this very synthetic tendency which the theorist brings into such different domains that facilitates his discovery of the hidden characteristics which may be possessed in common by phenomena apparently unrelated, and which thus enables him to construct new and higher syntheses. And we are at once reminded, as a typical instance, of the wonderful synthesis of optical and electrical phenomena based by Clerk Maxwell on theory alone. But if an attempt of the same kind is made by another "theorist" in the domain of the biological and sociological sciencesand more particularly the former-it is quite a different story. There is a general outcry, and he is accused of intrusion, of stepping out of his province. What earthly right have you to speak of biology, if you have never seen a cell in a microscope, if you have never made an experiment on the transmission of nervous currents or on muscular contraction, if you have never analysed a product of the physiological reaction of an organism under a stimulus?

Nevertheless, the useful part that is played in the physical sciences by the theorists, in so far as they 
are mathematicians, may be tried with advantage by other theorists, even in those domains of the knowable which do not lend themselves to the application of the mathematical method. There is not the slightest doubt that this method is a marvellous instrument for the working out of a theory from experimental facts; but it does not in the least follow that it is anything more than an instrument, and it certainly cannot claim to be the one and only instrument which our theorist has at his disposal.

The important thing in working out a theory is essentially the creative act, which consists in detecting new analogies, in proceeding to new generalizations, in opening up new horizons, and in framing new hypotheses. In this respect, the theorist who can employ calculation, and the theorist who is debarred therefrom by the very nature of the object of his researches, are on an equal footing. The former may often be assisted by the contingent resemblance of the formulas into which the two orders of phenomena to be compared may be translated; but the latter, on the other hand, may reap advantage from his unbroken contact with that reality which the complicated symbols of calculation frequently conceal or cause to be forgotten.

The superiority of the instrument at the disposal of the theorist-mathematician appears only later, when it is a question of deducing the consequences of all that has been conjectured, and of verifying in this manner the hypothesis suggested. This superiority consists in the much greater number and certainty of the consequences deduced, and in the much greater rigour in verification made possible by the quantitative 
nature of the phenomena studied. But the superiority is one of degree and not of principle, for mathematical reasoning does not differ substantially from ordinary reasoning.

Mathematics are very far from being necessary and indispensable in every method by which a theory is worked up, and there is therefore no reason to doubt the utility and fertility of theories constructed without mathematical aid in those sciences which, by their very nature, do not admit of the use of calculation.

As in the physical sciences, so in the biological and sociological-and in the former especially-there are many reasons, it is true, why the " theorist " is inferior to the man who has made experiment his special field of labour.

The former does not, in fact, possess an integral and complete representation of the phenomena which constitute the object of his research, and which he knows only by means of the data furnished by the skilled experimenter. What the latter describes and notes of his observations and experiments is but a very small part of all that he has really seen and observed. An infinite number of small details, most of which he has not considered important enough to be reported in his statement of results, and a considerable number of which he has not particularly noticed, constitute, however, a very rich and valuable store upon which he can draw to fill in the framework of the development of the phenomenon. No verbal description, no drawing, no photograph can ever give in all its fullness and richness the brilliant vision which has passed before the eagerly watchful and wondering eyes of the observer. 
The theorist may be compared to a man who is colourblind, who can see nothing but the dry, bare outlines of a landscape filled with light.

Moreover, all the small details of secondary importance which the skilled observer has noticed directly, but which he has not reported, all the attempts that have failed, all the tests and controls which were repeated over and over again before he succeeded in firmly establishing each of his experiments-all that, in a word, which implies an apprenticeship in this or that form of research, and of which nothing appears in his statement of results-all these furnish him with a rich harvest of facts, of the existence of which, however, the theorist must always be ignorant. Thus the theorist in each branch of research must necessarily be in possession of a much smaller number of particular ideas than the specialist; he is much less a master of his subject, and much less sure in his statements as to details.

The theorist, finally, can never put to an immediate test his own theories and hypotheses; he cannot dispel by direct observation the doubts by which he is incessantly assailed, nor can he verify at once the value of his ideas. For every additional observation or experiment he requires he is dependent on the work of some one else-work for which he may have to wait an indeterminate time, and which, even with the best will in the world, can never be carried out by others in perfect accordance with the criteria and conditions which the theorist himself would desire and require. Thus the theorist is often somewhat in the position of the paralytic who can neither grasp nor move at will what lies in 
front of him, and may therefore long remain uncertain as to the accuracy of the impression he has formed of this or that object which he can see but cannot touch.

But if all these conditions place the theorist in a position of inferiority to the experimentalist, there are other relations in which that position is reversed. For if the more schematic and less particularized representations of phenomena possessed by the theorist have their disadvantages, from another point of view their advantages are real and characteristic. They suggest a more abstract conception of phenomena in place of the much too concrete conception which has been impressed upon the mind of the experimentalist by the very length and care of his observations. A scheme is already in itself a generalization of the particular fact; it forms a preliminary synthesis, which thus represents the first and most important step to subsequent syntheses of a higher order.

The theorist in his search for wider and wider generalizations and syntheses does not merely begin his labours, thanks to the more schematic representations from which he starts, at a point in advance of the skilled experimentalist. He is also unhampered by the multitude of individual facts and concrete details which are vividly impressed on the other's mind, so that he is much more free and untrammelled in his path to ulterior generalizations and syntheses.

The theorist has also much more opportunity, and finds it very much easier, to place himself rapidly au courant with the present position of the fundamental questions which are dealt with in the most dissimilar divisions and subdivisions of a subject. Material opera- 
tions do not engage his attention at all ; and by reading for a few hours he can master the results attained by a specialist perhaps after a whole year's assiduous, prolonged, and difficult research. Besides, the technique is so delicate and varies'so much in the various branches of science, and even in the various subdivisions of the same branch of science, that the specialist finds the greatest difficulty in passing from one order of phenomena to another. The very long apprenticeship required by the nature of certain classes of research often leads the specialist to spend his whole life at it. On the contrary, if the faculty of rapidly grasping the essentials of a subject from a study of its literature equally requires a real and characteristic techniquewhich may seem to the skilled experimentalist much easier than it really is-at least it remains constant for all orders of phenomena. That is why the theorist meets with no difficulty as he covers the divisions and subdivisions of even a very wide field of research. It is thenceforth all the easier for him to embrace in a single glance branches of science of the most dissimilar character and with the fewest points of contact, and thus to span the wide abysses by which they are still separated.

It may be laid down, finally, that in general the theorist is less exclusive, less one-sided, and more objective than the skilled experimentalist. The latter, in fact, in his observations and experiments is always guided, consciously or unconsciously, by some idea, some view or hypothesis, which is his own or has been borrowed by him from some one else. Now, the very fact that during a very long time, through all his observa- 
tions and experiments, he is swayed by this single controlling idea, implies that it becomes crystallized, as it were, and transformed into a mental habit strong enough to dominate, readily and inevitably, any contradictory point of view. But the theorist, on the contrary, has a greater opportunity of becoming aware of the most varied and antagonistic points of view, is not delayed in his course by one of them more than by another, gives to each in turn the same time and intellectual attention, and, consequently, is not "polarized" in any particular direction, and does not feel himself irresistibly attracted towards any one standpoint in particular. $\mathrm{He}$ is thus the better disposed to judge calmly and objectively the arguments and objections of both sides, and in this way is often able to extract from the many points of view, which he has examined and found to be all more or less biassed, a less partial point of view of his own, which, consequently, will be more likely to approximate to the reality. Thus the theorist can figure as an impartial judge in those frequent, obstinate, and endless disputes in which the rival schools of specialists seek in vain to score an unequivocal triumph.

Things being so, we can quite understand how the work of the theorist and that of the skilled experimentalist, so far from being mutually exclusive, are really complementary. Moreover, the supreme importance which-far more than in the physical sciences-this action of the theorist in the biological and sociological sciences can and should have, is the more evident as in these sciences the mass of individual details to be systematized is so confused and complicated, and as the sub- 
divisions in separate and more or less autonomous subjects are so numerous and so specialized. The more this is realized, the more keenly is felt the need of co-ordination and synthesis in these sciences. This is proved even more effectively and thrown into broader relief by the following instances, which I have selected merely for the purpose of illustrating my argument.

Let us, for instance, take the question of vitalism. In the long run it must reduce itself to the acceptance or denial of the possibility of the reduction of the vital phenomenon to some already known physico-chemical " model," suitably modified by certain special additional conditions, which determine exactly in what this vital phenomenon differs from the phenomenon nearest to it in the inorganic world, and which thus reveal the fundamental and peculiar properties of life.

But has the question ever been set in such terms as alone are capable of restraining it within its real limits ? It has not! The biologists are divided into two diametrically opposite camps, equally opposed to any compromise. Some eagerly deny all possibility of ever understanding the nature of life, even by the medium of remote analogies with the inorganic world, however suitably modified and transformed. Others, on the contrary, refuse to allow that life possesses any peculiar property apart from the properties, known and wellknown, of the physico-chemical world. It is evident that there is exaggeration on both sides, and this must be so, because the question has been dealt with only by specialists, and therefore never with real impartiality.

The physiologist-chemist whose special technique brings him into contact only with the pure and simple 
phenomena of transformation which take place among the different organic substances, such as already exist or are produced in the already formed and functioning organism, sees but this one small side of the functions of the latter. Just as a man with intensely blue. glasses can see none of the other infinitely numerous colours before his eyes, so the physiologist-chemist, because of the very technique he employs, can see none of those other phenomena of life which are developed in the organism at the same time as the purely chemical phenomena. And the more closely he succeeds in following one after the other and in detail the successive stages of a given complex process, the more certain is his conviction that he is finding in chemistry an explanation of the whole of life. In this line of argument he forgets that, even in the narrow circle within which his technique is confined, the intimate vital phenomenonproducing certain exchanges rather than others which from the purely chemical point of view would be equally possible-that phenomenon completely escapes him. It is just as if a chemist, who happens to be ignorant of the existence and properties of the electric current, were to consider that his knowledge of the phenomenon of electrolysis was quite complete because he finds that the products obtained may be atomically derived from the primitive compounds originally employed.

Opposed to this is the one-sided tendency which considers it impossible to explain the vital phenomenon, and therefore necessary to appeal to a mysterious something, which is more or less directly or indirectly connected with the ancient conception of a spiritual soul detached from the material body, and which thus 
digs the deepest and most impassable abyss between the organic and inorganic worlds. This tendency is usually manifested in the other specialists, who take as their subject of study only those phenomena of life which are remotest from physico-chemical phenomena. Instances in point are ontogenetic development, during which that wonderful "machine" of the organism builds itself by its own activity; or, again, subjects of a psychical order, from the simplest instincts to the loftiest phenomena of thought, all processes in which the "finalism" of life appears most evident-that "finalism" of life which has on the contrary been almost ignored in physico-chemical research.

The middle course would consist in asking first of all if life may not be due to some special form of energy with its own characteristics, just as in the case of the different forms of energy in the inorganic world, and then in setting to work to find out, by means of successive modifications in one or another direction of some suitably chosen physico-chemical model, what characteristics of vital energy are partly like and partly unlike those of the model chosen. This course can be followed only by the man who can take into equal consideration all the biological phenomena, both those which closely resemble this or that other process of the inorganic world, and those which have no resemblance to such processes. No order of phenomena must be neglected, for each will show some feature of peculiar interest, which will help in bringing to light one or other of the elementary and fundamental characteristics of life.

The relations between physiology and morphology, for instance, must be studied with the object of dis- 
covering, not only how the morphological and chemical structure determines this or that function or specific physiological activity-a question in the domain of physiology, in the narrow sense of the word-but also, and principally, how this or that function, this or that specific physiological activity, determines the morphological and chemical structure. This also implies the study of all the phenomena known as phenomena of " adaptation," and indicates a line of research which is still too much neglected by the specialists. The phenomena of development, of regeneration, and the like, according to which the organism is "self-reproductive" -comprising in this wide order of research all that has been called the "mechanics" of development-will be compared with the physiological phenomena presented by the "organism machine" already formed, and especially with the phenomena of " adaptation " just mentioned, because in ontogenetic phenomena also we have in the long run to do with processes which determine the morphological and chemical structure of the different parts of the organism in the course of its formation.

But these phenomena of development, if once the transmissibility of acquired characters is definitively placed beyond a doubt, are indubitably and intimately connected with the mechanism of that transmission; it is even clear that they are nothing more than the resultant, the product, of the action of that mechanism. On the other hand, once this mechanism of transmission exists, and whatever may be its nature, it cannot be in the long run anything but a process of reproduction by internal causes of given structures or corresponding 
physiological states, already determined in the past by the external world. It is therefore appropriate to compare it-passing from biology to psychology-to mnemic evocation properly so called, which in the same way is a process of reproduction by internal causes of certain peculiar physiological states of the brain, constituting the "sensations," and also determined in the past by the external world.

The vague analogy which is thus manifested between the phenomena of ontogenetic development by means of the transmissibility of acquired characters and the psycho-mnemic phenomena compels further research in an entirely new domain, which has been only recently investigated, that of the psychology of the inferior organisms, and in another which has been entirely reconstructed during the last few years, that of vegetable physio-psychology. We must see if this mnemic property is really manifested, and with what peculiar modalities, by the inferior organisms deprived of nervous system and by the plants themselves. Jennings was the first to succeed in doing this in the lowest pluricellular organisms and also in unicellular organisms; Francis Darwin, Haberlandt, and many others have verified it in the case of plants.

This leads to the suspicion that the mnemic property is more general than we have hitherto had any reason to suppose, and then we are forced to return to the above-mentioned phenomena of "adaptation" in general, and to inquire if the phenomena which result from "specialization" of tissues, from cellular or nuclear "somatization," the inevitable sequel of this or that sufficiently prolonged functional habit, would 
not also be nothing but other different aspects of the same mnemic property. We are thus brought to a new and careful revision of all phenomena which have a "finalist" aspect-from the morphological and functional "Zweckmässigkeit" [finality] of the organism and of the ontological development to the instincts and even all the psychical facts of the highest orderto see if they also cannot be reduced, more or less directly or indirectly, to this very general tendency to reproduce, by internal causes, given structures and given physiological states, already determined directly by the external world in a more or less distant past. This would reduce finalism itself to a mere derivative from the mnemic property, which would thus be raised to the rôle of a fundamental property of life.

Assimilation, finally, is itself in the long run nothing but a process of continual reproduction, by which the specific substances destroyed in the period of functional activity become reconstituted, perfectly identical, in the subsequent period of functional repose (Claude Bernard). And it is also a phenomenon at once chemical and physical: a chemical phenomenon in so far as given nutritive substances come to form others of a different chemical composition; and a physical phenomenon in so far as very delicate investigations have recently seemed to show the intimate dependence of the process of assimilation on given and essentially specific physical conditions-as, for instance, this or that group of spectral rays with a well-determined vibratory period in relation to the specific metabolic process of this or that tissue or of this or that microorganism. Thus research will be carried into the very 
frontiers of biology, chemistry, and physics, with the object of discovering what analogies and what relations exist, on the one hand, between the mnemic property and assimilation, and between assimilation and certain phenomena of a chemical and physical order on the other.

These very rapid considerations will, I think, suffice to show how, at the very outset of an investigation of the question of vitalism and of the problem of the discovery of the most elementary and fundamental properties of life, we must enter the widest and most dissimilar fields of an all-embracing biological and psychological research. But if, in the sequel, these elementary fundamental properties of life, of which we have thus caught a glimpse, should be considered in their turn as depending upon some still more elementary energetic property belonging to a quite special form of energy at the basis of life, then, before we can construct the most appropriate "model," we must extend the field of research still further to all the phenomena of the physical world.

Thus it is clear that the theorist, and the theorist alone, can succeed in embracing so extensive a field of research, and that, consequently, he alone can properly approach a question so fundamental and problems of such extreme difficulty.

If $I$ have said so much on the question of vitalism, it is because it is perhaps the most typical and the most suitable subject to illustrate the task that the theorist must undertake, even outside the inorganic sciencesa task which is not merely useful but indispensable. But the same conclusion follows from the considera- 
tion of any other question, which by reason of its very generality embraces numerous subdivisions of the same branch of science, or still more, embraces several branches simultaneously.

The affective tendencies, for instance, which underlie all the fundamental psychological phenomena, from the attention and the will to even the loftiest mental processes, form by their origin and nature the closest link between physiological and psychological phenomena. Some of them, such as hunger, the sexual need, and the like, seem to belong almost exclusively to the domain of physiology; others, such as what we call the higher aspirations, seem on the contrary to come within the province of the psychologist. However, it is clear that the nature of the one group must be identical with that of the other. Hence, neither the pure physiologist nor the pure psychologist can understand their origin and nature. Such a study is possible to the theorist alone, for he can embrace within a single glance the whole of both domains.

And so in the case of consciousness : the psychologist, in the narrow sense of the word, i.e. the man whose appropriate technique consists solely in introspection, can never understand the nature and determine the conditions of consciousness. The phenomena, in fact, with which he is provided by his technique are never anything but conscious phenomena. The reason why the very same acts, the very same associations of ideas, the very same processes of reasoning, may be conscious at one time and unconscious at another, will be as impossible for him to discover as if he were a meteorologist, living in a valley in which it does nothing but 
rain, and trying to discover the conditions which determine at one time fine weather and at another bad: to effect his purpose he must of necessity leave the region of perpetual rain. Just in the same way the psychologist must get out of the region of conscious phenomena, and must therefore embrace a much wider field than that in which his own limited technique is effective.

The religious phenomenon, in its turn, has always been considered with a bias. Sometimes it is viewed from a purely psychological and sometimes from a purely sociological point of view. The result has been that psychologists, both those of the English " animist " school of Tylor, and those who belong to the school which has adopted Höffding's doctrine of the conservation of values, have completely missed the meaning of social significance and function; while the sociologists, as, for instance, those of the new French school of Durkheim, who have thrown into such bold relief and who have studied with such penetration the social side of the phenomenon, have shown themselves quite incapable of accounting for the process of formation of the intellectual and affective mentality of the believer. Neither psychologists nor sociologists have perceived that the elementary phenomenon itself, around which the immense scaffolding of religious beliefs and institutions has been organized and developed, is in its essence a phenomenon that is both psychological and sociological.

Similarly, the debate in the sociological domain between the champions and the adversaries of historic materialism has never been carried on impartially. We may venture to say that the expert economists have seen in the whole aggregate of sociological 
phenomena nothing more than the economical phenomenon, which they have thus raised to the rank of the supreme and only factor in the whole of social evolution. Lawyers and "ideologues" in general, each studying only law, or only ethics, or only some other order of normative phenomena, have awarded a no less excessive importance in the social determinism to the ideological factor, that is to say, to their phenomenon. The very tendency to bias with which the discussion has been carried on by both sides has prevented both from establishing the exact share of the two great factors in the struggle, the legal and the economic.

Finally, in the economic field itself, there is the fundamental antithesis between socialism and liberal economics, which, in the narrow domain to which the respective experts have restricted it, seems to be utterly insoluble. But it ceases to be so from the moment they leave this narrow domain and take cognisance of the supreme legal phenomenon of the law of property and of its different possible forms. Not till then can they state more clearly the terms of the question at issue, and acquire a wider conception of the different contingent ways in which the problem may some day be solved.

In this preface I have done little more than indicate a few examples. They will be more fully developed in the essays which I have collected together in the present volume. They will, I hope, serve to show the value of the function which, even in the biological and sociological sciences, the theorist may exercise in questions which, from their very generality and importance, emerge from the necessarily restricted domain of the specialist. 
I hope that they will be followed by an increasingly cordial and intimate collaboration between specialists and theorists, the former ever following with interest the work of the latter, borrowing new ideas to test, and new directions to give to their own researches; the latter, in their turn, obtaining from the former an unfailing supply of facts and of insight into things, of the greatest value for fixing and consolidating their own views or for suggesting new ideas and new systematizations. Such an intimate and cordial collaboration will, in a remarkable manner, enable the failings of the one to neutralize the failings of the other, and of itself will lead to a very rapid development of the biological and sociological sciences, which at the present moment demand, even more than the physico-chemical sciences, this very work of co-ordination and synthesis. 


\section{THE SYNTHETIC VALUE OF THE EVOLUTION THEORY}

THE theory of biological evolution or the transformation of species has always exercised a powerful attraction upon minds of the synthetic order. No other theory, perhaps, has succeeded in bringing into one general survey so many disparate phenomena, and in coordinating in one complete complex the numerous individual theories which hold their own in widely differing branches of science, and which, at first sight, seem to have nothing in common. It is just this synthetic power of the evolution theory in the sphere of biology that I propose to throw into relief in the following pages.

It is a matter of common knowledge that the French zoologist Lamarck, at the beginning of the nineteenth century, was the first to propound a complete theory of the transformation of species.

He suggested that continual change of environment leads to change in the requirements of living animals, and that the change of effort made to satisfy the new requirements produces in each species appropriate morphological modifications.

As these modifications are transmitted to descendants, 
and as the modifications acquired by each generation are added to those acquired by its predecessors, it follows that each species must be gradually transformed into another species, and that in this way we may suppose all living species to have been evolved.

It would take too long to dwell on the reasons why this theory was not welcomed as it deserved by the scientific world of the day. Perhaps the time was not yet ripe for it. It is certain that the preponderating influence of Cuvier, who obstinately clung to the doctrine of the fixity of species, was responsible for the opposition. Lamarck's theory was much discredited by the misinterpretation of his assertion that effort, and therefore the will, was the cause of transformation. Many gave to this statement a metaphysical interpretation, as if the species themselves consciously proposed or decided upon their own transformation, although the author very clearly speaks in numerous passages, and almost in the very terms we use to-day, of the trophic and atrophic action of the use and disuse of the organs and of the transmission of the effects of that use and disuse. But what did his doctrine most harm of all, and rightly so, was the insufficiency of facts in support of his theory.

For these or other reasons, Lamarck's theory, which attributed to the transmissibility of the acquired morphological modifications the essential rôle in the evolution of species, while it scarcely mentioned natural selection except in a few vague and unimportant sentences, remained for a long time almost ignored.

Darwin's famous volume on the origin of species, which appeared towards the middle of the last century, 
was welcomed at once by the majority of his scientific contemporaries, and in a short time absorbed the attention of the scientific world.

It was certainly an advantage for Darwin to have at his disposal in support of his theory the whole body of English experiments in artificial selection in the plant and animal worlds, and in the uninterrupted creation of new varieties from a few initial domestic races. Further, as we know, Darwin was directly inspired by the volume which the economist Malthus had written on population. Now, this book had given rise to the bitterest polemics, and one result had been that the British public had been made already familiar with the ideas of the struggle for existence and natural selection. This naturally was of the utmost value in the diffusion of Darwin's teaching.

This is not the place to write a history of the doctrine of the evolution of species. It is sufficient to remember that Darwin did not deny the effects of use and disuse, but as factors in transformation he considered them of secondary importance, and laid stress on the selective factor alone. And thus it came about that although Darwin never mentioned the name of Lamarck, the French zoologist was drawn from his temporary oblivion and compared to, or rather contrasted with, the English naturalist, because he had, on the contrary, neglected the selective factor, and had pronounced the one only important factor to be the transmissibility of acquired modifications.

Through this antagonism Lamarck reaped no small advantage from the notoriety his rival had obtained. Hence arose the two schools, the Neo-Lamarckians and 
the Neo-Darwinians, which, as we know, are still at daggers drawn, the latter holding to the selective factor only, and the former recognizing exclusively the factor of transmissibility.

I propose to show how the evolution theory, either alone or aided by the clash of Lamarckism and Darwinism, has played and continues to play a rôle of synthetization on a scale unrivalled hitherto by any other doctrine.

To start with, it is easy to see that the mere affirmation of the evolution of species was already in itself a vast synthesis, independently of the factor selected as of most importance in transformation.

All living organisms seemed to form one huge family. Man, the darling of creation, was now leaving his proud pedestal to descend to the humble level of the other animals. The differences between animals and vegetables, i.e. between the beings considered to be animate and those considered to be inanimate, now lost in their turn all appearance of true diversity.

Is there any synthesis of the inorganic world vast enough to be compared to that which was thus accomplished in the organic world by the evolution theory? The answer must probably be in the negative. Even the theory of universal gravitation has not yet succeeded in embracing under one and the same aspect all the forces of the physical world; the forces of capillarity, for instance, and those of chemical affinity are as yet outside its sphere. And concerning the chemical elements, we are only now scarcely beginning to suspect that they are so many varieties or modes of being of one and the same substance. 
However, when the first blinding glare, so to speak, provoked by the brilliance of so powerful a synthesis had faded away, men began to observe and to analyse the content of this new doctrine. This patient examination sent their minds in widely different directions to new research for the purpose of verifying the postulates or the most important and immediate deductions from the theory. At the same time it became necessary, for the support of the main hypothesis, to create subsidiary ulterior hypotheses, which, being all attached to the vast trunk of the evolutionary theory, have thus connected one with another the most divergent branches of the whole science of biology.

It will suffice to select a few of the most characteristic examples. Darwin held that natural selection must be exercised on the quite fortuitous variations presented, not only by individuals of the same species or variety, but also by the issue of the same pair of parents. Hence attention was focused upon these individual differences.

Well! it is difficult to imagine the importance to biology of this new field opened to observation and research.

Even a casual notice of the differences which distinguish the brothers of the same family would have been sufficient to reveal the striking phenomenon to which Galton gave the name of "particulate" inheritance-an expression which may be rendered by the following periphrasis: the autonomous and isolated inheritance of different peculiarities.

A child, for example, may have its father's eyes and its mother's mouth. Galton concludes that these 
two characteristics must have had a distinct origin, and that the causes which determined their appearance must have been exercised independently of each other. The phenomena of atavism, the characters of hybrids, the facts of spontaneous variation, were later added to the trivial observations that any one can make in his own household, to show that even the most minute characteristics may appear or disappear, may vary, may be inherited from the father or the mother, and each quite independently of the rest, i.e. without seeming to have any relation to the variability or invariability of the other characteristics.

So striking a phenomenon demanded an immediate explanation. Preformist germs were invoked. It was suggested that each of these characteristics, varying and being inherited independently of the rest, was represented in the mass of the germ or seed corresponding to the whole organism by an infinitely small germ or seed, distinct from the infinite number of germs or seeds belonging to the other characteristics. Darwin's gemmules, Galton's germs, the pangenes of De Vries, and the determinants of Weismann are, in fact, so many different names given to these preformist germs.

Thus we see the transformist doctrine caused observations to be brought to bear upon a fact which has nothing uncommon about it, but which had so far been completely neglected; and this observation immediately led to nothing less than an hypothesis (the question is not if it be sound or unsound) on the constitution of the germ.

But this is not all ; from its very nature the preformist hypothesis of the germ led inevitably to another 
still more remarkable and fruitful hypothesis, that of Weismann on the continuity of the germ plasm.

Darwin, in fact, admitted that each cell of the organism, whether developed in the course of heredity or acquired after the development of the individual in consequence of some new functional adaptation, produced its own gemmules, and that these, circulating afterwards in the blood, were collected in the reproductive organs considered as simple glands of reception and emission of the germinal substance. Galton tried the infusion of blood from one breed of rabbits into another, and finding that none of the offspring of the latter acquired any of the characteristics of the former, he proved that this circulation of the gemmules has no existence in fact.

Hence he supposed that the germ plasm is formed of an infinite number of different gemmules, each of which would produce an infinite number of other gemmules similar to it and incorporated with it in the protoplasm. At the beginning of the development, only a small number of this innumerable multitude of gemmules is transformed, each into a cell, and takes part in the formation of the body or soma ; the rest, which Galton called the stirp or stock, sets itself aside, and is subsequently utilized in the constitution of the future germ plasm of the new organism.

It will be seen that this hypothesis is in the main almost identical with the famous hypothesis of the continuity of the germ plasm which Weismann in his turn was to propound as the result of further more accurate and detailed elaboration.

We need not be surprised at the interest, I might 
almost say the enthusiasm, with which ,Weismann's hypothesis was received.

As far as the development of organisms is concerned, the biologist had, in fact, to solve the problem of two deep mysteries: how the microscopic morsel of matter which constituted the germ plasm could determine in its smallest details an organism so complex às that, for instance, of a vertebrate, and how in its turn such an organism could form anew this tiny morsel of matter endowed with the same astonishing properties.

The hypothesis of the continuity of the germ plasm accounted for the second of these great mysteries. It suggested that it is not the organism that forms anew its germ plasm, but it is the germ plasm which, continuing to grow, is maintained and transmitted from one organism to another without qualitative alteration, and that from it small portions are one after the other detached to form successive generations. These generations are not mothers and daughters, but sisters.

It is readily imagined what a ray of light this continuity of the germ plasm was to throw upon the mystery of generation.

Suppose, for instance, we have two very complicated solutions, each in chemical equilibrium, but of such a nature that if they are mixed and the mixture is warmed at a given temperature, the most varied and complex reactions are produced between the different substances. First we notice certain precipitates of a certain type, and then others of a different type; the precipitates which are formed the first will perhaps later disappear, while the liquid, colourless at first, 
may become coloured, and these colours may give rise to other colours, and so on, so that before the changes cease the liquid has passed through transformations of the most varied and interesting character.

If in the course of the experiment we have used the whole of the mixture, it will be hardly possible to reproduce the series of the same transformations. After all this disturbance, it is, in fact, hardly possible that the liquid will now return to its initial condition, because that would require such an aggregate of fortuitous favourable circumstances that its probability must be regarded as infinitely small. And if a chemist were to show us that nevertheless this is what really does happen, that, if we take a portion of the liquid which has already been through its very complicated series of transformations, we find it identically repeats them, the fact will appear to us so surprising and so inexplicable that we shall be amazed and perplexed.

But light breaks in when some one shows us that we have been duped, that the liquid which repeats the series of transformations is not the liquid we used at first, which had gone through the series of transformations and returned to its primitive condition, but on the contrary that it is another portion of the original mixture which has been hidden away, and is now for the first time heated by our juggling chemist to the same temperature as the former portion.

The doctrine of the continuity of the germ plasm has had the effect of a similar ray of light piercing through deep shadows, and this is sufficient to explain the immediate interest it aroused and the enthusiasm with which it was received. 
But what is the unforeseen consequence of this theory?

If the rest of the protoplasm, which remains after the tiny portion has been separated for the purpose of forming the new being, is lying latent in the soma and remains unaltered until the moment it is to form the sexual cells of the now adult organism, then the modifications, whatever they are, which the latter must undergo, i.e. the characters acquired after birth by the individual as the result of some new functional adaptation, will not affect the protoplasm. That, at any rate, is the conclusion which seems to hold good. And therefore these acquired characters are not transmissible to following generations.

So we see how Neo-Darwinism or Weismannism came into existence. It absolutely repudiates that transmissibility which was the essence of the teaching of Lamarck, and which Darwin himself confessed must be accepted, although he considered it of secondary importance. Neo-Darwinism is thus compelled to give to natural selection, the other factor in evolution, an exclusive rôle.

The extreme importance thus attributed to the struggle for existence and to natural selection, the wide diffusion of the brilliant essays and vigorous polemics of so great a dialectician and so formidable an antagonist as Weismann, and the considerable prominence they gave to his theory, had an immediate effect in the domain of social science as well as in that of histological biology. Thus it was that one and the same synthetic bond united certain phenomena of cells and tissues to the analogous phenomena of human societies. 
The sociologists will tell us that it is not only the individuals of different species that engage in a struggle for existence. Every homogeneous group of individuals also struggles for existence, or for a greater intensity of existence, against every other group, equally homogeneous, but different from the first. So the struggle of the brute against the brute throws a sinister light on the Marxian struggle of classes. And it is no longer the different homogeneous groups alone that are engaged in the struggle, but the social groups themselves, which, even if heterogeneous, nevertheless for territorial or other reasons constitute distinct units. War, vital competition between peoples, the birth and decline of civilizations, and social evolution as a whole thus appear to Kidd, the Neo-Darwinian sociologist, as so many aspects and so many consequences of the universal struggle for existence and of natural selection between societies.

And, as Wilhelm Roux will tell us, the struggle for food is not only between individuals but between all the different parts of the body of the individual The different organs of the same organism, the different tissues of the same organ, the different cells of the same tissue, and the different parts of the same cell are all engaged in this mutual struggle.

Thus the atrophy and hypertrophy of organs, tissues, and cells are also in their turn reduced to episodes and to different aspects of the Darwinian struggle for existence.

We see that Roux's doctrine of the struggle between the parts of the organism at once involves a generalization of the idea of the living being. It is not only the 
organism that is alive, but every organ is alive, every tissue, every cell, and even the minutest parts of the cells. Thus emerges the idea that minute portions of homogeneous, amorphous, and apparently structureless substances may be endowed with life; and we are thus led to inquire: What is life ? what are the characteristics according to which we assign to a given mass of substance, large or small, the epithet "living"?

This question, the most fundamental in biology, the very problem of the essence of life, joins in this manner with the other no less fundamental question-thrown into relief by the doctrine of the struggle for existence-of the irresistible tendency of life to extend itself beyond the limits assigned to it by the conditions of the moment. On the other hand, this irresistible tendency of life to expansion explains how so frail a flame still burns in the world in spite of the innumerable dangers that threaten its existence.

It is needless to remark that this simple question. What is life? is the incessant stimulus to all physiologists ; it spurs them on in their researches, although they are still so uncertain of the direction they should follow that they seem to be merely groping amid the deep shadows of the great mystery. And transformism in its turn gives a new and powerful impulse to these researches. If it allows, in fact, an ascent from the most perfect species to the earliest of all, to simple unicellular types, to the very simple infinitesimal monads, why place a limit to this bold ascent, and not go farther and pass from the organic to the inorganic?

All researches and theories on the chemical ferments, on organic ferments, on colloids the whole of organic 
and physiological chemistry in general, thus receive a fresh impulse to the eager desire to discover that passage from the inorganic to the organic, the possibility or impossibility of which is the subject of the age-long struggle between vitalists and materialists.

The assertion that the struggle for existence is the sole factor in evolution must give, as we have seen, great importance to those individual fortuitous variations which constitute, so to speak, the raw material on which selection is exercised.

Research into these hereditary variations, which depend on amphimixis receives a stimulus which, on the one hand leads to the discovery of the phenomenon of particulate inheritance and to the theoretical consequences I have examined above, and on the other raises the question of the significance, or of the why and wherefore, of sexual reproduction. It is asserted that sexual reproduction is in itself a cause of great variability, for children, as we have seen, in very different ways and proportions inherit at random the characteristics of their parents, or of maternal or paternal ancestors. Weismann even goes so far as to see the whole raison d'être of sexual reproduction in this multiplication of individual variability to which it would give rise. The discussions which have taken place on this subject throw into relief the as yet unsolved problem of the nature or rôle of fertilization. Thus they give the opportunity for a closer investigation of the relations existing, particularly in unicellular organisms, between fertilization or conjugation on the one hand and the phenomenon of rejuvenation on the other. They suggest, moreover, to Loeb his 
interesting experiments on artificial fertilization, in which the action of the spermatozoid is replaced by that of certain chemical substances, and parthenogenetic developments are produced in species in which this mode of reproduction never takes place in normal conditions.

These hereditary variations depending on amphimixis give in particular a great impulse to all research on crossings in general and on the hybrids derived therefrom, with the object of establishing the possibility of creating new species. Minute observations on hybrids lead in their turn to the discovery of certain numerical laws, known as Mendel's and Galton's laws, relative to the manner in which the characteristics belonging to each of two crossed species or varieties appear in the offspring and in the succeeding generations. And these numerical laws, which require for their explanation the calculus of probabilities, afford to mathematics its opportunity of making an unpretentious entrance upon the scene.

At the same time, these numerical laws of hybrid inheritance, because of this very'interpretation provided by the laws of probability, also contribute to the progress of research in the problem of fertilization, and even open up new lines of investigation in this subject. Here the field of research is extended in the most unexpected manner.

Research has already begun and discussion has opened on the respective degrees of importance to be awarded, in the hereditary transmission of characters of the species, to the egg and the spermatozoid, to the protoplasm and the nucleus. Experiments have been made 
on the fertilization, by the spermatozoid of one species, of the enucleated protoplasm of an egg of another species; on the fertilization of an egg by two or more spermatozoids of a different species; on the development of isolated blastomeres, from which the biologists have succeeded, by the aid of these multiple fertilizations of the egg and of the subsequent triple or quadruple first segmentation, in taking away a certain number of chromosomes; and so on.

We find as the outcome of all these experiments that the importance to be attributed to the chromosomes of the egg and of the spermatozoid in relation to hereditary transmission goes on steadily increasing. It is known that the chromosomes are met with not only in the egg and in the spermatozoid but also in all the other cells. They are, in fact, the famous rods in which the nucleus is collected and divided immediately before the cellular division, and which, each splitting longitudinally at the moment of the division, are doubled in number and are subsequently divided in equal proportion between the two daughter-nuclei. These chromosomes, as we know, vary in number with the species, but are constant for each species, i.e. are always in equal number in the cells of all the tissues of the body, the egg and spermatozoid not excepted before they are mature.

It is not yet known in what this maturation consists. Some light may be thrown upon the subject by the new process known as synapsis, discovered and studied during the last few years, in which the chromatin, i.e. the substance of which the chromosomes of the mature egg or spermatozoid are later constituted, goes through 
the strangest and most mysterious evolution. Does this phenomenon of synapsis mean that the real and appropriate germinal substance penetrates from without into the cell which, previously simply somatic, now first becomes really germinative? And, going back to a convenient modification of an old hypothesis due to Darwin, does what we call the maturation of the reproductive cells consist in this reception of the germinal substance, produced at some point of the soma exterior to the sexual organs?

The fact is that after synapsis both the egg and the spermatozoid undergo two successive cellular divisions, one of which is called the reducing division, because it reduces the number of the chromosomes possessed by the egg and the spermatozoid to exactly half the normal number. It might be said that the object of this reducing division is to secure that the normal number of chromosomes remains unaltered in the fertilized egg when the male and female nuclei are brought into contact by fertilization.

Now, when the egg has been fertilized by a spermatozoid of different species, it sometimes happens that the chromosomes of the two species which, during the act of fertilization, have apparently blended to form a nucleus in the state of repose, reproduce themselves, when the first segmentation of the egg begins, in such a manner that those of one group reappear distinct from those of the other in size, shape, or other character, each group retaining the characteristics of the species from which it springs. At other times the chromosomes of the two species never fuse, and retain, even during and after fertilization, their form of rods, each group 
keeping the characters of its species, in this case more easily than in the former. In both cases, we can follow these distinct chromosomes in the blastomeres to which the first segmentations of the egg give rise. Some investigators nowadays give themselves considerable trouble in trying to discover if it is possible to find the traces of the two varieties of chromosomes in the egg or in the spermatozoid emitted by the hybrid. They hope that if it were possible, in spite of the disturbance due to synapsis, to follow the behaviour of these varieties of chromosomes in the reducing division which takes place at the end of the maturation of this egg or of this spermatozoid, it would throw much light on the numerical laws of Mendel and Galton to which I have referred.

This hope implies two suppositions which are opposed to other suppositions perhaps more likely to be true.

In the first place, it implies the hypothesis that it is not at the moment of maturation, nor from any region of the soma external to them, that the sexual cells receive their germinal substance, but that it is received directly from the egg in the course of successive divisions.

In the second place, it implies a tendency to attribute undue importance to the size, shape, and in general to the external appearance of the chromosomes. This, in fact, suggests that as long as the external appearance remains the same, the internal chemical composition of the chromosomes, on which will evidently depend all the fundamental physiological properties, must in its turn remain identical. But the external form is probably nothing but an ordinary framework deter- 
mined in shape and size by the quite accessory circumstances of the cells, on the surface and within the interior of which are laid down the specific substances, infinite in number and of the most variable chemical composition, of which such a complex mixture as chromatin in the living state is composed-a mixture which has so far defied chemical analysis. It is in just the same way that in galvanoplastics, the same object, keeping its shape and size unaltered, may be covered at will by a layer of one metal or another according to the particular metallic salts in the bath into which it is plunged. And so, too, in electric accumulators, the same plates serve as a framework on which are deposited the different substances which are capable of charging them.

That is why, even when the two original forms of the chromosomes were found in the cells of the tissues of adult hybrids, we could not infer, with the opponents of nuclear somatization, that the nucleus remains germinal and therefore identical in all the somatic cells of the organism. At most it would mean that what is maintained from nucleus to nucleus without variation is just that framework, upon which would be deposited the most widely different specific substances of the chromatin, differing from one nucleus to another.

But all these objections, to which I have but referred en passant, and which give little support to the hope expressed above, are relatively unimportant to the thesis set forth in these pages. Even if all these interesting and often original researches, carried into the deepest intricacies of the microscopic and ultra-micro- 
scopic, should not be crowned with the expected success, they would, no doubt, give other results, probably unexpected, but perhaps even of greater importance. In this labyrinth of researches the priceless thread of Ariadne will always have been the fact of the variation which biological heredity undergoes in consequence of amphimixis and crossings, the fact on which the theory of transformation first fixed the attention.

Weismann's principle of natural selection considered as the unique factor in evolution is, however, exposed to old and new objections which as time goes on do not become less formidable. The polemics on this subjectof which the first and the most brilliant, which took place between Weismann and Herbert Spencer, has remained famous-have shaken the almost universal assent to that non-transmissibility of acquired characters which Weismann propounded, and which most people accepted as an implicit consequence of the doctrine of the continuity of the germ plasm.

The difficulties met with by natural selection when it claims to explain the wonderful structures of certain tissues and the conformation of certain organs and groups of organs so well adapted to their functions, lead to an ever-closer study of the nature and modes of manifestation of functional adaptation and bring to the front the importance of co-ordinated variations.

The objection that natural selection could not come into play in the case of insignificant fortuitous individual variations led De Vries to study the phenomena of mutations, i.e. of certain sudden and very marked variations which produce at a stroke real new species.

The sporadic character of this phenomenon, the 
important part that the phenomena of atavism seem to play in it, and the slight importance that can thus be attributed to it as a factor of evolution, induce other thinkers to prefer the orthogenetic doctrines of Nägeli and Eimer on the tendency of the germinative plasma, which according to Weismann is always continuous, gradually to become modified by its own internal conditions, and thus to give rise to a corresponding phylogenetic evolution, equally independent of the direct action of the environment in the Lamarckian sense and of its indirect action in the Weismannian sense.

But as these doctrines in their turn are incapable of explaining how this evolution, determined exclusively by internal forces, could eventually form organisms so well adapted to their own environment and to their respective functions, we are faced anew with this dilemma, which is now more boldly presented: either natural selection alone, or a co-operation, as a powerful factor of evolution, with the transmissibility of acquired characters. This dilemma thus clearly stated, and the now shattered faith in the exclusive principle of natural selection, lead even the most hostile to pay to Lamarck's principle a more friendly attention.

Observations, experiments, and arguments in favour of this principle are rapidly increasing in number. Light begins to dawn as soon as men become persuaded that a collective scientific aberration has excluded a principle which in itself throws a dazzling light on all the most fundamental problems of transformation, and without which little can be explained.

But side by side with this persuasion, which continued to grow stronger and more general, there also 
grew up a kind of uneasy feeling that the question of the mechanism of this transmissibility was going to be a formidable problem. This problem, this enigma, proved to be the inner and powerful impulse which, avowed or not, conscious or unconscious, feverishly urged a whole legion of workers to follow on the lines of Wilhelm Roux, and to take up the whole series of observations and experiments comprised under the name of the "mechanics of the development of organisms."

The long-standing and fundamental dispute between the preformist theories, according to which each part of the embryo, however small it may be, carries within it all the elements necessary for the determination of its future development, and the epigenetic theories, according to which the development of each part depends on that of all the rest, the quarrels about nuclear somatization, or the existence of preformist germs, which is directly or indirectly connected with it, became more vigorous than ever, because the mechanism of transmissibility must be imagined in quite different ways for each of these cases.

Experiments on the isolation and displacement of the blastomeres; the production of half-embryos; the production of two or more distinct organisms or of double monsters from a single egg; the production of a single organism from two or more blastulas which have fused, and each of which could have formed a separate organism; graftings of portions of embryos, taken from all parts of the body and of different sizes, on to other embryos or on to adults of the same or of different species; all kinds of amputations for the 
study of the phenomena of regeneration and of heteromorphosis; the artificial production of all kinds of teratological organisms: all this vast body of activity, varied in every possible manner, finds its immediate and guiding thread in the settling of the debate between the preformist and epigenetic theories, and their final aim is the search for some indication or clue which will disclose the mechanism by means of which can be transmitted to offspring those characters which the parent organism may have acquired after its development, and in consequence of some new functionál adaptation.

I may here be permitted to state that this immense collection of experimental results, a whole series of which tells dead against preformism, while yet another series is no less decidedly opposed to epigenesis, seems to be rather in favour of a centro-epigenetic hypothesis, due to the author of these pages, according to which the development of each part would depend, not on that of all the other parts of the soma, but rather on the continuous action which the germinal substance, situated in a well-defined zone of the latter known as the central zone, would exercise over the rest of the organism during the whole course of development; and that this hypothesis may of itself be capable of furnishing the longed-for explanation of the mechanism of the transmissibility of acquired characters.

Meanwhile, the most minute observations on the mode of succession of the different embryonic stages in all kinds of species increase continually in number and variety as a consequence of these investigations into the mechanics of development, and throw into 
bolder relief the wonderful phenomenon of the recapitulation of phylogenesis by ontogenesis.

This phenomenon, discovered by Fritz Müller, but more particularly developed by Haeckel, and generally known by the name of Haeckel's fundamental biogenetic law, had always been considered one of the soundest arguments in favour of transformism, but it now assumes, in the light thrown upon it by the hypothesis of the transmissibility of acquired characters, a new aspect of first importance-the aspect of a phenomenon which is mnemic in its nature.

Haeckel himself, and Butler, and Orr, and Cope will ask, What is this repetition, however abridged, of the phylogenetic stages during ontogenesis, if it is not a sign that the living substance remembers all the stages through which the species has passed in consequence of the continuous acquisition of the new characters which have in succession been added to the old?

And that is how, in spite of the obscurity of the hypothesis implied in the question as stated, the path was already smoothed for another still more synthetic and more remarkable outlook which we owe to Hering. The author himself expounded it for the first time in I870, in a celebrated lecture to the Academy of Vienna, the title of which was: Ueber das Gedächtniss als eine allgemeine Funktion der organisirten Materie, according to which memory is the general and fundamental function of all living substance. This brilliant synthetic view, which Semon made his own in a work which appeared in I904 under the title: Die Mneme als erhaltendes Prinzip in Wechsel des organischen Geschehens, was more widely developed by basing it upon a 
very numerous series of facts disclosing the profound analogies which exist between biological phenomena in general and those of biological development in particular, on the one hand, and the phenomena of memory properly so called on the other.

All can realize what an imposing synthesis of biology and psychology, i.e. of two of the five master branches into which the whole of human knowledge may be divided, is represented by this affirmation of profound and unsuspected analogies between the vital phenomenon in general and the mnemic phenomenon, enabling us to conceive of the latter as the fundamental substratum and the inner essence of the former.

Cellular specialization, by which each cell, even when stimulated by unwonted stimuli differing from the normal stimulus, answers in its usual manner; the transmissibility of acquired characters; the innate instincts of the animals; all psychic phenomena, whatever they are, from the simplest to the highest forms of memory, such as logical reasoning itself, which is but a complex memory: all these phenomena, owing to the mnemic substratum revealed in each, seem to be different forms of one and the same fundamental phenomenon.

And assimilation, the principal characteristic property of the vital phenomenon, what is it then, it may be asked, but an essential mnemic phenomenon? In fact, this living substance, being continuously destroyed during the so-called processes of disassimilation, of waste, of organic destruction, which accompany the organic activity, this substance which later is reproduced during the so-called period of functional repose, 
of organic reconstitution, of assimilating synthesis, always identical with itself, always ready to reproduce by further decompositions the same specific functional activities-does not it, too, and for precisely the same reason, appear to be attributable to a phenomenon mnemic in nature? And further, we see that it is precisely because assimilation begins to be itself a mnemic phenomenon that all vital phenomena are also mnemic in nature.

But here a fresh and formidable question presents itself. The comparison of the vital phenomenon in general with the mnemic phenomenon, in spite of the profound analogies which have been discovered, must of necessity appear to be artificial, even if it is not reduced to an innocent metaphor, if we do not know what in reality is the mnemic phenomenon properly so called. As the latter, the ordinary psychic memory, belongs to a category of phenomena more particular and more complex than the vital phenomenon-for every phenomenon of psychic memory is certainly a vital phenomenon, although the converse is not true-how can the mnemic phenomenon throw any light upon the vital phenomenon?

But, notwithstanding, the analogies and the comparison appear more and more legitimate. Here, then, we are compelled to ask ourselves if these two phenomena, the vital and the mnemic properly so called, cannot rather be both explained by a third elementary hypothetical phenomenon, more general and more simple, of which they would be only two aspects or two particular cases. It is easy to grasp the whole importance of this hypothesis, of an elemen- 


\section{SYNTHESIS AND EVOLUTION}

tary phenomenon which would serve as a basis for all biological phenomena, in making a little clearer to our minds the great mystery of life.

I cannot in this chapter stay to consider the most likely answers that the future progress of biological science may give to this question, or to all the other fundamental questions to which I have referred, and which still await explanation. My task has been to show that the transformist doctrine sheds a powerful light around it, and that it is a stimulus, a keen, continual, incessant stimulus, urging us day by day further and further forward towards new researches and new conceptions. 
III

\section{BIOLOGICAL MEMORY IN ENERGETICS}

The Centro-Epigenetic Hypothesis of Development

BEFORE passing on to the consideration of the questions of a very general order and of fundamental importance which are raised by biological memory, it will be well, to fix the ideas, to recall and to sum up as briefly as possible my centro-epigenetic hypothesis of development, which in essence is based on this biological memory. And here, considering the object of this summary, and for the sake of brevity, I may be permitted to invert the order I have followed in the volume in which the hypothesis is fully developed, ${ }^{x}$ so that I shall first of all state what the hypothesis is and then proceed to prove it through the more fundamental facts of development, at any rate as far as is possible in the limited space at my disposal.

The essential part of my centro-epigenetic theory may be summed up in the following statements :

- Eugenio Rignano, La transmissibilité des caractères acquis. Hypothese d'une centro-épigénèse, Paris, F. Alcan, I906; Italian edition, Bologna, Zanichelli, I907 ; German edition, Leipzig, Engelmann, I907; English edition, Chicago, The Open Court Publishing Company, I9II. 
The action to which the process of development is due irradiates from a special zone of the embryonic organism called the central zone of development, constituted by the germinal substance.

This formative action is due to the successive modes of being of the system of distribution or circulation of trophic nervous energy, constituted by all the nuclear excitations or discharges simultaneously active in the different cells of the embryo. These nuclear discharges meet along the intercellular protoplasmic bridges, compositions and decompositions of the respective currents taking place in turns; the resulting system of nervous circulation thus penetrates the whole organism at each stage of its development, and at each moment gives rise to its complex morphologico-physiological state.

The germinal substance contained in the nucleus of the fertilized egg consists of a large number of " specific potential elements" ; that is to say, of a large number of elementary accumulators of nervous energy, each of which is capable, as they are discharged, of giving rise, not to a generic activation of this nervous energy, as electric accumulators do for electric energy, but to the activation of one and only one specific mode of being of this nervous energy. These specific potential elements activate successively, one after another, from the beginning to the last term of the development.

Every nervous current, every nervous excitation, whether it is directly derived from a single nucleus or from the composition or decomposition of several nuclear currents or excitations, on subsequently crossing any other nucleus whatever of the soma, deposits 
therein a "specific accumulation" of itself; that is to say, it deposits a substance that is capable, as it decomposes, of accurately and exclusively regenerating the specificity of the nervous current or excitation by which it was deposited. Every nucleus, even if somatic, may thus be formed by numerous elementary accumulators in every way similar in nature to those of the germinal nuclei, but specifically distinct from the latter, and also specifically distinct from one somatic nucleus to another.

The germinal specific potential elements, contained in the nucleus of the fertilized egg, are integrally transmitted from nucleus to nucleus by the qualitative equality of the nuclear division. But in the nuclei, which in the course of development remain ultimately outside the aforesaid central zone, and which therefore belong to the cells which are destined for histological specialization, are progressively added fresh somatic potential elements, by means of the process of deposition already referred to. These specific somatic potential elements, increasing in number and mass, eventually, for reasons of space and of nutrition, replace gradually and completely the germinal elements, thus giving rise to nuclear somatization in the proper sense of the words.

If this be granted, let us note how development will proceed, beginning with the first segmentation of the fertilized egg.

By means of the qualitative equality of the nuclear segmentation, the nuclei of the different blastomeres will all be equal and will be equal to the nucleus of the fertilized egg from which they come, and they will 
remain so, at any rate in the morula and even in the blastula stages. All these nuclei will thus be equally adapted-especially if the respective blastomeres coming from holoblastic eggs are also equal to one anotherto undertake the same plasmatic action, each beginning to set in action the same series of specific energies.

But the time soon comes when the new specific excitations, being on the point of activation, are ready to determine an ontogenetic modification, which no longer can be uniform for all points of the blastular spherical surface, as it would be, for example, in the case of an invagination. The activation of the remaining nuclear energies can no longer therefore take place in the same way for all the blastomeres. At this moment such of the nuclei as possess, either in consequence of having had the chance of better nourishment or for some other accidental reason, a quantity of potential energy superior in however small a degree to that of the rest (or, in meroblastic eggs, those favoured with respect to the rest in some way or other by their position) will necessarily have an advantage over the latter, and will continue alone the activation, checked in the others, of the successive specific energies, which at the outset had been, on the contrary, activated simultaneously by all the blastomeric nuclei without distinction.

From this moment the rest of the nuclei, thus remaining outside the central zone of development, and henceforth dependent on those that constitute that zone, gradually become more and more differentiated and somatized; for they will be continually traversed by specificities of nervous trophic energy, successively 
different and differing from nucleus to nucleus, according to the system of general nervous circulation which at each moment will be determined by the corresponding activity of the central zone.

In fact, every fresh specific potential element activating in the nuclei henceforth constituting the central zone will disturb the dynamic equilibrium of the general system of nervous distribution which has just been constituted by the activation of the preceding specific potential element, and will thus provoke the transition to a new dynamical equilibrium relative to the following stage of development.

As the germinal elements of the central zone thus come into action in succession, the development of the organism will pass through its different successive stages, and the action will cease only when the germinal elements have all been activated. Now at this point will cease every disturbing influence of the central zone on the dynamic equilibrium of each ontogenetic stage, and in this way the organism reaches a state of definitive equilibrium-of "stationary" equilibrium, as Ostwald would say-of the adult state.

Just as, however, up to this point, the disturbing action of the central zone was continually breaking the barely formed equilibrium, and was thus provoking the transition to a posterior ontogenetic stage, so now, the organism having reached the adult stage, every non-ephemeral change of this or that external stimulus or of the complex of external stimuli, every lasting change of the general action exercised by the environment on the organism-to each of which changes it will also react with a different functional 
activity-will end in a fresh disturbance of the dynamical equilibrium, which otherwise would have been henceforth definitive, and in this way it will provoke the transition to a new morphologicephysiological state, which will constitute the next phylogenetic stage.

Each of these phylogenetic morphologico-physiological states will in turn give birth, in the point of the organism occupied by the germinal substance, to a single nervous current or excitation, the specificity of which will be a function and expression of the general system constituted by the infinite number of nervous currents or excitations simultaneously active in all the nuclei of the organism. This resulting nervous current or excitation will thus be the representative current or excitation of this phylogenetic stage.

Each of the successive phylogenetic states will then have had, relatively to the germinal substance remaining at the same point of the organism, its own representative current, and each of these representative currents will have in its turn left in the germinal substance itself a characteristic specific accumulation, representative of the corresponding phylogenetic state, and ready in every new ontogenesis to restore the specific current thus accumulated. It will therefore be sufficient to suppose that the germinal substance is always at the same point of the organism both when it receives and accumulates these representative currents and when it restores them unchanged at each new ontogenesis, so that the organism in process of development may again pass-more or less summarily according to the degree of conservation of the respective representative 
accumulations-through all the morphologico-physiological stages already traversed by the species in its evolution; just as it is sufficient for a single point of the membrane of a phonograph to pass through all the stages through which it passed when the membrane received a given series of loud vibrations, for the whole membrane itself to repeat the extraordinary complicated modes of being at first provoked by the external world, and now reproduced by the sole action of this single internal point.

The fundamental biogenetic law of the ontogenetic recapitulation of phylogenesis would thus be the immediate consequence of the process of the transmissibility of acquired characters.

Such in its fundamental features is the centro-epigenetic hypothesis which, as I have already pointed out, must now be confronted with the facts.

Pfeffer's celebrated experiments on the reformation of the cellular membrane, even in the fragments of enucleated cells, provided that they are connected by the protoplasmic bridges with other cells or portions of nucleated cells, lead to the conclusion that where intercellular protoplasmic unions exist, the different discharges or currents of the several nuclei flow together along the respective protoplasmic unions and thus give rise to a circulation of nuclear energy throughout the whole network of these protoplasmic connections. The universality of these connections in every cell of any kind of tissue, both in the adult state and at any period whatever of development, beginning with the original blastomeres, leads to the conclusion that this circulation of nuclear energy extends, at every instant of develop- 
ment as well as of the adult stage, to the whole of the organism, and penetrates to its minutest recesses.

Siegfried Garten had a disc of skin of ro $\mathrm{mm}$. radius cut from his arm, and then had this repeated when the wound was quite covered with new epithelium with the exception of a minute disc of $\mathrm{r} \cdot 75 \mathrm{~mm}$. radius. 'This experiment fully confirmed the suggestion of a circulation of nuclear energy through the clustered network of the intercellular bridges. The circulation of nuclear energy, in fact, which at first passed through the intracellular filaments and intercellular bridges of the cells situated on the removed disc, finding, when once the disc was gone, that its previous paths were blocked, must have been compelled to pass round the wound, thus increasing the quantity of nuclear energy of this zone. According to that, around the little circle of $\mathrm{r} 75 \mathrm{~mm}$. which remained uncovered, one saw in the microscope an annular layer of large cells in which the protoplasmic filamentation was extraordinarily developed both in number and in thickness, and in which alone appeared nuclear divisions. The growth of the thickness and of the number of protoplasmic unions thus denoted an increase in the circulation of nuclear energy; and the nuclear divisions, in their turn the sign of quicker nuclear and cellular proliferation, denoted that this increase of circulation had exercised a trophic action in the annular zone it traversed.

The last fact is very interesting, for it enables us to refer immediately to differences in the quantity of this nuclear energy in circulation all differences in the speed of growth which are to be met with either in the different 
points of the same tissue or in the different tissues of the same organism.

The following brief considerations will suffice, in their turn, to make it sufficiently probable that the nature of these nuclear energies is really the same as that of the nervous currents or discharges. In the unicellular organisms, among the direct or indirect effects of these nuclear stimuli there are some which are manifested in the form of contractions of the vibrating cilia and of resulting movements. These vibratory cilia are seen from many points of view to be of the same nature as the intercellular protoplasmic bridges, and, so to speak, their substitutes. In the higher animals, whose movements at the adult age are caused without the slightest possible doubt by nervous energy, these movements begin, however, from the earliest embryonic stages, when they are nothing but a simple mass of a few blastomeres, as we infer from all those organisms whose eggs develop freely in water, and which begin to swim as soon as the blastula and gastrula stages are reached. And, as we all know now, even plants present phenomena of sensitiveness, of transmission of stimuli, of motility, and other phenomena which if presented in animals would be unhesitatingly classed as nervous phenomena. As plants have no nervous system, in the proper sense of the term, these phenomena can be attributed only to the excitations of somatic nuclei and to their transmission through the intercellular protoplasmic bridges.

Garten's experiment, as we have seen, confirms the hypothesis, which attributes to simple differences in the quantity of trophic nervous nuclear energy all the 
differences in speed of growth which are observed at different points of this or that tissue. On the other hand, as has been well put by Wilhelm Roux, development is nothing but " a succession of unequal localizations of growth." An infinite variety of forms is produced by means of the most monotonous system possible: the coming into action of the proliferation of a cellular layer at a given point more than at neighbouring points, so that the surplus cells thus formed may be compelled to evaginate or invaginate. This shows that the system of trophic nervous circulation continues to be modified during development by the unceasing activation of some factor of disturbance.

The involutive ontogenetic processes, such as the involution of the tail of the tadpole, in which there is physiological atrophy of the embryonic tissues; the phenomena of the correlation of development in which given parts of the embryo, even if remote from each other and having between them no functional correlation, always simultaneously slacken or hasten their development; the compensating growths to which Ribbert has paid particular attention, in which ablation during the development of the one half of a double organ not yet functioning, such as a testicle or a lactiferous gland, provokes a further growth of its companion: not only do all these facts confirm this general circulation of trophic nervous energy, but in this circulation they find, and for the first time, their explanation.

The well-known researches of Francis Darwin on the movement of plants, which have led him to affirm substantial identity between the temporary variations of form, or movements, and the definitive variations, 
or morphological changes, corroborate the hypothesis that the latter changes, just like the movements, depend on the disturbances of the nervous circulation provoked by particular discharges of this energy.

At the same time a whole series of facts revealing the most intimate co-operation of the ontogenetic and the physiological functional stimulus, and therefore the contingent substitution of one for the other (as happens, for instance, in the latest stages of the development of the eye), are in favour of the identity of their nature and in favour of the idea that the former is, in short, nothing but a reproduction, by internal causes, of the latter, this being provokable only by external factors.

The centro-epigenetic hypothesis, finally, reconciles in one harmonious whole the very numerous and apparently contradictory facts which have made biologists propound the three famous and more or less interdependent dilemmas, of nuclear somatization or nonsomatization, of the existence or non-existence of preformist germs, of the epigenetic or preformist nature of development.

Thus, as far as the first of these three dilemmas is concerned, experiments on the isolation and on the displacement of blastomeres, on the formation of double monsters from a single egg, or of a single embryo from the fusion of two blastulas, on the reformation of complete organisms from fragments of hydra and fragments of Begonia leaves, all appeared to be in favour of nonsomatization or nuclear non-specialization.

On the other hand, the opponents of nuclear nonsomatization mainly insist, apart from other less important arguments, on this : that the nucleus is the part, 
or the organ, upon which in the main depends the specificity, or the various specificities, of the physiological phenomena of the cell itself, and that therefore histologically different cells can be conceived of only if provided with specifically different nuclei. In fact, a moment's thought shows us that if nuclear somatization be abandoned, it would follow that the nuclei of the nervous centres are all equal to each other and equal to the nuclei of the other tissues.

Now, centro-epigenesis disposes of this dilemma as follows: as we have already seen, nuclear divisions would take place by a process of qualitatively equal division, but, as development went on, somatic elements would be, in the nuclei of the cells remaining outside the central zone, gradually added to the germinal elements inherited by each nucleus in the process of this qualitatively equal division; and these somatic elements, solely by the growth of their number and mass, would be gradually taking the place of the germinal elements, owing to reasons of space and nutrition. But this substitution in the lower animal organisms and in some vegetable tissues, owing to the simplicity of their somatic functions, would never be complete; so that certain of their somatic nuclei would continue to retain their germinative faculty.

As far as the second dilemma is concerned, that of the existence or non-existence of preformist germs, there is here again a whole series of facts and arguments which seem to militate in favour of the existence of these germs, and another body of facts and arguments which seem to prove the contrary.

The phenomena of mixed heredity, from father and 
mother; the phenomena of atavism; the characters of hybrids; Mendelian heredity; all phenomena, in a word, of particulate inheritance, concur in showing that even the minutest characteristics of the organisms may be hereditary, independently of the rest. Whence the imperative necessity, according to Galton, De Vries, and Weismann, of admitting the existence of preformist germs which would be in relation to the respective separately transmissible characteristics, just as the complex germ is in relation to the whole of the organism.

On the other hand, apart from the fact that every cell and even every fragment, however small, of a cell must then have its own determinant or preformist germ, a little reflection shows that it is impossible to explain the phenomena of particulate inheritance by these preformist germs, unless at the same time we admit that the germs are united in a rigid structure, which is exactly what Weismann maintains. Now this rigid structure is quite incompatible with the capacity possessed by the germinative plasm of indefinite division producing equal germinative plasms. Besides, the great elasticity of which the embryonic organism gives us proof in adapting itself to eventually new conditions of development, and the whole vast field of teratology, both natural and artificial, demonstrate the possibility of the formation of an infinite number of morphological characteristics, which certainly could not be represented in the egg by any preformist germ.

Now the centro-epigenetic hypothesis presents in its germinal specific potential elements preformist germs sui generis, which, while possessing the properties 
required in preformist germs properly so called, do not lend support to any of the formidable objections which prevent us from admitting the existence of the latter. Instead of being the determinants or the representatives of each of the parts of the organism, they would be the determinants or representatives of each ontogenetic stage in its whole: determinants or representatives of each ontogenetic stage solely from the fact that each, activating after all its predecessors, would find the organism in a given mode of being corresponding to the immediately preceding ontogenetic state, and therefore would provoke its transition to the immediately posterior stage.

Hence is derived the most complete elasticity left to the embryo for its adaptation, with teratological forms, to conditions of development differing from ordinary conditions, and at the same time is derived the possibility of the phenomena of particulate inheritance. For many of these germinal specific potential elements, especially those related to the last ontogenetic stages, if they, owing to their very peculiar specificity, are capable of acting sensibly only on certain already specialized parts of the soma, will acquire by this alone the property of determining even entirely local and particular somatic variations.

Finally, we come to the third and last dilemma, partly independent and entirely distinct from, and partly depending on the second, just considered; it may be stated in the following terms: Has each portion of the embryo in itself all that is necessary, apart from nourishment, to determine its subsequent development ; or, on the contrary, is the development of each part 
of the embryo determined, not by causes internal to that part, but by the actions and reactions that all parts of the organism exercise on each other, during the whole course of development?

Now, the regeneration pure and simple of amputated organs, and especially certain particular cases of regeneration, place beyond a doubt the epigenetic nature of development. But a whole series of other facts appear on the contrary to show directly the preformist character of development. Thus the half-embryos of the frog in Roux's experiment, and the experiments of Born on the grafting of portions of the larvas of amphibians on complete larvas, would show how the development of certain parts of the organism continues without disturbance and in a perfectly normal manner, even when they are detached and isolated from the rest. At the same time innumerable teratological facts to be found in nature or experimentally provoked show the possibility of a complete check to the development of certain parts with the complete development of the rest, thus showing that the development of the latter is independent of that of the former.

Well, if it is admitted, with the centro-epigenetic hypothesis, that the formative action of the germinal plasm irradiates from a central zone of development, it is clear that a certain independence of development can and must subsist between the parts that are irrigated by different principal ramifications starting from this zone, and especially that it will be enough for any part of this zone to be present in the embryonic fragment detached from the rest of the organism to make that fragment capable of development on its own account. 
With this centro-epigenesis, the development of multicellular organisms is, in short, similar to that of the unicellular, for which, as we learn from experiments in merotomy on the infusoria, the nucleus functions as a genuine and characteristic zone of the development.

The above experiments of Roux and Born, the connection revealed between the check to the development or the incomplete regeneration of certain parts of the organism, and the atrophy or destruction of certain parts of the spinal cord, and other facts of normal or teratological development, seem to indicate that, in vertebrates, for instance, this central zone occupies quite a considerable length of the spinal cord : probably, although the boundaries are naturally not clearly delimited, it is situated in the peri-ependymal part of the spinal cord.

Hence the necessity in the centro-epigenetic hypothesis of distinguishing the effective from the apparent germinal zone. The former, constituted by the central zone itself, must be the real seat of emission of the germinal substance; the latter, constituted by the sexual organs or glands-and here we have a point of contact with Darwin's hypothesis-would be nothing but the place of reception, elaboration, and re-emission of the germinal substance itself.

Are the phenomena of what we call the "maturation " of the germinal cells, and especially those of the still mysterious "synapsis," more or less directly connected with this phenomenon of reception and arrangement of the precious material within the cell it has penetrated? can these phenomena thus find the beginning of an explanation, and will they, in their turn, 


\section{ESSAYS IN SCIENTIFIC SYNTHESIS}

bring support to the epigenetic hypothesis ?-these are questions which we cannot here discuss, and to which time alone can give an adequate answer, which in any case would be premature at the present stage of investigation. The mere allusion here made to them will have sufficed, we hope, to complete this rapid sketch of the centro-epigenetic hypothesis, before passing on to the questions of another order which it raises.

\section{II}

\section{Nervous ENERgy aNd its MNemic Property}

Having thus traced the broad features of the centroepigenetic hypothesis, and having shown its agreement with the principal facts of observation and experiment, I have now to show its connection with the widest biological questions, and with certain fundamental questions of organic chemistry and energetics.

We know how the phenomenon of the recapitulation of phylogenesis by ontogenesis-which I have just derived directly from the centro-epigenetic hypothesishas been considered from the outset as a phenomenon of mnemic nature. Starting from this first fact, we have been gradually led, especially by the work of Hering and Semon, to make of memory the general and fundamental function of all living matter.

This drawing together of ontogenesis and the phenomenon of memory, these extensions to all living substance in general of this mnemic faculty, although based 
on certain very suggestive analogies, were still obscure in their nature, and could not as yet explain any of the aforesaid phenomena.

Now this property which I have above assumed to exist in specific potential elements both germinal and somatic, and which is the corner-stone of the centroepigenetic hypothesis, constitutes in itself a real mnemic faculty. I allude to the property by which the substance of which each of these specific potential elements is composed, which is capable of giving as discharge a single well-determined specific nervous current, is still one and the same substance which this specific nervous current, when it acts as a "charging" current, can in its turn form and deposit. The specific potential elements thus appear to be genuine and characteristic mnemic elements, and they reveal themselves as the well-defined substratum of all the extremely varied mnemic manifestations presented by organized matter.

But we now have to decide if such a property of specific accumulation is admissible in the case of living substance. And in that connection two quite distinct although related questions at once appear: the one is concerned with the fact of the existence of specific potential energies, apart from their mode of origin, and the other is concerned with their mode of origin.

The first question is seen from several points of view to be connected with that raised by Johannes Müller and fully developed at a later period by Hering. Hering's theories-summed up and propounded anew in his address to the Academy of Vienna on May 21,1898 , 
Zur Theorie der Nerventhätigkeit-admit, however, perhaps unnecessarily, that to the different specificities or respective specific accumulations of the nervous energy in the different centres should also correspond as many specificities of the ways or lines of transmission of this nervous energy. These theories of Müller and Hering later received the support of Mach in his Analyse der Empfindungen, and again in his later work, Erkenntnis und Irrtum, in which he in his turn explicitly admits that for the various functional activities in each of the respective organs-from each gland and each muscle to the different organs of sense and the different points of the cerebral cortex itself-we must have recourse to as many accumulations of specific energies, which it is sufficient merely to let loose (déclancher).

But once specific accumulations are admitted, the other question presents itself. Can each be formed and deposited by that very specificity of energy that they are now capable of giving by their discharge?

It seems to me that we are compelled to this conclusion, if the ideas most commonly accepted by biologists as to the phenomenon of irritability in general are associated with certain conclusions which may be drawn more particularly from psychomnemic phenomena properly so called.

On the one hand it is, in fact, admitted that the irritable substance is " a system, in unstable equilibrium, of material particles provided with potential energy at high tension" (Oscar Hertwig), and the majority also admit-from the above-mentioned theories of Hering and Müller combined with those of Claude Bernard-that the different energies in the potential 
state, whose respective activations constitute the different forms of irritability of the living substance, represent in their active state so many specific modes of being of one and the same elementary phenomenon, characteristic of the living substance.

On the other hand, apart even from all the innumerable examples which go to show that the physiological effects of our recollections are identical with those of real sensations, Wundt's experiment alone-in which the very intense mnemic evocation of a given colour, while we look fixedly at any white surface or figure, causes the appearance of the complementary colourand all the other analogous experiments which this later suggested, are enough to show what Maudsley had all along maintained, that the remembrance of a sensation is nothing but the reproduction or reactivation of the very identical "specific" current which constituted the original sensation.

It follows that the specific accumulation, for example, of a certain sensorial psychical centre, on which therefore exclusively depends its "specific irritability," is really due to nothing but the accumulation made in the past in this psychic centre of the same specific nervous current which it can now give as a current of discharge, and which at that time on the contrary acted as a current of charge.

If this conclusion is, as we may say, self-imposed with respect to real psycho-mnemic phenomena, in which the fact of the nervous energy produced by the discharge of the respective centre appears in the first rank, while the physico-chemical phenomena accompanying this discharge pass to the second rank, then- 
conformably with the fundamental doctrine of Claude Bernard just referred to, as to the essential identity of all the irritability of organized matter, and taking into fair consideration the fact that memory has henceforth been generally recognized as the fundamental property of all living substance-we are justified in also admitting it in the case of real physiological phenomena properly so called, in which there are, on the contrary, the physicochemical phenomena of irritability (muscular contraction, glandular secretion, etc.) in the first rank, while the phenomena of a nervous nature which equally accompany this physiological reaction or function pass to the second rank or even remain quite ignored.

Here a third question crops up: In what does this "accumulable specificity" consist? Although at the present stage of investigation there will be many who consider it premature to dwell upon this question, I cannot refrain from doing so, even if it be only for the purpose of drawing to it the attention it deserves.

There are certain considerations in energetics which, it seems to me, must raise at least a vague conjecture on the subject. There is no need for me to warn the reader that in the following pages I am not setting forth an hypothesis properly so called, firmly established on certain facts, but am rather making a few simple provisional conjectures, on the admissibility or the greater or less suggestiveness of which I myself am the first to feel the need of having the advice of all who have studied the question.

We know that the different physical energies are represented by a product of two factors, one of which 
expresses a capacity and the other an intensity or a potential. Thus the capacity factor of electric energy is given by the quantity of electricity measured in coulombs or amperes, and the intensity factor by the potential or electromotive force measured in volts. If we admit two similar factors for nervous energy, can the specificity of the different nervous currents be in some way related to the capacity factor?

Let us note that in electric energy the capacity factor represented by the quantity of electricity is supposed to be constituted of elements or electrons all of equal capacity for all currents. But in mechanical energy, on the contrary, this same capacity factor, represented by mass, is supposed to be constituted of elements or molecular masses which are specific for different substances, i.e. their capacity differs with each substance.

Now, can we imagine that the capacity factor of the nervous energy is also subdivided into so many elementary factors-which we may call " nervous electrons" or "nervions"-all of the same specific capacity for any type of current? If that be so, we can easily imagine that these different elementary specific capacities can be determined by as many specificities or modalities of action of the physico-chemical energies which constitute the stimuli of both the external or internal environment. In other words, can we not conceive of the nervous current, constituting for instance the sensation of red, or the evocation of that sensation, as formed by a huge number of elementary discharges, or " nervions," of given capacity, while another nervous current, constituting for instance the sensation of green, or the evocation of that sensation, will be on the 
contrary constituted by other elementary discharges, by another sort of "nervions," also all of the same capacity, but of a capacity differing from that of the nervous current giving rise to the other sensation? Can a given quantity of nervous current, in short, be considered as composed of several specific elementary discharges-which for a twofold reason, by analogy and by their effective nature, we may call molecular discharges-just as every mass may be considered as composed of a certain number of small specific elementary masses, such as molecules?

We may note that this would enable us immediately to conceive of the reciprocally univocal correspondence between specificity of current and specificity of accumulation. We may, in fact, easily imagine that two molecules of different composition or structure must by their sudden decompositions give rise, not only to two different sorts of materials of decomposition constituting the chemico-physiological side of the discharge, but at the same time also to two energetico-nervous shocks of different capacity; and on the other hand this process is not improbably reversible, i.e. it is possible, for the reasons to which we will immediately allude, that the same identical energetico-nervous shock, produced in the opposite direction, may restore the shattered structure. In fact, in the case of our molecules, there would probably be no question of complete destruction, to which should correspond a reconstruction from the foundations ; but perhaps, more simply, of the separation of this or that lateral group of atoms, at first united to the principal central mass by the aid of links such as $\mathrm{NH}$ or $\mathrm{NH}_{2}$ or $\mathrm{COOH}$ or some other similar 
link; and then the problem would be how to bring back these lateral groups of atoms in order to reconnect them with the central mass.

Thus Verworn, in his "biogen" hypothesis, admits that in disassimilation the non-nitrogenized atomic groups alone are detached, while the nitrogenized remain and constitute the central group, which is reconstituted later on in its primitive labile complexity at the expense of new non-nitrogenized atomic groups, which are equal to those eliminated and which are provided by the nutritive liquid. Organic chemistry, on the other hand, teaches us that central groups of the same composition may serve as a base for lateral groupings of the most varied types. If, then, central groups and lateral groupings of all types are found already prepared in the nutritive liquid, it is quite admissible that when the same shock of the same identical quantity of energetic capacity, already provoked by the detachment of this or that lateral atomic group of a well-defined quantity of mass, propagates itself anew within this nutritive liquid, it will shake the atomic groups of the same quantity of mass, and these atomic groups alone, by selecting them, so to speak, from all the rest, and thus provoking anew their reunion with the central group.

The reversibility of this process would thus be partly comparable to that, but partly of a different nature from that, of certain catalytic processes in which the same enzyme favours both the hydrolysis and the synthesis of certain organic substances, i.e. both their decomposition and the inverse process of recomposition from the separated products of the decomposition.

But we may now ask if these properties attributed 
to the elementary nervous currents or discharges are likely to explain certain properties already met with in certain fundamental phenomena which depend directly on nervous currents.

For this purpose it will first be necessary to distinguish between the two extreme cases between which all possible intermediaries have still to be inserted, according as the molecules capable of giving rise to the same specific discharge are arranged all in parallel or all in series. In the first case we shall have a nervous current of very large total capacity and of minimum potential; in the second, on the contrary, a nervous current of small capacity-scarcely that of an elementary discharge-but of high potential. The nervomotor force in this case will be proportional to the number of molecules disposed in series, i.e. proportional to the mass of the accumulated substance.

Ciamician, in a lecture delivered at Parma, in September 1907, to the Congress of the Italian Society for the Advancement of Science, propounded the hypothesis that in vital energy the potential factor must be represented by the "will." According to him, plants are endowed with little vital potential, i.e. little will, but with great capacity or quantity of life. Animals in general would be more liv ? ${ }^{1} y$ for the inverse reason; in insects, in particular, considering the slightness of their dimensions, we must suppose that the factor of capacity would be small, and the will factor on the contrary very high.

The "force of will " being only a nervo-motor force, this would be much the same as saying that by this hypothesis the serial type would prevail in or ganisms 
with strong will, at least in certain of their tissues (nervous, muscular tissue). On the contrary, in those with a large capacity factor and with weak will-which we can figuratively call phlegmatics, a term particularly appropriate in the case of the plants-the parallel type would be more dominant.

We stop a moment to consider the second extreme case, the simplest of all, and moreover possessing for us the greater interest. As a disposition in parallel can always be considered as constituted by a certain number of dispositions in series, such consequences of a general character as we can draw from this second extreme case-disposition in series-may also be extended, with certain restrictions, to all other cases.

In this extreme case of the disposition in series of all the molecules constituting a given specific accumulation, the capacity factor of the discharge will be a constant; that is, the respective specific accumulator will give currents of one and only one capacity, always the same whatever may be the number of its molecules which discharge. We may therefore ask if it is not possible that it is precisely the powerlessness of this discharge to assume any other value which brings it about that in most cases it can put itself in activity-or " get loose," as they say-only when it finds already active about it these same currents, or at least a part of these currents, which have already accompanied it the first time, at the moment when, provoked with the latter by the external world, it has just deposited at this point its specific accumulation. For in this case, and most often in this case alone, the alterations which the discharge of such a predetermined capacity would 
provoke in the system of environmental nervous circulation, in which it thus found itself inserted, would be reduced to a minimum, so that a little nervo-motor force will suffice to overcome the resistance due to these energetic alterations. The following example will perhaps render more clear our thought: Take an electric accumulator and suppose, for a moment, that it can give, in discharging itself, not currents of all intensities according to the respective resistances of the circuit or according to the peculiar conditions of electric distribution in the system in which it is inserted, but one and only one intensity : if it is inserted at a given point of a network traversed by a given system of circulating electric energy, then it will discharge only when this system of distribution will admit in this point a current of that given intensity, or when its electro-motor force is sufficiently great to modify the whole system of distribution, in order to render possible in this point the only intensity of current it can give.

The psychological law of the association or succession of ideas, and more generally the phenomenon of the whole psychic and physiological association, which is the corner-stone and the fundamental base not only of psychology but of the whole of biology, as well as the contrary phenomenon of psycho-physiological inhibition in general, would thus be the direct consequence of the constancy of the capacity factor of the discharges of each specific accumulation.

This in particular explains-let this be said in parenthesis-why, in the centro-epigenetic development, the germinal specific potential elements can activate only when the embryo has reached the ontogenetic 
stages corresponding to the phylogenetic stages in which these specific potential elements have been for the first time deposited in the germinal substance itself.

Here it is sufficient to remark, especially on the subject of the association of ideas properly so called, that it is difficult not so much to understand how it comes about that certain ideas evoke others, but how certain ideas evoke only certain others. In fact, owing to the infinite number of nervous conductions by which all the psychic centres are connected-and which, according to the calculations of Flechsig, would mount up in the case of the human brain to several millions, and would be thousands of kilometres in length-it might be expected that every excitation of a single psychic centre would be transmitted to all the rest, on each occasion producing an extremely disorderly and chaotic association of ideas. To explain this limitation of association Hering, as I have already indicated, has found it necessary to have recourse not only to the specificity of the respective accumulations of nervous energy in the different centres, but also to a specificity of the ways or lines of conduction connecting up these centres one with another; and, on the other side, the advocates of the neurone theory compared it to the lifting of a drawbridge, that is to say, to the withdrawal of most of the dendritic extensions, by which retraction the neurone isolates itself from the other centres, and remains in communication only with those by which it should be exclusively stimulated. But Hering's hypothesis leads to a stereotyped association of ideas which is absolutely contradicted by the most familiar facts of 
mnemic evocation and of imagination, such as, for instance, the dreams, the artistic creations, and so on. The question is not exhausted by the other hypothesis, for it is not stated why the neurone would lift certain drawbridges and lower others; and, moreover, this neuronic hypothesis had very soon to give place to the opposite concept of the effective anatomic continuity of the whole of the nervous network. So that considering the effective existence and continuity of the very close network which unites to one another all the different nervous elements, and the inadmissibility of a specificity of the ways or lines of conduction, we are justified in supposing that the cause of the limited reciprocal discharging of the different nervous currents must be sought in the energetic properties of these currents, and in the dynamic relations which may be the sequel.

But I must be content with this rapid sketch and proceed to touch briefly upon the other fundamental and connected questions of assimilation, of the trophic action exercised by the functional activity, and of the rejuvenation produced by fertilization. I must, however, make the preliminary statement that the hypothesis I am about to set forth in explanation of these phenomena is merely provisional, and that its acceptance or rejection does not affect the other, that of specific accumulations, which although helping to suggest and to endorse what I am going to set forth is nevertheless quite independent of it.

What strikes the biologist in the first place on the subject of assimilation is that it is not a phenomenon of continual production, but of continual reproduction, 
since it reproduces incessantly the organic substance in proportion as it is consumed. "It may be said," writes Oscar Hertwig, "that life consists only in a continual process of destruction and re-formation of organic substance." And further, such a process has in itself all the characters of a real mnemic process. In fact, every specific substance which is destroyed by its own functional specific activation is reconstituted, whatever may be within certain limits its nutritive environment, always specifically identical with itself, exactly as if it were formed and deposited by its own specific discharge, which, instead of being as in the first instance destructive, becomes reconstructive. One may then suspect that the phenomenon of assimilation is at bottom composed of a double elementary phenomenon, to wit: the preliminary production of the specific discharge and of the subsequent deposition on the part of the latter of its own specific substance of accumulation.

Quite independently of these considerations, other fundamental manifestations of life have led biologists to conclusions which agree with this supposition: The facts of fertilization or of conjugation in general, which reduce to the simple "coupling" of the chromosomes of the male nucleus with those of the female nucleus; reducing division, which terminates the maturation of the ovules and of the spermatozoids alike, and which reduces by one-half the normal number of the chromosomes of the respective nuclei, with the object, one might almost say, of allowing the expelled half to be replaced by the chromosomes of the fertilizing nucleus, also reduced to half the ordinary number; 
the curious nuclear processes of synapsis, in which the very process of maturation both of egg and spermatozoid begins, and in which we see extremely fine filaments like coupled and parallel strings of beads, so accurately paired that in front of every tiny grain of chromatin of one of the filaments is another tiny grain of the other; the like coupling of granules of chromatin in many other nuclear phases, of nuclei both germinal and somatic ; the presentation, in a word, always in pairs, of all the microscopic nuclear elements in which we have the strongest reason to suspect the production of vital phenomena; all this has already suggested to more than one biologist the idea that vital energy cannot be produced and maintained if it is not between pairs of opposed elements of matter, functioning-as was vaguely said in default of a more definite hypothesis -like " antagonistic poles." .

At the same time the perfect qualitative equivalence between the chromosomes of both sexes-deduced indirectly from their identical capacity of transmitting the same hereditary characters and proved directly by certain very interesting experiments on the substitution of the nucleus of a spermatozoid for that of an ovule, and of auto-fertilization of the semi-nucleus of the ovule, subsisting after the reducing division, with its other half already expelled-leads us to believe that a like qualitative identity exists between the opposed material of elementary pairs.

We may therefore hazard the hypothesis that the so-called " antagonistic poles," constituting each vital element, are only two serial accumulators specifically identical to one another, but of different potential, 
face to face as object and image, between which, thus opposed, there is produced an intranuclear oscillating nervous discharge, comparable in certain respects to the oscillating electric discharges of Hertz's resonators. And just as these oscillations are reinforced by the Hertzian waves synchronous with them, so the intracellular oscillating nervous discharges may be reinforced, with increase of the respective specific substance deposited in both the opposed accumulators, by the synchronous oscillations of the thermic and luminous rays, which are nothing but Hertzian waves of much shorter vibratory period. In this connection the fact observed by Engelmann is very interesting : the colours of the spectrum which are preferentially absorbed by bacteria are also those most favourable to their metabolism. This metabolism can therefore be due only to a proecss of a vibratory nature also capable of resonance.

Thus we would have a process of automatic growth of the nuclear substance, liable, however, gradually to be checked by the equalization which would tend to be produced continuously between the nervo-motor forces of the two coupled and opposed accumulators.

Hence the trophic action exercised by every process adapted to re-establish the inequality between the two opposed nervo-motor forces, and therefore exercised by every extra-nuclear functional discharge; this is in conformity with experience, which teaches us that the phenomena of functional destruction are, in the words of Claude Bernard, "the precursors and instigators " of the organic reconstitution, effected in the so-called periods of functional repose.

Hence, too, the action of rejuvenation exercised by 
fertilization or conjugation, which would substitute, in each of the germinal mnemic elements, for one of the two accumulators of nervo-motor force equal to that of the other, another specifically identical accumulator, but of quantitatively different nervo-motor force. This fertilization or conjugation, according to Spencer, has been considered by most biologists as equivalent to the disturbance of an equilibrium which would make impossible the maintenance of the vital activity; and, therefore, we understand how it can be replaced by functional activity or any other similar disturbing process, as is shown by Maupas in his experiments on infusoria, and by recent experiments on artificial parthenogenesis.

And finally from it we see the universal tendency of life, under the action of thermic energy, to take an indefinite expansion, i.e. " to attract," as Mach says, "into its own sphere larger and larger quantities of matter," the tendency to indefinite self-expansion which has induced so many writers, and Ostwald in particular, to compare life to fire.

It was Ostwald, in his Vorlesungen, who was the first, as far as I know, to attempt to give a physico-chemical explanation of the mnemic phenomenon, and at the same time of the trophic action exercised by the repetition of the functional activity. However, he takes into consideration only " habit," which certainly does enter into the phenomena of memory, but which does not embrace them all. He holds that habit is due to the formation and growth of a catalytic accelerator during the functional reaction. Suppose, says he, that every action of the organism is due to the fact that in conse- 
quence of a stimulus or the activation of the will is produced a catalytic accelerator which releases the action itself. This catalytic accelerator can have but a short existence, for otherwise the organism could not return to its normal condition after accomplishing the act. We might suppose, continues Ostwald, that the catalytic accelerator is always present, although in a generally inactive form, becoming active momentarily under the influence of stimulus; and we might also suppose that this catalytic accelerator has the property of increasing in quantity, at the expense of the nutritive liquid present, only during its active state. Then the content of this accelerator will increase at each repetition of the act, and therefore the act itself may be provoked on each successive occasion with ever greater rapidity. Thus, concludes our author, we should have in such a catalytic accelerator the specific accumulation desired, corresponding to this particular functional activity.

This is not an explanation at all, especially if instead of considering a "physiological habit," isolated from all the rest, and also apart from the fact of its first acquisition, we embrace, on the contrary, in one survey, all the vital phenomena of the organism in all their complexity: it then appears very necessary to reduce them, so to speak, to a common denominator, to a single intermediary of reciprocal relations, capable of uniting and co-ordinating them in one harmonious whole such as the organism effectively is.

How are we, for example, to explain by means of catalytic specific accumulations, which have between them no substratum of common relation and of reciprocal dependence, the transmissibility of acquired habits ? 
Can we for this purpose venture to assume that as many different enzymes are received in the germinal plasma as there are habits acquired by the organism? We then simply fall back on the Darwinian theory of gemmules, and once again we have to explain how this infinite number of enzymes happens to present itself in the daughter-organism exactly at the desired point.

To quote other very simple examples, how can we explain the physiological and psychic association referred to above by unconnected catalytic specific accumulations? How can we account, moreover, by their means, for the mnemic evocation properly so called, for the simplest remembrance of a landscape or of a phrase, in which we have to deal with as many " habits," as many specific accumulations, as there are evocations of elementary sensations composing the recollection?

Certainly, with our nervous energy, endowed with the property of specific accumulation, and constituting this desired intermediary, this desired circulating medium of general correspondence and co-ordination, we introduce one form of energy, which is not reducible to one of those forms of energy which we know in physico-chemistry, i.e. a form of energy such that, although naturally obeying the general laws of energetics, it would, however, differ by certain well-defined elementary properties from other forms of energy, just as these other forms differ from one another. But it does not seem to me that this conception contains anything that in itself is inadmissible from the scientific point of view.

Ciamician, who in his syntheses of organic substances 
has perhaps kept closer than others to the path followed by nature itself, finally had recourse, as we have seen, to a vital energy, with its own peculiar properties. And Ostwald, too, when he speaks of different energies, mechanical, electrical, chemical, which in the nerve they stimulate are all transformed into nervous energy, seems to me not far from the admission that the latter may be a form of energy in itself different from the rest.

I conclude with the following words of Mach, which I am pleased to make my own: "As long as we believe in the possibility of reducing all physics to mechanics, and as long as we believe in the possibility of reducing mechanics itself to the simple doctrines we know at present, life must appear to us effectively as something hyperphysical. But for my own part, I cannot associate myself with either of these conceptions." 
ON THE MNEMIC ORIGIN AND NATURE OF THE AFFECTIVE TENDENCIES

\section{I}

IF we study the "behaviour" of the different organisms from the unicellular to man, we see that a whole series of their acts, and especially the most important, may be interpreted as the manifestation of a tendency of the organism to persist in or to return to its "stationary " physiological state-to use an epithet from Ostwald's energetics.

In other words, if we reserve the name of "affertive" for that special category of organic tendencies which are subjectively manifested in man in the form of " desires," " appetites," or " needs," and which objectively in man and the animals are translated into " nonmechanized movements," completed or nascent, then a whole series of the principal "affective tendencies" thus defined may be reduced to the single fundamental tendency of the organism to maintain its " physiological invariability."

We see, for instance, that the most fundamental affective tendency of all, that of hunger, is in the long run nothing but the tendency to maintain or to re- 
establish the internal nutritive environment in the qualitative and quantitative conditions which enable the stationary metabolic state to continue. This tendency of the organism towards the invariability of its own metabolism has in the course of phyletic evolution become a tendency to pass through all those transitory physiological states that can re-establish the requisite conditions of the internal environment, i.e. a tendency to perform all the acts which have food as their object, and this without loss, at any stage, of its essential and original nature. The proof of this lies in the fact that, once the internal nutritive environment is restored to its normal conditions, every tendency in the animal to seek for further food ipso facto disappears.

Thus the hydra and the sea anemone react positively to food " unless metabolism," as Jennings says, "is in such a state as to require more material "; for instance, food placed on the disc of the large sea anemone, Stoichactis helianthus, when the animal is not hungry, provokes the same characteristic reaction of "rejection" as if it were any other disturbing object. All other organisms, higher or lower, from the top of the scale to the bottom, behave in the same way. ${ }^{\mathrm{I}}$

Schiff's experiments, in which he injected nutritive substances into the veins of dogs, show directly, on the other hand, that the fundamental condition of hunger is the impoverishment of the histogenetic substances of the blood. For these injections succeed not only in nourishing the animal but in appeasing its hunger.

'H. S. Jennings, Behaviour of Lower Orgenisms, New York, Macmillan, 1906 , for instance, pp. 202, 205, etc. 
The fact that hunger, especially when it is moderate, assumes in man the form of a localized special sensation, originating in the wall of the stomach, of itself sufficient to determine the same acts as those induced by genuine hunger, is, as we need hardly remark, only a natural consequence and of but secondary importance. It is only one of the many forms of that substitution of the part for the whole which is characteristic of all the physiologico-mnemic processes: in fact, these special sensations localized in the gastric mucous membrane, and due to its swelling or to some other more or less similar change produced in the mucous membrane by the empty condition of the stomach, these phenomena, from the fact that they usually precede and accompany the actual impoverishment of the histogenetic substances in the blood, become thereby representative and vicarious signs of hunger.

The same may be said of thirst and of its vicarious localization in the upper parts of the alimentary canal.

If we pass on from hunger and thirst to the other more fundamental "appetites" or " needs," we find that all their external manifestations reveal to us that their one and only end is the restoration of the stationary physiological state, which in some way or other has been disturbed or destroyed.

Thus, for instance, there exists for every animal species an optimum of environment relative to the degree of saturation of the solution in which the animal lives, to the degree of temperature, to the intensity of light, and so on, above and below which the organism can no longer maintain itself in its normal physiological state, and in which the animal therefore makes every 
possible effort to maintain itself. For example, we see that the infusorium Paramacium at $28^{\circ} \mathrm{C}$. reacts negatively to a rising but not to a falling temperature, while at $22^{\circ} \mathrm{C}$. it reacts negatively to a falling and not to a rising temperature. We also see that Euglena in a moderate light reacts negatively to a decrease but not to an increase in the intensity of the light, while in a stronger light the reaction is reversed. ${ }^{1}$

The tendency of organisms to the invariability of their own stationary physiological state thus changes into a tendency to the invariability of their external or internal environments. Oysters and actinians, for instance, close when exposed to the air; i.e. they "behave" so as to keep invariable the humidity of their internal environment."

In this invariability of environment is also comprised the position of the organism in relation to the direction of the different external forces to the action of which it is exposed, particularly of the force of gravity. Thus, for instance, the amœba usually draws in its pseudopodia when they come into contact with solid inedible bodies; but if it is lifted off the bottom of the aquarium and is suspended in the water, it stretches out its pseudopodia in all directions, and as soon as one of them touches a solid body, it takes hold of it, and draws its body over to it, so as to resume on this new support its original position. An inverted starfish tries to "turn over," i.e. to return to its

H. S. Jennings, op. cit., pp. 294-5.

2H. Piéron, L'évolution de la mémoire, Paris, Flammarion, 1910, pp. 29,74 . 
normal conditions of environment with respect to the force of gravity. ${ }^{3}$

And further, all "needs" to throw off the products of the general metabolism for which the organism has no further use are no exceptions to this general rule that applies alike to the smallest and simplest infusorium or the most complex vertebrate. For the " need" of throwing them off, even if it is contingently provoked by certain "vicarious" local sensations, capable of determining in advance the act of elimination, is in the long run seen to be due only to the fact that the accumulation of these waste substances within the organism would eventually disturb the normal physiological state.

To this category of eliminative affective tendencies also seems to belong the sexual "instinct" or sexual " hunger."

We know, in fact, that certain recent theories are disposed to assign to sexual hunger-just as in the case of hunger proper-not a limited local zone, constituted in this case by the sexual organs, but the whole organism, and at the same time to regard it as due to the "need" of eliminating the germinal substance. ${ }^{2}$

It is, for instance, not impossible that just as the infusoria after a certain number of simple bipartitions become subject to " senile degeneration," so also the germinal substance of the adult organism may suffer a similar " degeneration," especially after it has under-

× K. C. Schneider, Vorlesungen über Thierpsychologic, Leipzig, Engelmann, I909, pp. 5, 37 .

2 Cf., but only for certain points of view, J. Roux, L'instinct d'amour, $\mathrm{P}$ aris, Baillière, I904, ch. i : Base organique de l'instinct sexuel. 
gone the reducing divisions, and has not yet experienced karyogamic rejuvenation.

Hence there is something plausible in the hypothesis that "sexual hunger" is in its origin nothing but the tendency of the organism to get rid of the "senile corruption" which the germinal substance, from its very nature of a nuclear substance ready for fertilization, produces and diffuses throughout the whole organism by its hormonic secretions or its substances of disintegration.

The more or less brilliant and striking "wedding garment " assumed at the period of courtship by nearly all animals, and due to an eminently abnormal condition of general hypersecretion, provoked in its turn by the hormonic products of the sexual organs, is in every case the outward and visible sign of the profound physiological disturbance which is caused in all somatic cells by the germinal substance awaiting fertilization.

The tendency to get rid of so profoundly disturbing an element would later become a tendency to copulation as an effective means of securing this expulsion.

Hence the "fundamentally selfish" nature of sexual love upon which Ribot rightly lays such emphasis: "In the immense majority of animals and often in man, the sexual instinct is not accompanied by any tender emotion. Once the act is accomplished, there is separation and oblivion." $\mathrm{I}$

It still remains to explain why the copulation of the sexes has become tine sole means for expulsion of the germinal substance, while the single individual suffices

Ribot, La psycloologie des sentiments, Paris, Alcan, I906, p. 258 ; and Essai sur les passions, Paris, Alcan, 1907, pp. 67 et seq. 
for the elimination of the other more or less analogous waste substances.

It is easy to suppose that this must in the long run be due to the peculiar nature of the substance to be got rid of. And two facts may perhaps, if considered together, throw a little light on the subject : the attraction exerted at a distance by the ovule on the spermatozoid, by means of secretions diffused in all directions, and the fact that hermaphroditism probably preceded sexual dimorphism in the phylogeny of multicellular organisms. It must, however, be confessed that the phylogenetic process, by which this elimination from the organism of the germinal substance has become so closely associated with copulation, is still far from a satisfactory explanation.

But even though incomplete, this hypothesis, which gives to the sexual instinct the significance of a simple tendency to eliminate a disturbing element, enables us to present the instinct itself in a very different light from that under which it has so far been considered. If we accept this hypothesis, in fact, it would be no longer for the good of the species, but for that of the individual, that such an instinct originated and was developed. It would no longer represent the "will of the species" imposing itself upon the individual, as most people now maintain with Schopenhauer. But it would, as do all the other fundamental physiological needs, rather represent also here the "will" of the individual itself, i.e. its ordinary tendency to maintain invariable its own stationary physiological state. There is no need to follow Weismann and all the Neo-Darwinians, and to see in it an argument in favour of the 
alleged omnipotence of natural selection. Lamarck's simple principle of individual adaptation, combined with the transmissibility of acquired characters, would suffice to account for this as well as for all the other instincts.

Further, the "elimination" hypothesis enables us to explain certain peculiarities of this instinct which would be quite incomprehensible from the point of view of Schopenhauer and the Neo-Darwinians.

Thus, for instance, Ribot is surprised that an instinct of such essential importance in perpetuating the species is so easily liable to perversions which seem to imply its complete negation. $\mathrm{r}$

Passing over genuine and characteristic pathological perversions, the very readiness with which normal people adopt neo-Malthusian practices and the like is difficult to reconcile with the hypothesis that the sole reason for the existence of such an instinct is the propagation and conservation of the species.

Finally, the fact that both animals and man now desire copulation and the other secondary sexual relations for their own sakes-i.e. independently of the act of elimination of the germinal substance, and even sometimes when there is no germinal substance to eliminatethis also, as we shall better appreciate later on, is only the consequence of the mnemic law already mentioned of the substitution of the part for the whole, and of the law of "transference" of affective tendencies which is derived from it. According to this law all the phenomena which constantly accompany the satisfaction of certain affectivities become in their turn the object of

x Ribot, op. cit. : La psychologie des sentiments, pp. 263-5. 
desire, and all the habits acquired for the satisfaction, or in the course of the satisfaction, of certain affectivities become in their turn affective tendencies.

Once the sexual instinct itself has been referred, phylogenetically, to the category of tendencies serving to maintain invariable the stationary physiological state of the organism, such a law, as far as the fundamental organic tendencies are concerned, is open to no exception. It may therefore be summed up as follows :

Every organism is a physiological system in a stationary condition, and tends to maintain itself in that state or to return to it whenever that stationary state has been disturbed by any change that has taken place in its internal or external environment.

This property forms the basis and essence of all the " needs," of all the " desires," of all the most essential organic "appetites." All movements of approach or withdrawal, of attack or defence, of taking or rejecting, that are made by animals, are nothing but so many more or less direct or indirect consequences of this very general tendency of each stationary physiological state to remain constant. We shall soon see how this tendency may in its turn be connected with the fundamental mnemic property of all living substance.

This single physiological tendency of a very general kind is sufficient, therefore, to give rise to a whole series of particular effective tendencies of the most varied character. Thus, every special cause of disturbance will provoke a corresponding tendency to repulsion with characteristics of its own, determined by the nature of the disturbance, by its degree of intensity, by the modes of reaction suitable for avoiding the disturbing 
factor ; and, on the contrary, for every means capable of-preserving or restoring the normal physiological state there will be a quite distinct corresponding tendency of "longing," " desire," " attraction," and the like.

The "instinct of preservation"-understood in the restricted ordinary sense of preservation of one's own life-is also nothing but a particular derivative and direct consequence of the same very general tendency to preserve physiological invariability; seeing that, evidently, every situation which would in the long run lead to death first presents itself as a mere disturbance, and it is only as such that the animal tends to and learns to avoid it. The amœba, for instance, which Jennings tells us was completely swallowed by another amœba, and after many efforts succeeded in escaping, did not in all probability make these efforts to avoid a danger threatening its life, but to avoid a change in its normal environment which, though representing a profound disturbance, was nevertheless nothing but a disturbance.

It is well known that Quinton was the first to develop a theory that organisms tend to maintain in their internal intercellular environment the same physicochemical conditions which existed in the primordial environment when life appeared on the earth. ${ }^{x}$

But it is easily seen that our theory is limited to the consideration of this tendency to invariability only in so far as it manifests itself at every moment by the

× R. Quinton, L'eau de mer milieu organique. Constance du milieu marin originel comme milieu vital des cellules, à travers la série animale, Paris, Masson, 1904; in particular Bk. II : Loi génćrale de constance originelle, pp. 429-56. 
behaviour of each individual. And instead of serving as a point of departure, taken from a far too one-sided point of view, for the explanation of the evolution of species, it forms the basis from which may be derived all the most important affective tendencies of the animal world.

Being a factor of invariability for the individual, this tendency to the conservation of its own physiological stability has become, indeed, one of the principal factors in the variation and progress of the species, but its mode of action is not the mode suggested by Quinton. For this tendency has aroused and developed the faculty of movement, constituting the greatest distinction between the plant and animal worlds. The growth of this faculty in its turn proceeds step by step with the development and improvement of the whole locomotor apparatus, including that of the nervous system, which in itself alone plays so important a part in determining the fundamental characteristics distinguishing one animal species from another.

Finally, as a factor of individual invariability it has proved by its action on man to be one of the principal factors in the whole of social evolution. All technical inventions and the whole economic production, from the first cave-dwellings, the first garments of skin, the first discovery of fire, to the utmost refinements of the present day, have, in fact, directly or indirectly, but the one object-the artificial maintenance of the greatest possible constancy of the environment, that being the necessary and sufficient condition for the conservation of physiological invariability. 
To this fundamental property possessed by every organism of tending to maintain invariable its normal physiological condition, or to restore its equilibrium if disturbed, is now to be added another which in its turn becomes the source of new affectivities.

When the stationary physiological state is disturbed and cannot be restored by any means, i.e. by any kind of movements or displacements, the organism tends to take up a new stationary state consistent with the new external or internal environment. We thus have a new series of phenomena called "adaptations."

As an instance we may mention the classical experiments of Dallinger on the acclimatization of the lower organisms. They were suggested by the observation that a number of organisms usually living in water of a normal temperature also live and flourish in water of the hottest thermal springs. These experiments have shown that the infusoria may become accustomed to gradually increasing temperatures, and that after a year of slow and gradual increase of temperature they can live under conditions which would kill an unclimatized individual. We also know that the same species of Protozoa are found both in fresh and in sea water, and that it is possible gradually to accustom the fresh-water amœbæ and infusoria to live in seawater so salt that it would have killed them if they 
had been placed in it at first. And there are further instances of the kind. .

Now, it is interesting to note that the new conditions of the environment to which the animal becomes gradually accustomed tend in time to become its optimum: "Individual adaptation (e.g. to each change of saline density) is effected according to the law by which the conditions of density under which an individual is constrained to live tend in time to become the optimum conditions for that individual." 2

The fact may be verified even in plant organisms. Plasmodia of the Myxomycetes, which would die if suddenly plunged into $\mathrm{I}$ or 2 per cent. solutions of glucose, and which draw back from solutions of $\frac{1}{2}$ or $\frac{1}{4}$ per cent., may yet gradually become so accustomed to 2 per cent. solutions that they finally show by their "behaviour" that they prefer the new environment to the original one without glucose. 3

The diatom Navicula brevis normally shuns even the weakest light, and tries to hide itself in the darkest part of the drop of water in which it is being observed. But a culture which is placed in the bright light of a window for a couple of weeks exhibits exactly the opposite tendency. It moves into the brightest part

× C. C. B. Davenport and W. E. Castle, On the Acclimatisation of Organisms to High Temperatures. "Archiv f. Entw. Mech. d. Organismen," II. Band, ii. Heft, July 1895 ; C. B. Davenport and H. V. Neal, On the Acclimatisation of Organisms to Poisonous Chemical Substances, ibid., 11. Band, iv. Heft, January I896.

'Davenport and Castle, ibid., p. 24r.'

3 E. Stahl, Zur Biologic der Myxomyceten, "Botanische Zeitung," March $7,14,21, x 884$, p. 166 . 
of the drop as soon as it is restored to the weaker light of its former conditions. ${ }^{\mathrm{I}}$

The common actinia (Actinia equina) which is found clinging to the rocks in all possible positions with relation to the direction of the force of gravity, for the axis of its body may be directed upwards or downwards or cross-wise, seems to become so accustomed to one particular position that when removed elsewhere it tends to take up the same position as before. So that, if actinians found in different positions are collected and placed in an aquarium, "they show an unmistakable tendency to assume the position they formerly adopted." 2

Examples might be multiplied, but here we are mainly concerned with their significance. They prove that when once the new physiological state arising from adaptation to the new environment has come into existence and lasted for a certain time within the organism, it tends, if disturbed, to be restored. This tendency thus possessed by any past physiological state to "remanifest" or "reproduce" itself, is nothing but the tendency to evoke itself possessed in general by every mnemic accumulation. Hence it is a tendency of purely mnemic character.

But then the same mnemic character may also be attributed to that tendency to physiological invariability from which we have seen are derived the fundamental organic tendencies of all organisms without exception. For if in the above examples an entirely new and recent physiological state can leave behind it a

Davenport and Castle, ibid, p. 241.

- H. Piéron, op. cit. : L'évolution de la mémoire, p. 144. 
mnemic accumulation, capable in itself of giving rise to a distinct tendency to its own reproduction, we can quite understand that, in proportion as the normal physiological state has lasted much longer, it must possess a correspondingly stronger tendency to selfrestoration when subject to disturbance.

This, then, implies that each of the innumerable different elementary physiological states, of which each is active at one definite point of the organism and all combined constitute the general physiological state, possesses the faculty of depositing a proper "specific accumulation, similar to that deposited in the brain by each of the nervous currents which make up the different sensations and leave behind them a mnemonic residue capable of being reactivated or revived. By "specific accumulation" of the various nervous currents we must understand no more or less than this: that each accumulation is capable of giving as a discharge only that particular specificity of the nervous current by which this accumulation has been deposited.

The extension of this faculty of " specific accumulation" to all physiological phenomena in general is in harmony with the hypothesis that nervous energy is the basis of all vital phenomena. If in the psychomnemic phenomena properly so called the fact of the nervous energy produced by the discharge or " excitation " of the respective centre appears in the foreground, while the specific physico-chemical phenomena accompanying this discharge remain in the background, so that until quite recently they were almost completely overlooked, yet-according to Claude Bernard's fundamental concept of the essential identity of all the differ- 
ent forms of irritability of living matter-the difference between psychic and physiological phenomena properly so called would be one of degree alone and not of kind. In fact, if in the latter the specific physico-chemical phenomena (muscular contraction, glandular secretion, etc.) would appear with the greater distinctness, a specific nervous discharge would nevertheless likewise accompany this physiological activity, but would remain much less perceptible. In this manner I have tried to explain the fundamental mnemic property of all living matter, emphasized of late by Butler, Hering, Semon, and Francis Darwin in particular, a property which is capable of explaining a whole series of the most important and characteristic biological phenomena proceeding from it either directly or indirectly. ${ }^{\mathrm{I}}$

With this extension of the mnemic faculty to all the elementary physiological processes we are led up to a somatic or visceral theory of the fundamental affective tendencies in the following sense: The tendency towards physiological invariability or toward the restoration of this or that former physiological state, corresponding to this or that previous environment, would be due to an infinite number of elementary specific accumulations, differing from point to point of the body and whose

"Eugenio Rignano, Sur la transmissibilité des caractères acquis. Hypothèse d'une centro-épigénèse, Paris, Alcan, I906; Italian edition, Bologna, Zanichelli, I907; German edition, Leipzig, Engelmann, 1907 ; English :edition, Chicago, The Open Court Publishing Company, I9II. See especially the last chapter : The Mnemic and the Vital Phenomena.

See also Rignano, Die Zentro-epigenese und die nervose Natur der Lebenserscheinung, "Zeitschrift für den Ausbau der Entwicklungslehre," II, I908, Heft viii-ix.

And Rignano, La mémoire biologique en énergétique, in "Scientia," 1909, XI-3, and in "Annalen der Naturphilosophie," VIII, 1909 (reproduced in the preceding Essay). 
combined potential energy would form, as it were, a "force of gravitation" towards that environment or those surrounding conditions which allow the conservation or restoration of the combined physiological system represented by all these elementary accumulations.

Naturally, in organisms possessing a nervous system, side by side with each of these affective tendencies of purely somatic origin and seat, there would arise and be gradually developed, co-operating with it, and often acting as a substitute for it, a perfectly similar tendency represented by the corresponding mnemic accumulations, deposited in this particular zone of the nervous system, and particularly of the brain, directly communicating with the respective points of the body. In man, for instance, this zone would be Flechsig's "Körpersfühlsphäre," to which in certain cases would also be added the frontal zone. ${ }^{x}$

Once these cerebral mnemic accumulations/ have arisen phylogenetically by direct somatic action, they will eventually, even if all communication with the body were severed, represent, in themselves the former affective somatic tendency to which they owed their origin. This is due to the two fundamental mnemic laws of the gradual independence of the part with respect to the whole, and of the substitution of the part for the whole-laws arising directly from the fact that each specific elementary accumulation may exist independently when once deposited. Sherrington's "spinal " dog, for instance, continued to display the same repugnance to the flesh of other dogs, and to

P. Flechsig, Gchirn und Seele, Leipzig, Veit \& Co., I906, pp. 19, 21-22, 82, 99-100, 
exhibit other similar affectivities and even the same emotions, all undoubtedly of visceral phyletic origin, just as a normal dog would do. ${ }^{x}$

But this co-operation and this possibility of an eventual substitution of the affective tendency whose seat is in the brain for the corresponding affective tendency whose seat is somatic, do not prevent the former from usually remaining in the absolute control of the latter. Accordingly, modern psychology generally admits that the affective life " has its cause below, in the variations of the cœnesthesis, which is in itself a resultant, a combination of vital actions." 2

These affective tendencies, whose seat is in the brain, will also, consequently, conserve the two fundamental properties due to their visceral origin : that of possessing a "diffuse" seat, and that of being eminently "subjective."

In fact, every physiological system which is produced within the body in such a way as to be in equilibrium and to assume a stationary state with reference to its environment, will permeate the whole organism, and therefore the whole of that part of the brain in which the organism is reflected. In contrast to the mnemic sense-accumulations, each of which we have every reason to believe has its seat distinctly localized at a single point or in a single centre of the cortex of the brain, everything leads us then to conclude that each affective

I Cf. C. Sherrington, The Integrative Action of the Nervous System, London, Constable, I906, pp. 260-5; and Lloyd Morgan's apposite criticism in Aximal Behaviour, 2nd edition, London, Arnold, I908, p. 292. See also Revault d'Allonnes, Les inclinations, Paris, Alcan, 1908, pp. ror et seq.

Ribot, op. cit. : Psych. des sent., p. ro. 
tendency must be, on the contrary, made up of an infinitely large number of elementary mnemic accumulations, deposited respectively at every point of the body and at every corresponding point of the brain.

Finally, the affective tendencies owe to their physiological origin also their eminently "subjective" character, from the fact that the organism finds itself potentially equipped with this or that "idiosyncratic" affective tendency, with this or that "nostalgic" desire, according to the various environments or particular surrounding conditions to which the species and the individual were exposed for a longer or shorter time in the past, i.e. according to their individual history.

Hence result the "subjectivity" and the infinite variety manifested in the needs, appetites, desires, and consequently in all that is subject to "affective evaluation."

\section{III}

In support of the hypothesis I have sketched of the mnemic nature of all affective tendencies in general, I may invoke other examples of more special affectivities which also have originated by way of " habit," but which reflect more particular relations of environment, affecting only one part or other of the organism, and exercising an action which is periodic, or in some measure intermittent rather than continuous. They are especially in evidence in the higher animals, and particularly in man. 
Maternal love will suffice as a typical instance.

It is clear that the habit of certain parasitic relations, or of symbiosis in general, with the progeny, a habit continued for a long series of generations, has become gradually changed mnemically into affective tendency towards these relations. "Comparative ethology," in the words of Giard, "shows us very clearly that the relations between the parent organism and its offspring are in principle absolutely the same as those existing between an animal and its parasite, and that after a period of unstable equilibrium, in which one or other of the organisms in contact suffers to the advantage of its companion, there is a tendency to the establishment of a definitive position of mutual equilibrium." I

This applies, for instance, to relations of internal incubation, which, though at first sought and effected by the embryo itself in one or other stage of its development, for the purpose of food or shelter or some other advantage, and at first endured by the parent organism, either father or mother, finally become for that parent so many actual " needs."

This also holds good in the case of the relations of external incubation, arising at first from some special circumstance, and becoming in this way a habit. For instance, the attachment shown by the female spider Chiracanthium carnifex for her nest, whether her own or one of which she has taken possession, increases with time, i.e. with the duration of her occupation of it. Thus " maternal love" in her case seems to be at

" A. Giard, Les origines de l'amour maternel, "Revue des Idées," April I5, I908, p. 256. 
bottom merely her attachment to a house to which she has 'grown accustomed. I

And so with the brooding of birds and of certain reptiles, which at first is due to the pleasant sensation which the cool contact of the eggs gives to the feverish condition accompanying the generative functions, but which by habit has become in itself an instinctive affectivity. ${ }^{2}$

Finally, as far as lactation is concerned, the young, by sucking the secretions of the perspiratory glands on the breast of the brooding mother, have gradually transformed the latter into lactiferous glands, and they have so accustomed the mother to this sucking, that a genuine and characteristic need to be sucked has arisen. "In mammals it is in the phenomena of lactation that we must look for the origin of the symbiotic relations uniting mother and child. The physiological disorders of pregnancy and parturition lead, among other very curious trophic effects, to a hyper-secretion of the mammary glands, which are, as we know, only a specialized localization of the sebaceous glands of the skin. The young animal licks and sucks this secretion, which is its first food, and alleviates the discomfort of the mother, thus becoming a means to her comfort." 3

That the need for lactation is the origin of maternal love is seen from the fact that if she is deprived of her offspring she will feel the need of finding foster-nurslings. "The necessity of getting rid of a troublesome

- Lécaillon, Sur la biologie et la psychologie d'une araignée, "Année psychologique," Ioth year, Paris, Masson, I904, pp. 63-83.

2 A. Giard, op. cit., p. 226.

3 Ibid., pp. 269-70. 
secretion is powerful enough to induce the mother deprived of her young to steal the offspring of another mother. These robberies have been noticed even in the case of mothers who were still suckling their own offspring, the satisfaction of a need leading them, as is generally the case, to seek a greater satisfaction which may even lead to excess." I

In the cases observed by Lloyd Morgan, this need of the mother takes the form of a maternal love full of solicitude for the nourishment of her young, and it is even possible that it really represents the initial stage 'of disinterested affection for the young: "I have seen both bitches and cats get up and again lie down so as to bring the teats into closer proximity to the mouth of any young which failed to find them. It has been noticed by a man who is a remarkably good observer and has had much to do with animals, and also by myself, that when a lamb is weakly and fails to find the teat, the mother not infrequently uses its shoulders, head, and neck as a lever to place the lamb on its legs; and, having accomplished this, straddles over the lamb, and brings the teats against its lips; and these efforts are continued until the little animal sucks." 2

This is a characteristic example which shows us clearly how the necessity of getting rid of the milk must end in arousing an affection for the nursling as a usual means of attaining this end, just as the need of getting rid of the germinal substance, as we have seen above, must produce an affectivity for the

A. Giard, ibid., p. 270.

' Lloyd Morgan, Habit and Instinct, New York, Arnold, I896, p. II5. 
opposite sex, also as an habitual means of eliminating this substance.

And, in fact, just as "sexual attraction" ceases as soon as the germinal substance has been got rid of, so, in most mammals, "maternal affection" disappears as soon as the need for lactation is no longer felt: "Maternal affection does not in general survive the causes that produced it, and very vague traces of it are noticed as soon as lactation is over." I

Finally, the fact that maternal is stronger than paternal love, and that the love of parents for their children is stronger than that of children for their parents, confirms the hypothesis that all these affectivities have arisen exclusively by way of habit, for it shows that affection for those with whom we have given relations is the more intense in proportion as the relations are more numerous and more continuous. " In animal life taken as a whole," observes Ribot, "paternal love is rare and inconstant, and among the lower representatives of humanity it is a very feeble sentiment and forms but a slight bond." It is met with only in sexual unions that are stable, in which life in common " creates a current of affection in ratio to the services rendered." 2

"Every one recognizes," remarks Pillon in his turn, " that parental love exceeds in intensity that of children for their parents, and that of the two parents it is the mother who has the stronger love for the child." "This is because in the mother's case, much more than that of the father, by reason of her special

A. Giard, op. cit., p. 273.

2 Ribot, op. cit.: Psych. des sent., pp. 285, 286. 
functions, the love for the child is nourished and strengthened by the continuous performance of the acts it dictates." 1

But maternal love, and family love in general, thus arising out of given relations which become habitual, represent but one particular case of a universal law. Every other relation, in fact, established with things or with persons, however special it may be, becomes a thing "desired" as it passes into a habit." In other words, in every environmental relation, whether general or particular, we find a verification of Lehmann's law of " the indispensability of the habitual," which he established for every stimulus to which one grows accustomed, and in the absence of which we become conscious of a " need." 2

A friend once wrote to G. E. Müller : "I have in my room a small clock which does not run more than twenty-four hours without being wound up. So it often stops, and when that happens I notice it at once, while naturally I do not notice it at all when it is going. The first time this occurred I felt something like this : I suddenly became aware of an indefinite unrest, a kind of emptiness, and I could not say at the moment what was the cause. It was only after some reflection that I discovered the cause in the stopping of the clock." 3 Besides, we all have noticed that habit gives pleasure to things which at first were disagreeable, and certain

" F. Pillon, Sur la mémoire et l'imagination affectives, "Année philosophique," I7th year (I906), Paris, Alcan, 1907, pp. 69-70.

"A. Lehmann, Die Hauplgesetze des menschlichen Gefühlslebens, Leipzig, Reisland, 1892, pp. 194 et seq.

3 G. E. Müller, Zur Theorie der sinnlichen Aufmerksamkeit, Leipzig, Edelmann (no date), p. 128. 
habits contracted in a man's life become needs as peremptory as those we call " natural." " Smokers, snuff-takers, and those who chew tobacco furnish familiar instances of the way in which long persistence in a sensation not originally pleasurable makes it pleasurable-the sensation itself remaining unchanged. The like happens with various foods and drinks, which, at first distasteful, are afterwards greatly relished if frequently taken." I

Hence arises the longing we experience when something to which we are accustomed is suddenly missed. "In some animals there is produced a kind of homesickness, expressed by a violent 'desire' to return to the old haunts, or by a slow pining away resulting from the absence of persons or things to which they have grown accustomed." 2

Thus, as we have seen in the case of family love, similar but more comprehensive affectivities may be caused by habit to originate and take root in animals and in man-gregariousness, sociability, friendship, and the like. "The perception of our fellow-creatures, perpetually seen, heard, and smelled, will come to form a predominant part of consciousness-so predominant a part that the absence of it will inevitably cause discomfort." 3

Finally, we know what a very great influence is exercised by habits of conduct contracted in the home during the earliest years of child-life-of " nurture" in its

I Herbert Spencer, The Principles of Psychology, 4th edition, London, Williams \& Norgate, 1899, vol. i, p. 287.

- Th. Ribot, Essai sur l'imagination créatrice, 3rd edition, Paris, Alcan, rgo8, pp. 78-9.

3 Spencer, op. cit. : The Principles of Psychology, vol. ii, p. 627. 
wide meaning, as Galton would say-in awakening and developing sentiments and moral tendencies which, as though they were "innate," leave upon the whole life an indelible mark. ${ }^{\mathrm{x}}$

From these few examples, which I have given simply as illustrations of my thesis, we see how profound is the truth contained in the adage that " habit is second nature."

But if we can see to a certain extent before our very eyes this origin by way of habit of affectivities of the most varied nature, we are justified in going further, and in attributing a similar mnemic origin to all the affective tendencies, since innate and acquired tendencies do not differ in their nature. We are authorized to suppose that, just as, in the case of morphological evolution, Lamarckianism is quite justified in concluding, from the few cases of functional adaptation acquired during life that it has succeeded in observing, that the whole structure of the organism must be the outcome of an infinite series of similar functional adaptations.

We may therefore complete the adage by adding that, inversely, " nature " is nothing but " first habit."

\section{IV}

In confirmation of the hypothesis of the mnemic origin and nature of all the affective tendencies, there now intervenes one of their very general properties,

* F. Galton, Inquiries into Hunzan Facislty and its Development. London, Macmillan, I883, pp. 208-16. 
that of transference (Ribot), which is also itself essentially mnemic, and by which all other affectivities are derived from those of direct mnemic origin, and thus come to have an indirect mnemic origin.

For by the fundamental mnemic property, already frequently mentioned, of the substitution of a part for the whole, it happens that mere parts or fragments of given environmental relations, which at first were striven for in their totality, or " analogous" environmental relations, i.e. resembling only partly those desired, or again environmental relations constituting the " means " adapted to the attainment of an " end," and being therefore its necessary precursors, or finally environmental relations always accompanying that " end "-all evoke the affectivity of this original " end." This affectivity is thus "transferred" from the whole to the part. And this affectivity for the part is then strengthened because this partial relation, which at first is sought as a " substitute" for the whole, becomes in its turn an habitual environmental relation, henceforth desired or sought for its own sake, quite apart from the original affective "transference."

This is what has happened, as I have already shown, with respect to the copulation of the two sexes, in so far as it is the habitual means of getting rid of the germinal substance, and also with regard to the secondary sexual relations as phenomena usually accompanying this copulation. The "conquest" of the opposite sex, in its turn a necessary means for the satisfaction of sexual hunger or appetite, finally becomes with some individuals an end in itself. . As cases in point we have seduction for the sake of seduc- 
tion, the "sexual vanity" of both male and female, and the other similar affectivities.

The same holds good of the tearing to pieces of an animal's prey, at first the habitual means of satisfying hunger, which finally gave rise to cruelty for the sake of cruelty: "Half the animal world lives on prey; and as there is a pleasure in eating, so there must be a pleasure in killing. And the same pleasure is aroused at the sight of all the signs of defeat, the helpless struggles and the dying movements of the victim." 1

And as the sequel of further transference we have in man the desire of victory for its own sake, the thirst for dominion, the lust of power, the passion for fame and glory, and the endeavour to surpass one's fellows.

In these and in all other similar cases of "affective transferences " to environmental relations ever becoming less material and more moral, besides the real and proper "affective transference" which transforms the part into a new "end," we find, in man and the higher animals, the unceasing co-operation of the intellectual development.

The intellect, in fact, is constantly discovering new and unsuspected analogies between the most diverse phenomena, even between material and moral phenomena, thus extending to the one the affectivities that have been experienced towards the other. For instance, the physical distaste for certain foods recognized as unhealthy by taste or smell is extended to certain objects which can only be touched or seen (viscous

"Bain, The Emotions and the Will, 4th edition, London, Longmans, Green \& Co., I899, p. 65. 
bodies), and then by further analogy to simple " objects" or relations of a moral order. ${ }^{\text {I }}$

At the same time the intellect, with its ever-increasing foresight of external phenomena as effects of given causes, continues to discover new more or less indirect and complex means for attaining certain ends, and thereby opens up for " affective transference" an ever wider sphere of action. The weapon, for instance, which was first invented by man as a means for selfpreservation, has made possible that affective transference to itself which is typical in the warrior and the hunter; and the land which provides food for man has made possible that intense love of the soil which is to be found among the peasantry.

Further, the intellect, with its ever-increasing anticipation of internal psychic processes, gives rise to a whole series of new affectivities with the object of preventing future affective tendencies from remaining unsatisfied. For instance, the anticipation of future hunger gives rise even in the satiated man to a direct affectivity towards storing up and retaining in his possession the food that is left after his meal. This leads to the sense of property in general, and so also the anticipation of the innumerable other desires now cherished by civilized man develops in him an intense longing for wealth, the lust for lucre, and similar passions. ${ }^{2}$

Finally, it is the intellect that makes possible that infinite variety of delicate "shades of difference"

I Ribot, op. cit. : Psych. des sent. p. 212 ; ditto, op cit. : Essai sur les passions, pp. 65 et seq.

2 Spencer, op. cit.: The Principles of Psychology, vol. i. pp 488 et seq. ; Ribot, op. cit. : Psych. des sent., pp. I 10, 269-70. 
which affective tendencies may assume in man. For it has the power of considering simultaneously or almost simultaneously, from different points of view, each environmental situation, as soon as it becomes slightly complicated, and thus succeeds in evoking at the same time a variety of affectivities. These then, as Bain would say, by association, combination, confluence, interference, and reciprocal inhibition, ultimately give rise to an exceedingly complex affectivity, capable, therefore, of the finest possible gradations from one case to another according to the number and quality of its components.

Thus, for instance, the instinct of self-preservation in its purely defensive form had already developed in animals fear, anxiety, and similar feelings. In man it produces all the propitiatory affectivities in innumerable varieties and shades-prostration, humility, hypocrisy, flattery, and the like. Even the religious sentiment in its lowest forms is directly derived from such a propitiatory affectivity. The loftier religious sentiment and the similar feeling experienced in the presence of the sublime, are the later and most highly developed forms of the same thing. ${ }^{1}$

Similarly, from the instinct of self-preservation in its twofold form, at once offensive and defensive, had already developed in the higher animals the instinct of attack and all the different varieties of counterattack. In man this instinct has assumed the most varied forms and shades, from the deepest hatred to a scarcely perceptible antipathy, from the rage of

'Cf. Ribot, op. cit. : Psych. des sent., p. Ioo; Eugenio Rignano, Le phénomène religieux, "Scientia," III-I, I900 (see Essay VI in this volume). 
destruction to the merest envy, from the most violent feeling of vengeance to the slightest trace of resentment. The noble sentiment of justice itself can be identified as a very remote product of the same instinct. ${ }^{x}$

The high degree of complexity which may thus be reached is shown, for instance, by maternal love, since from the purely physical necessity for lactation it has grown to the tenderest feelings of the purest altruism, and especially, too, by the transformation of conjugal affection from the gratification of a coarse and brutal sexual appetite to the harmonious co-operation of the gentlest and most delicate of moral affectivities. ${ }^{2}$

It will be seen that there is no need to continue such an analysis of all the affectivities and of all the shades of difference which in this way have arisen and been developed in the higher animals, and especially in man. Let these few very cursory indications suffice to explain the fact that as soon as the organism has acquired, in the direct mnemic way, a reserve or "stock" of affective tendencies, and as soon as the intellect has attained an adequate development, there is no limit to the number of these tendencies which may be derived by "transference" and by "combination," i.e. by indirect mnemic way.

'Bain, op. cit. : The Emotions and the Will, pp. II7 et seq. ; Ribot, op. cit. : Psych. des scnt., pp. 229 et seq., 271 et seq. ; ditto, Problemes de psychologie affective, Paris, Alcan, 1910, ch. iii : L'Antipathie.

- Cf. Spencer, op. cit. : The Principles of Psychology, vol. i, pp. 487 et seq. 
A few words will now be sufficient to mark the place of the affective tendencies among the fundamental psychic phenomena most closely connected with them, such as the "emotions," the "will," and the states of "pleasure" or "pain."

"Emotions" are only sudden and violent modes of setting in action these accumulated energies of which the affective tendencies consist. Naturally we cannot always establish a clear distinction between the affective tendencies and the emotions, because the former are perceptible neither objectively nor subjectively as long as they are maintained in the potential state, and become perceptible only as they come into action-and this coming into action, if sudden and violent, represents the corresponding emotion. But the importance and the necessity of distinguishing clearly between emotions and affective tendencies-a distinction which most psychologists have entirely neglected to make-lie in the fact that one and the same affective tendency may, according to external circumstances, give rise to the most diverse emotions, to the most varying degrees of their intensity, and even to no emotion at all, properly so called.

For instance, if we see a vehicle coming towards us we quietly step out of its way ; but if, on the contrary, it appears to us quite suddenly at a corner of the road, we experience a very strong emotional shock. And the same affective tendency of the dog towards a piece of meat may give rise to flight, anger, or the careful 
and coolly calculating search for a safe hiding-place, according to the circumstances which threaten his toothsome meal.

In short, every emotion, as Stout rightly remarks, always presupposes an affective tendency; but the reciprocal is not true, for an affective tendency, even when on its way to realization, may imply no emotion. ${ }^{\mathbf{1}}$

Every affective tendency "impels" to action; it is what "sets going" the organ of motion, either directly as in the lower organisms, or by means of the nervous system as in the higher. So from the first moment of its realization it presents itself as a "movement in the nascent state" (Ribot).

If its translation into action is sudden and intense, the action of the locomotor muscles is accompanied also by that of all the viscera. This "visceral cooperation," which thus takes place in the emotions properly so called, is not due solely, as Sherrington maintains, to the fact that the rapidity and vigour with which the muscles are set in motion involves the immediate and intensive action of the viscera which furnish the muscles with the material for the recuperation of their energy; but also and especially because there is, as it were, an overflow of nervous energy, which, suddenly released in great quantities, spreads and pours forth in numerous other outlets than those which are closely connected with the locomotor apparatus. ${ }^{2}$

" G. F. Stout, A Manual of Psychology, $4^{\text {th }}$ impression, London, Clive, 1907, pp. 306 et seq.

a C. C. S. Sherrington, op. cit. : The Integrative Action of the Nervous System, pp. 265 et seq. 
And this visceral disturbance thus produced by the sudden and intense affective impulse is echoed centripetally in the brain in the form of an "emotion" according to the well-known theory of James, Lange, and Sergi. ${ }^{x}$

It is not, then, the emotion which impels us, as Sherrington asserts, following the prevalent deplorable confusion of affective tendencies with emotions; but, on the contrary, it is the affective tendency which gives the impulse, and emotion is but the reaction of a too rapid and intense realization of the affective tendency.

If, on the other hand, the realization of the affective tendency, owing to external circumstances or to the psychic constitution of the individual, is neither too sudden nor too intense, we may see brought into play only the action of the strictly necessary muscles, without any emotion at all. In these cases, the affective tendency thus gives a greater amount of useful work, in proportion as the part of the discharge which is lost in the disorderly and useless movement of a purely emotive character is smaller. That is precisely why it is just the "unemotional" people who more than others display the most tenacious, the most intense, and the most profitable activity.2

As far as the "will" is concerned, an act of volition takes place whenever an affective tendency to a future end triumphs over an affective tendency to a present

" IV. James, What is an Emotion? "Mind," April 1884, pp. I88-205; R. d'Allonnes, op. cit. : Les Inclinations, pp. I08 et seq.

2 Cf., in spite of the difference in certain points of view, E. Meumann, Intelligenz und Wille, Leipzig, Quelle und Meyer, I908, pp. I8I et seq. 
end, i.e. whenever a far-sighted affectivity is victorious over one that is short-sighted. Thus the man who is sweating and panting after a long run, and who throws himself down to drink greedily from a spring, does not thereby exercise an "act of will" ; that term belongs rather to the prudent man who abstains from slaking his burning thirst for fear of greater ills to come. Nor is an " act of volition" performed when an exhausted man throws himself down to rest, but rather when the mountain-climber defies his own fatigue or inertia to reach the desired summit. And what demands a great " effort of will" is not the act of the man who on the slightest provocation hurls himself on his opponent with insult and blows, but rather the act of the man who, being master of himself, bridles his just anger until he has coldly estimated in its remote consequences the most appropriate way of dealing with the offender.

The will is thus at bottom nothing but a true and characteristic affective tendency, which by its farsightedness checks other tendencies, and which in its turn, like all other affective tendencies in general, impels to action. "There is always present in the action of the will," writes Maudsley, "some desire of a good to be obtained or of an evil to be shunned, which imparts its driving force." I

Two extreme instances are here of interest, for they include all other cases. The first may be divided into two.

Sometimes one of the affective tendencies is so strong

x Maudsley, The Phy'siology of Mind, London, Macmillan, 1876, p. 339. 
and persistent that it constantly dominates all the others, strengthening those which are in harmony with it, and checking all those which are opposed to it. Such an "hypertrophied" affective tendency is called "passion" (Ribot, Rendal). If directed towards some present aim, we usually say that it "destroys the will," because it successfully resists the inhibitive action of every other affective tendency with an aim in the future ; while if its own aim be in the future towards an "ideal " which may barely be attained even by the effort of a lifetime, we then say the individual is "tenacious," "obstinate," " unyielding," endowed with a "will of iron," because every other affective tendency with an immediate aim in view dashes itself against it in vain.

In other cases, on the contrary, the two conflicting affectivities may nearly balance each other. At one moment the far-sighted tendency, by calling up in the mind new consequences in the future, gains more strength and seems to prevail; but a moment later the short-sighted tendency, by discovering new or more clearly recognized aspects of the object desired for the time being, becomes more intense and threatens to get the upper hand. In this case the individual falls into a state of what is called "indecision." When that happens to a "philosopher" who observes himself by introspection, he will be struck by the fact that the two motives which would incite him respectively to two different actions, by balancing each other, compel him to inaction, and that, vice versa, the slightest and most insignificant psychic fact is sufficient to give one of them the ascendancy over its rival. It is then but a step to the subjective illusion that a mere nothing, a 
perfectly arbitrary fiat on his part, will be sufficient to secure to one of them the ascendancy over the other. This is the subjective illusion of "free will" which, as we all know, has for ages constituted the greatest and most difficult problem that philosophy has been called upon to solve.

Finally, to come to the consideration of "pleasure" and "pain,". it is the merit of the modern psychological school that it has shown the fallacy of the old theories that the fundamental fact of animal life is the "pursuit of pleasure," i.e. the search for everything pleasant and the avoidance of everything that is disagreeable, and of having, on the other hand, clearly emphasized the fact that "agreeable" and "painful" states represent only the superficial part of the affective life, "of which the deep element consists in affective tendencies, positive and negative."- "These are the elementary processes of the affective life, of which pleasure and pain represent only the satisfaction or the failure." I

And as to every "satisfaction" of an affective tendency would correspond an activation of nervous energy, and as each "disappointment" would correspond to an interruption or cessation of this energy, "pleasure" would thus in the long run correspond to every state of discharge or revival of the vital or nervous energy, and "pain" to every state of inhibition or suppression of it.

In fact, every act of inhibiting nervous activity is "annoying" ; every too perceptible change of surround-

\& Ribot. op. cit. : Psych. des sent., p. 2 ; ditto, op. cit. : Probl. de psych. aff., p. 16. 
ing conditions which prevents the continuance of the hitherto active physiological state is "disagreeable"; the sudden and very marked change of environment which produces in some part of the organism the complete arrest or entire destruction of life brings "pain" or "anguish" ; and when there is a general diminution of vital functions within his organism, the individual is "sad" or " melancholy."

Inversely it is "agreeable" to exercise the muscles in play and sport; the cessation of mental strain is a "relief" ; the return to the ordinary environment and the resumption of one's habits is accompanied with "pleasure"; and in general every state of nervous dynamogeny of the organism is full of "joy" and " mirth." I

Let it suffice to note at this point how the theory of the mnemic genesis of all affective tendencies, which I have endeavoured to develop and to defend in these pages, furnishes an additional argument in support of these more modern psychological views upon the inmost nature of pleasure and pain. For the nature of mnemic accumulations attributed to affective tendencies implies that the fundamental fact of affective life can be nothing but the tendency of these accumulations to activate, a tendency identical with that of every other reserve of potential energy; and that therefore "pain" and "pleasure," "agreeable" and "disagreeable" states, can be nothing but the respective superficial and subjective aspect of each of these activations or of their inhibitions.

x Ribot, op. cit. : Psych. des sent., Part I, ch. i, ii, iii, and in particular pp. 52 et seq., pp. 83 et seq. ; Ostwald, Vorlesungen über Naturphilosophie, 3 rd edition, Leipzig, Veit, I905, pp. 388 et seq. 


\section{VI}

I shall close these short notes on the nature of the affective tendencies by adding a few remarks, which seem to me to be indispensable, on the fundamental character of these tendencies, namely, that they constitute as it were a force determining the end to be attained. but leaving undetermined the path to be followed.

Affective tendencies owe this property of gravitating towards an "end" without any preference for the "means" to the fact of the existence in a potential state of a given physiological system or state, general or partial, which has been already determined in the past by the outside world or by a few particular environmental relations, and which now tends, like every other kind of potential energy, to become active again-as soon as it is " released " by the permanence or the return of even a small part of this environment or of these environmental relations. In fact, the existence of this tendency has as its sole result the gravitation of the organism towards that environment or those environmental relations which make the recurrence of the activity of this physiological state possible; but it does not in itself imply any preferential "impulse" towards one or the other series of transitory physiological states or movements, which, while contingently capable of restoring the organism to the desired environment, have nevertheless nothing in common with the definitive physiological state.

It is only when a series of movements has happened 
to bring back the organism to the desired environmental relations earlier than any other series, that then, from that moment, it will be "preferred" to the others; a result expressed by saying that the affectivity has exercised a "choice" (James, Baldwin, and the American school in general).

Hence it will be only from that moment that the affective tendency will constitute by mnemic association a force which "impels" these movements leading to the desired end, just as certain reflex movements "impinge" one on the other (Sherrington). And it will be therefore only from that moment that these movements will be stimulated to self-reproduction (so long as they have not become mechanical in the form of reflexes), exclusively under the influence of the corresponding affectivity or of the equivalent "act of volition."

But before reaching this point, the affectivity has no tendency to discharge in one series of movements rather than in another. From this arises the great difference between the affective tendency or the act of will on the one hand and the reflex on the other; the latter-in which the act so "chosen," if often repeated, gradually becomes mechanical and quite autonomousrepresents a tendency to discharge along one given path, already determined before the discharge. The point of application of the force and its direction are known beforehand. We might therefore represent it graphically by the usual arrow-head used to represent the forces in mechanics. On the other hand, the affective tendency represents a force of which we know beforehand merely the point towards which it 
tends, and not its point of application and direction. It is a "disposable" energy which may be applied indifferently to any act whatever as long as it leads to the desired end. It may therefore be represented at the same time quite indefinitely by one or other of the infinite number of arrow-heads which converge to the vertex of a cone and fill its whole volume.

The reflex, therefore, admits of but one solution. On the contrary-as long as none of the possible movements has chanced to take place and has given rise to a choice, or as long as numerous equivalent paths are offered, all leading to the same goal-the affectivity is capable of a very large and indefinite number of solutions.

This possibility of numerous solutions constitutes the "unforeseen," the " anti-mechanical " nature of behaviour dependent on the affectivity or the will, as compared with the predetermined and mechanical behaviour of reflex movements, or of such complex combinations of reflexes as certain instincts.

Finally, it is this fundamental property of the affective tendency of constituting as it were a force gravitating towards that environment or those particular environmental relations that allow of the reactivation of the mnemic accumulations forming this very affectivity, which gives to this environment or to these particular environmental relations the appearance of a vis a fronte or "final cause," essentially different in its nature from the vis a tergo or " actual cause," which alone is operative in the inorganic world. ${ }^{\mathrm{r}}$

' Cf. W. James, Principles of Psychology, London, Macmillan, rgor, i, pp. 7 et seq. 
"The organism," in the words of Jennings, "seems to work towards a definite purpose. In other words, the final result of its action seems to be present in some way from the beginning, determining what the action shall be. In this the action of living things appears to contrast with that of inorganic things." I

Now this "final result of its action" really exists from the beginning in the form of mnemic accumulations. For that environment or those particular environmental relations towards which the animal is gravitating now operate as a vis a fronte, in so far as they were formerly vis a tergo, and in so far as the physiological activities then determined by them in the organism have left a mnemic accumulation which now in its turn constitutes the real and true vis a tergo, which moves the living being. ${ }^{2}$

Thus one and the same explanation is revealed as valid for the whole of the "finalism" of life.

For, from the ontogenetic development which shapes the organs which can fulfil their functions only in the adult state, to the property of all physiological states, already determined by certain environmental relations, of becoming active on the first appearance of phenomena which usually precede but which do not yet in any wise constitute these environmental relations; from the perfect morphological adaptation of the organism to its environment even before that environment can exercise its formative influence, to all the marvellous special conformations and structures so accurately calculated

' Jennings, op. cit. : Behaviour of Lower Organisms, p. 338.

- Cf. E. Mach, Die Analyse der Empfindungen, 5th edition, Jena, Fischer, 1906, pp. 70, 78 . 
in view of the most probable conditions to which this organism may later be exposed; from the simple mechanical reflex movements so perfectly arranged for the preservation and welfare of the individual, to the most complex instincts by means of which animals prepare in advance for future conditions of which they themselves know nothing-all these "finalistic" phenomena of life, identical in their nature, can be explained, as I have already pointed out in the volume $I$ have referred to, as so many manifestations of a purely mnemic nature.

And now in this essay we see that it is the affective tendencies themselves, manifestations which are, if possible, even of a more "finalistic" aspect than all the rest, that are likewise based on the mnemic property of the living substance, and therefore, in the last analysis, on the property of " specific accumulation," a property which belongs exclusively to the nervous energy which is the basis of all life.

This mnemic property, this property of "specific accumulation," which by its absence from the inorganic world leaves it at the mercy of forces a tergo and deprives it of every finalistic aspect, is, on the contrary, everywhere present in organic nature, and because of its presence makes the world of life a world apart, of which the most essential characteristics cannot consequently be explained by the laws of physics and chemistry alone. 


\section{V}

\section{WHAT IS CONSCIOUSNESS?}

Perhaps no word has been so much discussed, and is still so obscure in significance, as this word "consciousness." We are all of us ready, without the slightest hesitation, to say that this particular action or that particular psychic state is "conscious" or "unconscious," but when we come to inquire in what consists this character of "conscious" which we give to one psychic state and refuse to another, in most cases we are quite unable to give a satisfactory answer. ${ }^{\mathrm{X}}$

Some psychologists go so far as to consider this problem as insoluble: "To define the state of consciousness," writes Ribot, "would be a vain and idle task; it is a datum of observation, an ultimate fact. Physiology teaches us that its production is always connected with the activity of the nervous system, particularly with the brain. But the reciprocal is not true; if all psychic activity implies nervous activity, all nervous activity does not imply psychic activity. Nervous

IV. Bain, The Emotions and the Will, 4th edition, London, Longmans, Green \& Co., I899, c. xi : Consciousness, pp. 539-46. "Whoever endeavours, faithfully and firmly, to obtain a definite idea of what is meant by consciousness, will find it nowise so easy a matter as the frequent and ready use of the word might imply" (Maudsiey, The Physiology of Mind, London, Macmillan, 1876, p. 45). 
activity is much more extensive than psychic activity; consciousness is therefore something superadded. In other words, every state of consciousness must be considered as a complex event, which implies a nervous process; this nervous process is not an accessory, but an integral part of the event; and further, it is the basis, the fundamental condition of the event; as soon as this nervous process is produced, the event exists in itself ; and as soon as consciousness is added to it, the event exists for itself ; consciousness completes it, and ends it, but does not constitute it." I

Others use a term that is very fashionable nowadays, and call the consciousness purely and simply an epiphenomenon, and think that thereby they can dispense with the necessity of a closer examination of the question, as if the giving of a name had completely exhausted it.?

I should like to see if it is not possible, by examining a few suitably chosen instances of "consciousness" and "unconsciousness," to throw some light, if not upon all, at least upon some of the characteristics which most frequently accompany the cases we call "conscious" and which are not met with in the cases called "unconscious." Such an inquiry may thus be a first step towards the discovery of the conditions on which consciousness depends.

It will be well to begin with an example which to some may appear to lie outside cases of consciousness properly so called, but which, nevertheless, is closely

- Ribot, Les maladies de la personnalite, Paris, Alcan, I906, p. 6.

- Vide, for instance, Binet, La Psychologie du raisonnement, Paris Alcan, 1902, p. 165. 
connected with them. I look at the portrait of some one I know; I recognize that it represents that person, but that it is not really that person. The complex sensation aroused by the portrait awakens simultaneously, through association by resemblance, the image of the real person. Thus on the one side we have, for a certain time at least, the co-existence of the present sensations with the past sensations now evoked and of less intensity; on the other, at least metaphorically, we have the superposition or fusion, for the sake of their identity, of a limited number of the first with some of the second. The co-existence for a certain space of time, coupled with the partial superposition or fusion of the two psychic states or complex systems of sensations, seems then, at first sight, to be just what enables me to recognize that the portrait represents the particular person, and which also prevents me from taking the portrait for the real person it represents; or, in other words, what makes me "conscious" of the fact that the object I have just seen is merely the portrait of a person I know.

It may be, however, asked if, in addition to the purely perceptive sensations, present and evoked, there come into play affective elements also, as the determining conditions of the state of mind in which $I$ am when I recognize that the object is the portrait of a person $I$ know : when I look at the portrait I feel, perhaps without noting it, the same sentiments of tenderness or dislike, of sympathy or antipathy, and so on, that I am accustomed to feel at the sight of the original; and perhaps these sentiments would also contribute to make me conscious of the fact that this is the portrait 
of that particular individual. We shall see that certain other examples lead us to believe that the superposition and fusion of a part of the perceptive sensations alone, unaccompanied by the superposition and fusion of the affective or emotive sensations, are not sufficient to give us the consciousness of a fact as it is.

Before we demonstrate this-continuing to confine ourselves for the moment to the comparison of but two psychical states, the one original and the other evokedlet us consider two typical cases in which the evocation of some event in the past presents itself to our minds as quite isolated and separated from other recollections of preceding or subsequent facts:

"A lady, in the last stage of a chronic disease, was carried from London to a lodging in the country; there her infant daughter was taken to visit her, and, after a short interview, carried back to town. The lady died a few days after, and the daughter grew up without any recollection of her mother until she was of mature age. At this time she happened to be taken into the room in which her mother died, without knowing it to have been so; she started on entering it, and when a friend who was along with her asked the cause of her agitation, she replied: 'I have a distinct impression of having been in this room before, and that a lady, who lay in that corner, and seemed very ill, leaned over me and wept." "I

A man of very marked artistic temperament became conscious, as he approached the gateway of a castle

1 Ribot, Les maladies de la mémoire, Paris, Alcan, I901, pp. 143-4. [English edition, Diseases of Memory, London, 1885 (from the third French edition), p. I79. The story itself is taken from Abercrombie, Essay on the Intellectual Powers, p. 120.] 
in Sussex, of a very vivid impression of having seen it before, ánd he seemed to himself to see, not only the gateway, but donkeys beneath the arch and people on the top of it. He learned from his mother that when he was eighteen months old he had been taken there on an excursion, in the pannier of a donkey, and that his recollection of the visitors was quite correct. ${ }^{\mathrm{I}}$

The coincidence of some of the present sensations with some of the past sensations, now conjured up by the association of ideas, would seem to be the sole cause of the "recollection," i.e. of the "consciousness" of having been present in person at the event in question. But that is far from being certain. Here again it may be doubted if the emotion the lady really experienced anew at the moment of entering the room, and which the artist felt when he once more saw the castle-an emotion similar to that which they had already experienced in the past and of which they had not lost the recollection-was what gave them the consciousness of having lived through the circumstances which now came back to their minds.

On the other hand, the difference between the remaining present perceptions and the others evoked is certainly, even in these cases referred to by Ribot, what prevents the individual from believing that he is at the present moment living through the event evoked. This is so true that during a dream, in which one in the same way lives through some past event, but in which no aggregate of different present sensations accompanies the sensations evoked, there is no "conscious-

1 Ribot, ibid., p. I44. [The story is told in Carpenter's Mental Physiology, p. 431.] 
ness" at all that we are dreaming; and the individual, on the contrary, takes his own dream for a real event in which he is really taking part. In the words of Maury, "when we dream, the mind is completely absorbed by the internal perceptions; an absorption which prevents us at the time from realizing our condition, or at any rate leaves us but a vague and fugitive consciousness of it."' 1

I have now twice suggested that it is doubtful if the identity of certain present sensations with certain others evoked is in itself sufficient, when it is a question of pure perceptions, to evoke the past event and to make us conscious of it. A typical case of the absence of mind of which I am often the victim seems to me to justify that doubt.

When I leave my study table, I usually put my notes into a drawer and lock them up. Sometimes the act of locking the drawer appears to me afterwards as "conscious" ; at other times, if while I am doing it my mind is full of my thoughts, this act, on the contrary, appears to me afterwards to have been " unconscious." In the second case, the fear lest I may not have locked the drawer often comes upon me the moment $I$ have left the room, and as it is impossible for me to remember if I have locked it or not, I feel that I must go back to the room, and as the drawer has no handle I must assure myself that it is locked by opening it and shutting it again.

The desire $I$ have of attaining my purpose, to lock the drawer, a desire which is manifested by my care to see if that purpose has been really effected, this time

' Maury, Le sommeil et les réves, Paris, Didier, 1878, p. I6. 
accompanies my act, which as soon as I have left the room for the second time now seems to me to be a "conscious" act. Note that at the moment I lock the drawer for the second time the similar preceding act still seems to me to be unconscious; and yet it is certain that the same aggregate of visual, auditive, tactile, and muscular sensations is being reproduced which must have accompanied the similar act of a few moments before. However great may be in this case the common part of the purely perceptive sensations, it is not therefore sufficient as yet to evoke and make conscious an act which has taken place so short a time before.

And how does it come about, on the contrary, that if the desire of attaining my purpose of locking the drawer has accompanied for the second time the corresponding act, then when I have again left my study the act now appears to me to be a conscious act? There is no longer any common part of the perceptive sensations which can connect my psychic state of the moment I am leaving the study with that of the moment at which, I was locking the drawer. And yet, if I now ask myself once more if I have locked the drawer, my act comes back immediately to my mind, and I am completely conscious of it.

It would therefore seem that it is this aggregate of affective sensations relative to the end desired-or an equivalent aggregate of emotive sensations in generalwhich really constitutes that particular kind of sensations, common to the present and to the past state, which are necessary and sufficient to evoke that past state and to make it conscious. 
I say "necessary and sufficient to evoke that past state and to make it conscious," because there are certain examples which would seem to prove, and to place beyond a doubt, that we may very well have the recollection of a past event, and that the event may nevertheless continue to remain unconscious to us.

Thus Maury, in the classic work on dreams already referred to, tells us that one night he dreamed of an individual whom he did not know even by sight. In the morning when he awoke, the face of the unknown who had appeared to him in his sleep still remained very clearly in his memory. What was his astonishment to meet in the street a few days after, in flesh and blood, the unknown of whom he had dreamed. After long reflection, and only after some days had passed, he happened on the explanation of this strange coincidence. Several times, some months before, he had passed through the street in which he met the individual, and then he had no occasion to pass that way for more than a year, until the day before he had the dream. As for professional reasons he had taken to passing through this street rather frequently, he noticed that it often happened that he met this individual, who, no doubt, must have lived in it. So Maury thinks it extremely probable that the year before, when he passed through the street so often, he must have frequently met the man without taking any particular notice of him, and as the day before the dream he had been through the street, even if on that occasion he had not met the man, the fact was sufficient to evoke by association of ideas during the dream the recollection of the same individual. 
Hence, when Maury was awake and the image of his dream came back to his mind, that image constituted a real and characteristic mnemic evocation of an event which so far had been unconscious to him, and which, in spite of this evocation, still remained unconscious to him. The evoked image now succeeded in fixing his attention and interest, awakening in him sentiments of pleasure or dislike, sympathy or antipathy, or other analogous sentiments, but not one of these sentiments could now act as tinder to the spark to make "conscious" to him the moment at which he had really seen the individual.

If, on the contrary, preoccupations in other directions had not at that moment prevented him from feeling towards the man he passed the same sentiment which he now felt towards the image, this tinder, this common portion of affective sensations, would not have failed him then, and the event would in a flash have become "conscious" for him.

To sum up all I have so far said, it would seem that we cannot speak of the "consciousness" of a psychic state in itself, but only of the "consciousness" that a present psychic state has of a past psychic state; and that this "conscious" character of a past psychic state, now evoked, with reference to another present state, is met with whenever there is co-existence, for a certain time at least, of the first with the second, and partial superposition or fusion of one with the other. It is, however, necessary that this partial superposition or fusion should be principally produced in the affective part of the two psychic states.

We may now roughly picture to ourselves this partial 
superposition or fusion of the two psychic states by imagining that the cerebral zones, to the activity of which are due these 'two psychic states, the one present and the other evoked, coincide partially one with the other-that is to say, have a certain portion in common. It must here be remarked that the cerebral zone, to the activity of which the psychic state evoked is due, will be the same zone which was active in the past when the psychic state was produced for the first time.

Sometimes, particularly in the phenomena of introspection, if the past psychic state, conscious with respect to a new psychic state, lasts or continues to exist during the formation of the latter, only long enough to give the illusion that the two psychic states are contemporary and are blended into one psychic state, it is more difficult for us to see that in this case also it is a question of the consciousness of one state with respect to another; we then speak, although erroneously here also, of a psychic state "conscious in itself."

From the conscious character of one psychic state with respect to another we readily pass to the conscious character that the whole of a series of acts or successive psychic states have the one with respect to the other. Such a series we have when, with respect to the present psychic state, it is a just evoked antecedent state which appears as conscious, and when, with reference to the last evoked, another psychic state antecedent or subsequent, and also evoked, appears in its turn as conscious, and so on.

If we reflect on what we have done since the morning, it should convince us that parallel to the series of 
our conscious acts there are always succeeding corresponding complex affectivities, such that each, beginning to be activated before the cessation of the preceding act, continues afterwards during the first phases or the complete development of the following act, and sometimes even during a whole series of successive acts. Thus the sense of pleasure that I feel in approaching the end of a difficult piece of work, because I am tasting in advance the leisure that will follow, serves to link the two states, my present state to the following one in which I am really at rest. The desire not to fail at a rendezvous continues during the whole series of acts which have as their object the making haste and the not losing time.- The complex sentiment of pleasure and fear which the child experiences while he is greedily munching the stolen cake is common both to the moment at which he is eating the cake and to the following moment when he is taking pains to remove all traces of his little theft, and constitutes the affective bridge which connects the two lived episodes.

Let the axis of abscissæ represent the time. To fix the ideas, suppose that points and segments on the axis of ordinates represent by their position and magnitude the different portions of the total cerebral surface to the activity of which are due the different complex psychic states: as if the different sensitive and affective centres could be arranged along that axis without altering their respective contiguity or proximity. Then for our schematic figure representing a series of original psychic states, $a, b, c, \ldots$ capable, as long as time has not effaced the mnemic impression left, of ultimately appearing as conscious one to another, we shall have a 
series of rectangles of different sizes and shapes, overlapping one another so that each, especially with respect to their affective portions, is partly superposed on its immediate predecessor.

If above and below this connected series of rectangles others are drawn connected in the same manner, none of which having any portion, especially an affective portion, common to any of those of the first series, the second would represent a series of psychic states $x, y$, $z$, . . ., also conscious one with respect to another, but unconscious with respect to the principal series $a$, $b, c$, . . constituting the " consciousness," properly so called, of the individual; they would thus represent with respect to that individual a short series of unconscious states, giving rise to the beginning of a doubling of his personality. On the contrary, two series of rectangles, the one produced in a certain period and the other in another period, even distinct and remote from the first, may by their simultaneous evocation be considered as one single series, provided that some rectangle of the first series has an affective portion in common with another rectangle of the other/series.

These short series of unconscious states constituting the beginning of a doubling of the personality, are, as is well known, common enough even in normal individuals.

During a summer holiday at Riva Valdobbia, at the foot of Monte Rosa, I used to walk every day along the mule-path of $\mathrm{Ca}$ ' di Janzo. The descent, especially at that time, was rough and broken. One had to jump from one stone to another, and as some of the stones were in unstable equilibrium, one had to watch where the 
feet were placed. The first few times I made the descent the little difficulties amused me, and kept the interest alive in surmounting them one by one. I remembered the principal stones that I had come across on other mornings, and if I remembered that the day before certain of these stones had given way under my feet and threatened to roll down the slope, I took my precautions accordingly. At the end of my walk, all the little events of the descent, all my most difficult steps and jumps, came back to my mind and appeared to me as "conscious."

At first for a few days this walk served as an excellent diversion from my usual meditations, because it awakened all my interest. Little by little, however, this interest, and the preoccupation with the little difficulties that had to be surmounted, diminished to such an extent that ultimately I made the descent quite mechanically, thinking of something else, just as if I were walking on the high road. All my steps, however difficult, the leaps from one stone to another-even those I had to take so as not to move the stones, and although some of the stones had certainly been moved from their places since I went by last-had become to me so many unconscious acts. In fact, I found myself returning to my hotel without the slightest recollection of any of the surmounted difficulties which would have made me conscious of the descent.

And yet, even during this unconscious descent, I must certainly have paid considerable attention to the stones, judging from the manner in which I carefully placed my feet on them so that they should not roll down ; moreover, a large number of them had changed 
position day by day from the incessant traffic up and down the path, so that my steps cannot have been simple reflex actions, but must certainly have been guided by connected acts of reflection.

In this example, what appeared to me as conscious at the end of my walk was the series of my meditations, and what appeared to me as unconscious was the series of sensations and reactions provoked in me by the external world. Sometimes, however, the exact opposite happens: the series of external sensations remains conscious to us, and the internal meditation remains unconscious, for all depends on the fortuitous circumstances which decide one of the two series to link up with the one which will then be the principal series, the consciousness, properly so called, of the individual.

Thus, when one is exhausted after a fruitless attempt to solve a problem, and goes out for a rest and change, all the agreeable sensations aroused by the walk, and they alone, appear to him on his return as conscious; but suddenly, like a flash, the solution of the problem he had attacked in vain comes into his mind: the internal meditation, without which it would have been impossible to have reached the sought-for solution, has therefore, no doubt, taken place, but it has all the while been unconscious to him. Cases of the solution of celebrated scientific problems reached in this unconscious way are too well known for it to be necessary to give instances of them here.

Sometimes the series of internal meditations remains unconscious to us as well as the series of sensations of the external world. Maury tells us that one day " finding myself near M. F., a man of very absent- 
minded habits, and much given to meditation, I noticed that he was not taking the slightest notice of what I was saying, and ceased to answer me. He seemed in a state of deep reflection. He was so motionless that I thought he had fainted. I shook him violently by the arm. 'What do you want ?' said he. 'Are you ill ?' I replied. 'No!' 'What is the matter with you, then?' 'I was thinking.' 'What about?' ' Well, that is very odd. I have not the slightest idea, and yet I feel as if I was tired out with thinking." " I

In this case, the series of sensations provoked by the questions which Maury had continued to put to him for a certain time, as the series of his own thoughts, had remained unconscious to him.

From these normal cases of transient doubling of the personality, which embrace all cases of so-called absentmindedness, we pass by degrees to pathological cases of genuine and characteristic doubling of personality. Very characteristic in this respect is the case reported by Taine: "I have seen a woman who, while she was talking or singing, wrote, without a glance at the paper, consecutive phrases, and even whole pages, without the slightest idea of what she had written. I believe her to have been perfectly sincere: now she declared that when she had reached the foot of the page she had no idea of what she had written; when she read what she had written she was astonished, and sometimes alarmed. Even the writing was unlike her usual script. The movement of the fingers and of the pencil was stiff, and seemed automatic. Her writing always ended with a signature, that of a dead person, and bore the mark of 
intimate thoughts, of a mental background that the writer would not like to reveal to others." I

Quite analogous is the case related by Janet: he suggested to an hysterical subject named Lucie, then in the state of somnambulism, that when she was awakened she would write a letter at a given signal. When awakened she wrote as follows: "Madame, I cannot come on Sunday as arranged. Pray accept my excuses. It will give me great pleasure to come with you, but I cannot accept for that day. Your friend, LUCIE.-P.S. Please give the children all sorts of messages." "This automatic letter," says Janet, " is correct, and shows reflection. While she was writing, she was talking, and answering several people on all sorts of subjects. Besides, she knew nothing about the letter when I showed it to her, and stoutly maintained that I had copied her signature." 2

In another experiment Janet suggested to the same subject during the hypnotic sleep: " "You will multiply 739 by 42.' When she awoke, at the given signal her right hand began to write down the figures in order, and went through the whole operation and without a stop until the work was finished. The whole time she was broad awake, and was telling me how she had spent the day, and she continued to talk the whole time her right hand was correctly working out the sum." 3

Other genuine and characteristic doublings of the personality, substantially similar to these now mentioned, prove most clearly what I have above remarked :

Tuine, De l'intelligence, 8th edition, Paris, Hachette, I897, i, pp. 16-17.

2 Janet, L'automatisme psychologique, Paris, Alcan, I907, pp. 263-4.

3 Ibid., p. 263. 
the psychic states $x, y, z, \ldots$, unconscious with respect to the principal series $a, b, c, \ldots$, may, on the contrary, be conscious to one another, if the conditions I have laid down are also satisfied. In fact, double personality consists in just this: a long series of states, unconscious for one of the personalities, constitute, on the contrary, for the other a series of conscious states.

Thus, for instance, in the case of the somnambulist, what he does during the attack appears to him unconscious as soon as he "comes to," but becomes in many cases conscious to him in the next attack. Dr. Mesnel's patient continued during an attack the preparations for suicide she had planned and commenced during the previous attack, of which she had no recollection at all during the lucid interval. She then remembered the whole of the circumstances of the other attack. Macario quotes the case of a young somnambulist who was violated during an attack, and in the waking state had no recollection of what had happened. It was only in the next attack that she told her mother of the outrage.I

Sometimes one state is conscious of another, while the latter is not conscious of the former. Thus, for instance, Dr. Azam's case of a young woman with double personality, "who had a normal state-though itself pathological, for she was an hysterical subject-and another state in which her character and ideas were quite different from those in the first state. In the latter state she remembered what she had done in the former, but in the former state she completely forgot

I Maury, op. cit., p 234. 
what she had said and done in the latter. So she seemed to be two distinct persons, and his alternation of personality presented a significant analogy to natural somnambulism, without the young woman being, properly speaking, a somnambulist." I

These examples, which could be multiplied to any extent, are peculiarly appropriate to show that each psychic state is not in itself either conscious or unconscious, but becomes one or the other only in relation to some other psychic state. In other words, consciousness is not in itself a character which belongs, as its very own, to a psychic state: it characterizes a relation between two or more psychic states.

A psychic state, even when considered in isolation, may always be recognized as having, for instance, one emotive character rather than another, as imaginative rather than volitive, and so on, while, as long as it is isolated, we can never say that it is conscious or unconscious. So that only when it is referred to another psychic state can we say, with respect to the latter, it is conscious or unconscious. And if it is conscious with respect to a psychic state $\mathrm{A}$, it may be unconscious with respect to another psychic state $B$.

Consciousness is thus not an intrinsic or absolute property of psychic states, but a property extrinsic and relative, which accompanies certain modalities of reference existing between those states.

Maury, ibid., pp. 237-8. 


\section{THE RELIGIOUS PHENOMENON}

THE religious phenomenon presents itself at first sight as a double paradox-psychological and sociological. We see, formed and fixed in the human mind, beliefs which are the very antithesis of what is suggested to us by the experience of our daily lives. We see the rise and development in the social organism of a wellspecialized organ, the principal function of which from the very outset seems to be nothing but the useless squandering of valuable collective energies. We see, for instance, individuals offering food to inanimate objects, and repeating the same act day after day, although the food thus offered is never touched; or we see them offering up daily prayers to motionless images, although their prayers have never the slightest effect; and we see societies, whose economic situation is still precarious, consecrating to the construction of noble temples efforts and wealth far greater than they spend on their own dwellings, consuming in sacrifices or votive offerings whole herds of cattle and other capital of enormous social value, and maintaining at great expense a numerous priestly caste, apparently unproductive and parasitic.

Thus two fundamental problems present themselves, 
quite distinct although connected, the one psychological and the other sociological; and it may be added that because of the vital questions connected with them their solution has been the preoccupation of every philosophical mind.

As far as the psychological problem is concerned, and here I will touch on it but briefly, it is now generally admitted, with Hume, that at the base of all religious conceptions is found the preconceived opinion that primitive man makes for himself, by an irresistible association of ideas and the hasty generalization resulting from it, at every unexpected happening in the physical world in which he lives - the opinion that events are caused by one'or more wills similar to that of man. As soon as his mental attitude is thus turned to " animism," the different religious beliefs may have respectively different origins-of euemeristic, zoolatrous, fetishistic nature, and so on-these multiple origins being then quite compatible one with another.

The fact that very often, even in real life, if the effects of hostile acts emanating from the will of an enemy are tangible, the latter remains unknown to the victim, explains the persistence of the bias to animism, although experience has never furnished a direct proof of it; moreover, the notion of the double, which in Spencer's opinion is spontaneously formed by the intermediary of dreams, of our own reflected image and of our shadow, gives the opportunity of substituting for the proven and undeniable inertia of a sensible object the action of its invisible double.

' V. G. Foucart, La méthode comparatie'c dans l'hisloire des religions Paris, Picard, 1909, p. 108. 
But that is not enough, for then we must attribute a religious character also to the similar beliefs of the higher animals which, as their behaviour shows, also attribute to hostile beings the unexpected cosmic events which particularly strike their attention. It is here that we find coming into play and affirming itself one of the most remarkable intellectual and affective differences between man and animals, on which in general sufficient stress is not laid. I allude to the mental and emotive form of the propitiatory act.

The attitude of animals in the universal struggle for existence is that of either flight or attack; they ignore the propitiatory act. The new intermediary attitude appears only in the struggle between man and man. It required a notable development of the highest intellectual faculties of observation, inhibition, and reasoning, so that experience could teach the conqueror the advantage of sparing the conquered when he surrendered, and at the same time could teach the conquered the advantage he could secure to his safety by the very act of propitiation. It is therefore only in these ancestors of man who were the first to practise the propitiatory act with respect to their fellows that this habit could be extended to other beings, whose conduct they supposed to be inspired by motives analogous to their own. The first man who threw himself prostrate, but no longer before another man, was the first believer and the first founder of all religions.

Experience, moreover, teaches us that among the propitiatory acts addressed to our fellows, some succeed and others fail; but the latter cannot invalidate the 
utility of the former. There will rather be a tendency to attribute the failure, as is most frequently the case, to some mistake or flaw in the propitiatory act itself. Thus in the case of acts of religious propitiation, failure after failure cannot shake the general belief in their utility, a belief which is strengthened by the rare successes due to chance, and which then in return strengthens the animist bias in which it found its source. It is thus that a large number of complicated religious rites, the rigorous and minute observances demanded by prayer and sacrifice, spring precisely from this desire to perfect and complete the propitiatory act itself, to whose supposed imperfection and insufficiency is attributed the precedent failures. ${ }^{x}$

The mental form of propitiation is thus added to the original animistic bias to awaken, develop, and strengthen religious faith in primitive minds. But this is not yet sufficient to explain how this tenacious faith persists in minds infinitely superior to those of the first men, in spite of a wider experience, which far from providing positive support is ever undermining it by fresh denials that the progress of the reasoning faculties should cause to be appreciated at their full value, and in spite of the contradiction which gradually appears, and daily becomes more marked, between thental form which connects cosmic phenomena with the free play of one or more quite arbitrary wills, and the scientific concept "which makes slow but continuous headway and recognizes in nature the existence of invariable laws.

We find invoked as an explanation the inhibitive G, Foucart, op. cit., p. 155 . 
and deformative action exercised upon the faculties of observation and reasoning by the intense affective states. In fact, a strong, keen affection or emotion, which prevails in an exclusive and durable manner over all others, quickens our sensitiveness to certain sensations and dulls them to others; it provokes or reinforces the evocation of certain recollections, while it checks or weakens that of certain others; it impresses a given direction upon the imaginative process and assigns a well-determined end to that of reasoning; and in this way it produces and maintains only such mental states as directly or indirectly support, strengthen, or satisfy it, while it succeeds in eliminating all that remain incompatible with it. This affective selection of mental states operated by the religious sentiment of fear, may thus serve to explain the duration of beliefs conforming to it, although reality is continually giving them the lie.

But if every individual were left free to observe and to form his own opinion, apart from outside suggestion, of all that is going on in the world around him, we cannot understand-given that at any time his natural conditions of existence ought not to have been such as to keep him in a state of perpetual terror-how there could have sprung up in him and have been maintained a religious emotivity so intense and so capable of opposing with so much success the most obvious experiences of daily life.

Here, then, we must appeal to the incessant operation of an external suggestion exercised by the community, so as to maintain and renew artificially in each individual and at every moment of his life, the state of religious 
dread that natural circumstances would produce only in some individuals and by accident.

Thus before the psychological problem can be completely solved, we must first solve the sociological problem relative to the existence of this social organ of religious suggestion.

Following the principle of Lamarck, which holds good for the organism of animals as well as for society, the mere fact of the existence of an organ implies the utility to the organism of the function exercised by that organ. It is, in fact, to the exercise of such a function, demanded and supported by the vital needs or necessities of the aggregate of the organism, that are to be attributed the formation and development of the organ in question. Thus there can be no doubt whatever as to the utility of the social function of the religious organ, and the less or greater development of the latter must take place in direct ratio to the need of society for its functional activity.

The very fact alluded to above of the act of submission and propitiation, which makes its appearance and is developed as a substitute for flight, tends to show that man was at grips with man since the stage of pre-social development and that, as soon as that state of isolation was succeeded by even a semblance of collective life, it must have been characterized by a certain parasitism or exploitation of some to the advantage of others, and therefore by a kind of differentiation or rudimentary division of labour. Otherwise, had there been no struggle of man with man, we could not understand how pacific relations could ever have given rise to a propitiatory act imploring pity; and inversely, 
without parasitism or any other analogous form of the exploitation of man by man, we could not explain how any interest could urge the conqueror to spare the vanquished, which was the very object of the act of submission and propitiation.

In animal species in which the individuals live in pacific relations, e.g. among the herbivorous mammals, the propitiatory act neither exists nor can exist, and collective life is formed without parasitism or differentiation of activity, solely for the advantage it affords against the attacks of the carnivorous species; in such societies of animals the mere spirit of gregariousness, so admirably analysed by Galton, then constitutes the necessary and sufficient psychic link. On the other hand, in the other type of animal societies, with more or less partial or total parasitism and social division of labour, such as we see in polymorphous social insects, it is the very diversity of structure and the corresponding variety in the instinct which assigns to each its individual rôle, while for the unity of the whole, and for the uniform acts of all the members who are often called upon en masse to flee or to attack an enemy, to emigrate, etc., all they require is that rapid suggestion or individual transmission of the corresponding emotive state, and the psychic unity which results from it throughout the whole group, of which Espinas was one of the first to give us a masterly description. ${ }^{x}$

Let me repeat that in man, on the contrary, the very existence of the act of submission, of propitiation,

Cf. Francis Galton, Inquiries into Human Faculties, London, Macmillan, 1883 : Gregarious Instincts, pp. 68-83 ; Alf. Espinas, Les Socićtés animales, 2nd edition, Paris, Germer Baillère, 1878 , sect. iii, c. ii : La Société chez les insectés. 
of appeal for pity, teaches us that human society has emerged from a pre-existing fratricidal struggle, and from the advantage that the conqueror reaped when for the death of the vanquished he substituted certain parasitic relations, or relations of exploitation, which mark a beginning of differentiation or division of labour. Now, these dependent relationships, these relations of economic and technical inequality, given the organic equality of individuals, could be preserved only by maintaining in the vanquished that same state of fear with respect to the conqueror which provoked the first act of submission, and which ought now to reduce the vanquished to the blindest obedience.

Thence arises the necessity for the conqueror, now the chief of a small society of his vanquished and subjugated fellows, to keep them in a state of healthy terror, and therefore of using every available means capable of giving to his subjects, always increasing in number, the highest possible idea of his formidable power. $\mathrm{He}$ would therefore have to draw more and more advantage from each and every cosmic event inspiring terror or fear, and from each and every painful accident which befell any member of the community, by representing each of these facts as a menace or a personal punishment emanating directly from him, or that he had expressly solicited from some other occult authority, his potent ally. And in this there is not always a question of pure astuteness, for as he himself believed in the animism of nature around him, he could not do less than attribute his own success to the propitious aid of this cosmic force or that, his ally and protector, and therefore he must believe in his intervention and 
must have recourse to it at every serious conjuncture of life. ${ }^{\text {I }}$

This vague religious sentiment, already naturally more or less diffused among all human beings, was thus, owing to this action of religious suggestion exercised incessantly by the chief, and owing to the uniformity thereby given to the different animistic beliefs of individuals, bound to become day by day more powerful and more definite. By the submission and devotion it secured in this way from the vanquished to the chief whose efforts had succeeded in giving rise to the first nucleus of the social group, by the blind obedience it imposed upon all the members to the commands of a single mind directing and regulating the first still rudimentary social relations, religious sentiment itself thus assumed from the outset the task of consolidating the social order. We understand then how its activity and the development of its own organ (the special and distinct formation of which dates from the first delegation of certain religious functions exercised by the chief to priests charged with the duty of representing him) have of necessity followed a path parallel to the development of society; for as the numbers increased, the need was more and more felt of such a function of social consolidation and regulation, adapted to make of a simple amorphous and fluid aggregate of individuals, otherwise each capable of leading its own independent and isolated life, one single consistent whole, and, in fact, a real social organism:

I Against the theories of the eighteenth century on "imposture" vide, among others, Salomon Reinach, Orphcus, Histoire générale des religions, Paris, Picard, 1909, pp. I2-19. 
It follows that in ancient societies religion constitutes in itself alone the whole "psychic" scaffolding so indispensable to the solidity of the social edifice, and that it penetrates, regulates, directs and stimulates the energy of each member of the community at each moment of his existence.

Thus it is that religion raises and sustains all the social institutions-beginning with that of individual or collective property-which serve as dikes, either to contain and canalize the course of certain series of social facts or relations, or to oppose an irresistible barrier to antisocial acts or relations. Every " social thing," i.e. that it is of collective interest to fix and to preserve, becomes at the same time a " sacred thing," which may not be touched without "sin." Civil obligation and religious duty are, as Sumner Maine also shows, one and the same thing. As Reinach puts it, religion is therefore nothing but an aggregate of taboos opposed to the free exercise of individual faculties. I

All law has thus a purely religious origin, and the social order which it now guarantees in our civil societies was based at first entirely on religion, the sanction of which, at a time when other sanctions were technically of no avail whatever, remained the only one which could be really efficacious. Note that every infraction of the taboo, every antisocial act, by the very sanction that it necessitated, gave occasion to the religious organ to exert its function, and that with an energy proportioned to the extent to which society had experienced

' Sumner Maine, Ancient Law (186r), London, Murray, r908, pp. 3 et seq., 16 et seq.; Salomon Reinach, op. cit. : Hist. gén. des relig., p. 4 . 
injury and to the consequent need of strengthening by this sanction the respect due to the prohibition which had just been infringed: hence the continuous exercise and correlative development which were thus assured to that organ.

To these institutions regulating individual acts or relations must be added others which classified all the members of the society into a multitude of social compartments according to age, sex, celibacy or marriage, profession, caste, and so on. Each of these special groups is essentially organized on religious bases, and to pass from one to the other it is necessary to submit to the corresponding ceremonies prescribed by religion. From birth to death the individual is therefore involved in an interminable series of rites of fellowship, initiation, consecration, of which those which linger on in our society of to-day, like circumcision, baptism, communion, extreme unction, religious marriage, etc., give us 'but a very feeble idea. As Van' Gennep observes, every society may be compared in a way to a kind of house divided into many rooms and corridors, with their walls the thicker and their doors the narrower in proportion to the multiplication of the religious ceremonies necessary to pass from one to the other. ${ }^{\mathrm{I}}$

Besides this work of static consolidation and ordinance, religion was further entrusted with the task of determining and provoking directly all activities of social interest, especially those the efficacy of which absolutely depended on their simultaneous and coordinated character. It might be a matter of folding

${ }^{x}$ Cf. Van Gennep, Les rites de passage, Paris, Nourry, 1909, e.g. pp. 2 , $36,271-6$. 
up one's tents and migrating to another region, and making a choice of a new temporary or permanent residence; it might be a question of assembling or going a-hunting, or distributing and consuming the game; but there was no economic act, collective or individual, which religion had not clothed with a sacred character, and had thus imposed on all the forms necessary to general observance. In this connection there is nothing more typical than the agrarian rites and sacrifices-e.g. those of Adonis, Attis, and Osiris, so widespread in the ancient world, and of which we still have a remembrance left in the unleavened bread and the paschal lamb-by their very origin and their primitive significance they ultimately directed, guided, and regulated in general all the works of the field-sowing, harvest, irrigation, etc. ${ }^{I}$

It is this need of disciplining and regulating all the details of everyday collective life which thus gives rise to the primitive function of the calendar, which, as Hubert and Mauss point out, is essentially religious. The first calendars, in fact, do not undertake to measure the course of time as quantity; but they proceed from the qualitative idea of time composed of parts considered by religion to be heterogeneous. Every part of the calendar, every portion of time, whatever it may be, always has in it a sacred char-

Cf. J. G. Frazer, The Golden Bough, 3rd edition, Part IV : Adonis, Attis, Osiris, London, Macmillan, 1907, in particular Bk. iii, c. iii : The Calendar of the Egyptian Farmer, Rites of Irrigation, Rites of Sowing, Rites of Harvest; Grant Allen, The Evolution of the Idea of God, London, The De La More Press, c. xiii : Gods of Cultivation; c. xiv : Corn and Wine Gods; Goblet d'Alviella, Les rites de la moisson et les commencoments de l'agriculture, "Revue de l'histoire des religions," Paris, Leroux, I 898 . 
acter : every day is a holiday and has its Saint; every hour has its special prayer. Every moment of the year thus carries with it religious prescriptions, positive or negative, which impress a fixed and regular course on the whole of the development of social life.

We may note that the more solemn and complicated was the rite that accompanied a given social fact, the more the recollection of the fact itself was perpetuated in the whole community. Thus the rites which consecrated the boundaries of a recently occupied territory fixed in the imagination of all the bond established between this fixed portion of land and its proprietor, whether an individual or the community. The excommunication inflicted on any one who broke a taboo marked with indelible mark the antisocial individual against whom all were now fully warned. The rite which accompanied the entrance of a member of a tribe into one of the social compartments alluded to above formed a kind of mnemic registration, the utility of which for the individual and the community cannot be doubted, if we think of the value of our own administrative registrations which are their equivalents and substitutes. The ceremonies which accompanied the completion of a given kind of rural work helped to keep alive in all the idea of that act, with all the necessary details which might otherwise have been forgotten or altered. The appropriate rites of the successive feasts of the calendar assured the annual return of the same social acts; thus they gave rise to and strengthened the traditional and preservative tendency of society, which is not one of the least factors in social cohe- 
sion. Religion therefore acted quite properly as a real mnemic organ, adapted to preserve in the community all the memories and to communicate to it all the habits or routines which would be of any advantage to it. And the more the social organism felt the value of reinforcing certain mnemic registrations, or of stereotyping certain acts, the better was it understood that the corresponding rite must be complicated and become invested with a greater solemnity, so that here again the need created and developed the organ capable of satisfying it.

Religious action contributed, finally, to the consolidation of the social edifice by developing in all the meilibers of the same community that sense of psychic communion, equivalent in many ways to the sense of gregariousness referred to above, and an immediate consequence of the same mental and affective orientation which religion succeeded in producing in all its ceremonies and on innumerable occasions by means of the most varied suggestions.

Such in broad outline are the different means by which religion succeeded in satisfying the need for cohesion and organization felt by society-a need which grew as the number of members in the community increased and its territory became more extended. But it was in time of war that this need for consolidation and unification became particularly marked, and that the religious function assumed the importance of a matter of life or death.

No social activity, in fact, set the religious organ in motion more notably than war, and it therefore exercised on it an intense trophic action. 
The ancient fratricidal struggle between man and man, from which as we have seen the first social embryos arose, continued in their successors with no less fury than in the past. As war, i.e. as struggle of the whole of one community against another, it claimed from the social organism the same co-ordinated, simultaneous, and rapid action of its different elements that the animal organism is capable of providing for the individual struggle. It was a question, in other words, of giving to a naturally incoherent assemblage of individuals the supple and powerful vigour of a beast of prey;

If an act of insubordination were harmful in time of peace, reluctant obedience in time of war might be absolutely fatal. Then more than ever it was necessary to guarantee the blindest and promptest obedience of all to their leader, to compel isolated individuals to behave themselves towards their chief in the same way, so to speak, as the somatic cells of the organism with respect to the higher psychic centres.

Now it was precisely this absolute submission that religion was above all called upon to guarantee and that it secured to perfection. "It cannot," says Spencer, "be repeated often enough, that from the most remote times to our own days the unvarying and essential action of the priesthood at all times and in all places and in the name of every creed has been to inculcate obedience." I

Thus, for instance, the sacred or divine character of the prince, which the religious organ tended to fortify incessantly in countless different ways, made the smallest act of insubordination in general an act of sacrilege.

× Spencer, Principes de sociologie, Paris, Alcan, I887, t. iv, p. I74. 
To guarantee fidelity and discipline in given circumstances of unusual importance, recourse everywhere and always was had to the oath, i.e. to a religious act by which the man who pledged his word called down upon himself, through the priest who administered the oath, the divine anger in case of perjury.

It was religion again which succeeded wonderfully in evoking and intensifying all the "social instincts" most likely to guarantee by their " release" the simultaneous and overwhelming outburst of the whole community, such as tribal or racial hate, or the most ardent fanaticism. ${ }^{\mathbf{I}}$

The favourable responses of the oracles, the construction and consecration of votive temples, and the other solemn ceremonies at the beginning of each war, the blessing of the troops, of arms, or standards, sacrifices, prayers, and thanksgivings before, during, and after each battle, the carrying of the gods, the holy ark, or other sacred objects on to the field of battle-all these were so many religious manifestations satisfying the need of inspiring the combatants with a great faith in victory, which is in itself an essential element in success. ${ }^{2}$

By these means, which thus we see always employed by religion to adapt more effectively the community for the collective struggle, we see how war must double the feverish activity of the religious function. It will consequently appear to us very natural that at each period of prolonged and bloody wars the religious organ

- Cf. Letourneau, L'évolution religieuse, Paris, Vigot, 1908, p. 553 ; and La guerre dans les diverses races humaines, Paris, Bataille, I895, pp. 4I, 128, 131, I61-80, 354, 384, 405-7, 413, 448, 522, etc.

${ }^{2} \mathrm{Cr}$. Spencer, op. cit., t. iv, c. $\mathrm{x}$ : Fonctions militaires des prêtres. 
should be developed, and the intensity of the religious sentiment should be increased; and inversely every prolonged interval of peace must have lessened the religious activity of the organ and therefore have weakened the religious sentiment.

Thus we see that eminently warlike tribes and peoples are also the most religious, and that among the different characters belonging to the militarist type of societies may be distinguished that " of an enormously developed priesthood." I

After the great Roman peace we see the religious sentiment weakened to such a point that it can no longer offer any resistance to the proletarian agitation of Christianism, and inversely we see in the Middle Ages the most intense fanaticism side by side with a state of perpetual war. ${ }^{2}$

Buckle also shows us in his masterly pages how the incessant struggles between the Christians and Moors in Spain, and the no less furious and bloody struggle between the English and Scotch, which lasted from the end of the thirteenth century to the middle of the sixteenth century, provoked on both sides a violent religious exaltation of which the effects were felt long after in the history of those countries. 3

To sum up these far too cursory remarks, we see then that to all the causes mentioned above, which have

"Cf. Lubbock, On the Origin of the Civilisation of Man, London, Longmans, Green \& Co., 1889, p. 214 ; and Spencer, op. cit., t. iv, pp. 162-3.

af. Renan, Histoire des origines du Christianisme, Les Apôtres, Paris, C. Levy, 1884 , c. xviii : Etat du monde vers le milieu du premier siècle; and Kidd, L'évolution sociale, Paris, Guillaumin, I896, pp. I2I-7.

3 Buckle, Histoire de la Civilisation en Angleterre, Paris, Marpon et Flammarion, 1881, t. iv and v. 
tended to develop in societies the religious organ, even in times of peace, there must yet be added another, that produced by war, which we must consider as the greatest, the most universal, and the most fundamental of all social activities. ${ }^{x}$

Hence if we consider the nature and importance of all these causes which have never ceased in all societies to contribute to the formation and progressive development of the religious organ, the religious phenomenon from the sociological point of view loses the paradoxical character it had at first.

But then this paradoxical character is also lost if considered purely from the psychological point of view. For we cannot fail to understand the enormous formative influence that must be exercised upon the mental and affective life by this ever-acting organ of collective suggestion, of social hypnotization; which daily, and almost at every hour of the day, laboured to spread the growth of faith and to inculcate dogma; which maintained believers in a continuously emotive state, by the nightmare of the awful vengeance of the gods or by the mirage of ineffable celestial rewards; which appealed to every form of art--architecture, sculpture, painting, the dance, music, and poetry-to present the divinity in the most awe-inspiring forms, to increase the mysterious sense of sacred things, or to raise mystical exaltation to the point of ecstasy; which made a wonderful use of ritualism, that is to say, of the mechanical and always identical repetition of the

I For a more complete development of this thesis vide Eugenio Rignano, Un socialisme en harmonie avec la doctrine économique libérale Paris, Giard et Brière, 1904, last chapter, sect. 3 : De la fonction sociale de la religion. 
same ceremonies, to turn the mind in certain fixed directions, and to impress upon it irresistible habits of thought.

However, thanks to the progress of human civilization, we see all these causes, which have contributed in the past to the creation and development of the religious organ, growing now weaker and weaker, especially in the civil societies of our own time, and tending one after another to disappear, because there have been gradually formed distinct organs for those functions, always useful, which religion alone hitherto exercised, or because the need of others for these functions of religion is no longer felt.

It is needless to insist at length on the fact that the legal organ and the administrative organ, in the widest sense of the word, which used to be attached to that of religion, have been gradually differentiated and separated from it, until now we may call them completely "lay." Every new need for the consolidation of the social order no longer sets in motion the religious organ, but only the legal or the administrative apparatus. Social institutions and law in general have been transformed and developed without the slightest intervention of the religious organ. To all forms of antisocial activity are now opposed legal sanctions or preventive measures of more or less value, but recourse is no longer had to any new or better devised religious sanction. For the old religious organization, founded on the division of society into so many compartments with

' Cf. Guyau, L'irréligion de l'avenir, Paris, Alcan, 1905, pp. 107-8, 227-312 ; and Letourneau, op. cit. : L'évol. relig., p. 385. 
a religious basis, the modern tendency is to substitute a purely administrative or civil organization.

On the other hand, it is science applied to all the arts which now directs the practical and economic activity of the whole of society; it is to it alone, i.e. to a later development of the social organ of scientific research, of teaching and popularization of knowledge and of the best technical methods, that appeal is made under all circumstances in which a new and imperious necessity makes itself felt. Thus also in this domain, in which religion in former days exercised its regulating functions, it has gradually lost all the ground.

In the same way the regular and ordered course of social life, that the calendar established by its daily prescriptions, is naturally secured at present by a mass of social machinery, springing from an ever more specialized and extended division of labour.

No longer do we utilize the mnemic function, which as we have seen was connected in a more or less accessory manner to all religious ceremonies, because its place is taken by administrative registration, which in practice has given rise to notable progress; for example, the mnemic function of the so-called rites of passage, to which I have referred above, and whose mystic symbolism contained so much suggestive poetry, is now better done by dry civil formalities; the solemnity of the pact or contract sworn before the god or on the sacred writings, which was remembered only in its general lines and only by those who were present at the ceremony, is replaced by the legal transcription of the contract which sets forth the act in its smallest details, and 
which all concerned may examine when need arises; for the consecration of boundaries we now prefer, as somewhat safer in case of dispute, the ordnance map or cadastral survey, and so on.

As for the need of "psychic communion," it corresponded formerly to an essential and vital condition of the social organism, when, from the importance at that time of domestic economy, and from the fact that division of labour was still rudimentary, the different family units, or other fractions of the community, were individually capable of an autonomous and independent life, and would therefore have had a continual tendency to disaggregation and separation but for the artificial psychic bond by which religion kept them united; but this need became felt less and less as a much more natural and powerful bond was formed and strengthened, namely, that multitude of economic relations which are directly derived from a more and more specialized and extended division of labour, so as to create between the different units or social fractions a material and indissoluble dependence. Thus we see that the religious bond is replaced in society by the economic, and to "psychic communion" succeeds the sentiment of social solidarity which is no longer the result of suggestion, but of the action of the reasoning faculty.

And finally war, which as we have seen was only the continuation under the collective form of the presocial individual struggle for existence, from being chronic as it was when produced by the violent pressure of the population on the means of subsistence, has gradually occurred only from time to time, and then has become rarer and rarer. 
In fact, parallel to the destructive work of war, the productive forces followed an ascendant progress, which was partly due to war itself : for example, slavery permitted for the first time an embryonic division of labour, and made labour compulsory and therefore more intense and better co-ordinated to the common effort; similarly, the fusion of small groups into larger and larger social groups gave an opportunity for the unceasing specialization and extension of the division of labour. For a greater part this progress was due, on the contrary, to the normal course of internal economic evolution, continuously kept in motion by the moderate stage of food pressure. This continual improvement of production rendered rarer and rarer the violent crises of social pressure on the means of subsistence which necessarily brought war in their train. At the same time, owing to the absolute increase in population made possible by economic progress, war became less and less capable of relieving this food pressure, by such means of destruction as cannibalism, the raiding of flocks and herds, or slaughter of the enemy in order to occupy the territory on which he grazed his cattle or grew his crops.

In proportion, however, as food pressure, properly so called, ceased to be a cause of war, another and ever more potent cause arose, due to the economic interests of the ruling class-a class' co-existing from the outset with, society itself, evolving and perpetuating itself under the most divergent forms of economic exploitation. But in the same manner as the continual progress of productive forces lessened food pressure, and at the same time made war an absolutely unsuitable method 
of relieving it, so the fresh progress realized later in production, and in particular the remarkable advances of modern times, have not only opened a number of new markets for the money lust of the different dominant classes and sub-classes of capitalists, but by the very fact of creating international economic relations, ever growing in number and in intimate relationship, they have led to the following situation, that even should their own country win a war, these dominant classes and sub-classes, instead of making profits in the course of a war between civilized nations, would make enormous losses. The present war will be the most conclusive and convincing demonstration of this truth.

With this very high stag of productive perfection attained by human society, wit this very remarkable degree of development now attained for the first time by economic evolution, war is condemned to disappear, as, for analogous economic reasons mentioned above, have disappeared from among us the ancient horrors of cannibalism or the total destruction of the enemy population. ${ }^{x}$

And this fact, that war is ever becoming rarer, and tends gradually to disappear, deprives the activity of the religic's function of another of its most powerful stimulants.

To sum up, we see, then, that if in the past innumerable d.fferent and pressing social needs were always setting in motion and had the effect of developing the religious organ, in modern times, on the contrary, in consequence of the progress of social evolution, all the

* For a development of this thesis vide Eug. Rignano, op. cit.: Un socialisme, etc., last chapter, sect. 4 : De la gwerre. 
essential motives of the activity of the religious function have insensibly ceased to act, so that the religious organ is condemned to a state of more and more marked disuse, the slow but inevitable consequence of which isatrophy.

It is not surprising, then, that to this state of increasing inactivity corresponds in the human mind of to-day the gradual shaking off of every 1-ind of dogma and a general weakening of faith. The more so as, side by side with this progressive inaction of the religious function, we have, on the one hand, the wonderful development of the productive processes involving that of all science in general, and, on the other hand, the fact, still more important, of the diffusion in all social strata of an ever-growing technico-scientific culture, due to the never-ceasing application of industrial discoveries and to the technical instruction of the working classes which the dominant capitalist class itself directly encourages, as the skilful workman is now indispensable to it. The prodigious development of science in every branch of knowledge, the diffusion of technical culture and of instruction in general, the popularization of the conception of natural laws, immutable, and regulating the various transformations of matter, all these facts, which give to the mind a scientific as opposed to a religious outlook, ultimately exercise a destructive influence on religious beliefs, which becomes more and more efficacious, in proportion as the organ destined to support and strengthen those beliefs has lost from day to day its functional energy.

Thus was accomplished, not merely in the restricted circle of an intellectual elite, but gradually in all the 
social classes, that transition of human thought from the primordial animist or theological to the positive scientific form, the evolution celebrated in Comte's famous formula. But it was not accomplished, as the great philosopher thought, solely by the innate virtue of the human mind tending inevitably of itself to move in the philosophical-positive direction, requiring no external stimulus and without any possibility of recoil. The transition, on the contrary, has been aided by a number of social circumstances, all of which now cooperate for the first time in the same direction, of which the first and most important are the slow but continuous atrophy of the religious organ, and the simultaneous development of a marvellous technique of production, more and more regulating and subordinating the forces of nature and all the manifestations of matter. ${ }^{x}$

But other psychological and sociological factors of secondary importance are acting in their turn, either retarding or hastening this gradual enfranchisement of society from the obsession of the "divine."

The rapidity of such a progress differs, for example, according to the mental character of each people or race. From this point of view we see a typical diversity between the Anglo-Saxon and the French mentalities.

While the former excels in the capacity of registering and retaining a number of facts of the most disparate and independent nature, and is less inclined to the protracted tension accompanying a long process of

- Vide Eug. Rignano, La sociologie dans le cours de philosophie positive d'Auguste Comte, Paris, Giard et Brière, I902, pp. 38-40 ; Italian edition, Palermo, Sandron, I904, pp. Io9-13. 
reasoning, the latter, on the contrary, seems incapable of assimilating so large and chaotic a mass of facts, and tends to connect them as far as possible by a logical bond and to embrace them in a synthesis. The first of the two mentalities, first and foremost practical, is, to use a strong expression of Taine, nothing but a simple collection of facts; the other, the classic mentality, as the same writer calls it, is nothing but a reasoning machine. In fact, the qualities of breadth and depth, which according to Duhem form the essential distinction between the mentalities of scientific Englishmen and Frenchmen, also form the difference we mark between the average mentalities of the two races.I

It is precisely to this nature of the British mentality, less ready than the French to seize upon the logical incompatibilities between religious beliefs and scientific truths, that is at least partly due the fact that the weakening and disappearance of faith is taking place more slowly in the Anglo-Saxon than in the Latin race. While the Latin race passes suddenly and without transition from Catholicism to real and complete irreligion, the Anglo-Saxon, on the contrary, proceeds by steps, rejecting one by one and not in the mass the different religious absurdities, and permitting the appearance of sects which are constantly springing up, whose common feature is the more and more marked tendency to eliminate all beliefs that are

' Cf. Taine, Notes sur l'Angleterre, Paris, Hachette, 1845, c. viii :- De l'esprit anglais; Les origines de la France contemporaine, Paris, Hachette, Bk. iii, c. ii : L'esprit classique; and Duhem, La théorie physique, son objet et sa structure, Paris, Chevalier et Rivière, 1906, Part I, c. iv, par. i : Les esprits amples et les esprits profonds. 
precise and concrete, and to reduce religion to a mere symbolical morality.

Further, the religious organ, by favouring the development of a priestly caste economically distinct from the rest, and especially as a consequence of the use that is made of it by the leading social classes in the defence of their own interests, also enters into the great historico-materialistic drama of the struggle between classes. In past times, when certain classes had become so powerful that they could successfully resist those who till then had been the dominant classes, they were urged by their economic interests, when they were checked in their efforts to bring the religious organ to their side, to provoke religious revolutions or reforms, without shaking the religious sentiment itself. In more modern times, on the contrary, this same interest leads to a frontal attack on the very principle of religion, and thus on its side contributes a notable impulse to the more or less rapid propagation of irreligion. Before the French Revolution, for instance, the vogue of the Voltairean spirit is explained by the conflict between the bourgeoisie and the religious organ, which was then in the service of the feudal rights ; but the secret or open support which, on the contrary, it nowadays receives from the same bourgeoisie, and the appearance of a religious reawakening which sometimes follows from it in certain countries or districts, finds its economic explanation in the powerful help that religion can now

- Vide in Renan, Études d'/listuire religieuse, Paris, Michel Lévy, I864, the typical religious movement of Channing in the United States; and Guyau, op. cit., Part II, c. ii : La foi symbolique et morale : dissolution de la foi symbolique. 
give to the capitalist class by delaying the outbreak of proletarian demands. ${ }^{\mathrm{I}}$

But the religious sentiment is endangered by this very reliance of the capitalist classes upon its aid: in the struggle with the supporters of capitalist privilege, the labour classes and Socialists, all the world over, are carrying on active anti-religious propaganda.

Differences in ethnic mentality, economic motives of interested classes, and many other factors of less importance-such as the frequency of earthquakes and other tellurian cataclysms in certain countries (Buckle), the dangers inherent in certain local industries (the Breton fisheries), the solitude in which certain scattered populations are forced to live, and many other causes besides-may thus more or less hasten or retard the tendency of the modern society towards an irreligion which day by day is obviously extending its frontiers; but these are merely disturbing elements, more or less negligible, in comparison with the powerful movement of general evolution which the other much more deeply seated causes I have referred to seem to render henceforth irresistible and inevitable.

We know, however, there have been of late various arguments against this definitive decline of the supernatural and the sacred, announced by so many signs on the social horizon; they may be grouped into two not quite independent classes, to which I will now devote a few remarks.

Kidd maintains that religion must always be a condition of social survival, in the sense that irreligious societies are doomed to perish in the universal struggle

- Vide the following Essay: Historic Materialism. 
for life in which they come into conflict with societies that remain religious. His fundamental idea appears to be that a society composed of individuals guided by reason alone will be so occupied with the present, i.e. the greatest happiness of the greatest number of their own generation, that they will pay no attention to the future of the species. The rôle of religion would therefore be to bring society to that anti-rational outlook on things which would secure it the best conditions for future success.

And what is the nature of this supreme principle of anti-rational conduct inculcated in modern societies by Christianity with the object of guaranteeing to it the best conditions of success ? According to Kidd it would be a principle, the nascent germ of which is in this religion, but which, having been latent for some eighteen hundred years at least, can only now at last develop and bear fruit. It is the principle of equality, with which is interwoven the henceforth irresistible tendency to make equal for all individuals the initial conditions of the economic struggle; this system which guarantees the survival only of the best would ipso facto secure the survival of the Christian society as a whole over any other society persisting in a less equalizing regime. ${ }^{\mathrm{x}}$

Kidd's theory is really very curious ; for it destroys in its development everything that is at first attractive in the fundamental idea on which it is based. We could have understood, for instance, how, given the author's

I Cf. Kidd, op. cit. : L'évolution sociale ; and Principles of Western Civilisation, London, Macmillan, I908; and The Two Principal Laws of Sociology, "Scientia," I907, IV-4, and I908, V-I. 
point of departure, he might have been inclined to prove that a non-equitable regime, i.e. one that does not guarantee the greatest happiness of the greatest number of its living members, may also be the better adapted to secure victory in the mass-struggle, or war, against other societies-as is the case in societies of a despoticomilitary type; from which he would have concluded that religion, the guarantee and support of such a nonequitable regime, has up to now been the condition sine quá non of social survival. But no! in spite of all the teachings of history, and of even the most obvious facts lying before our eyes, led astray by the spirit of the proletarian demands of primitive Christianity which quickly gave place to the contrary tendencies common to all religions, Kidd attributes to faith, which he supposes to be still alive, the movement of the society of to-day in favour of the working classes, a movement which on the contrary is the direct result of the general weakening of the religious sentiment, bringing in its train the rational proletarian agitation for a greater measure of social justice.

But apart from the particular development which he has given to this concept, we are bound to reject as inadmissible the very principle from which he has started. I refer to the power he attributes to natural selection to fix the social conditions which, while harmful to our present society, may secure its success in the future. Kidd, saturated with the theories of Weismann, has extended to society Weismann's biological coriception, by which, in natural selection, the utility of the individual comes after that of the species, so that somatic characters and functional particularities would be fixed, 
beginning with physiological death itself, which, while prejudicial to the individual, are none the less useful to the species. But this conception of Weismann's is now out of date, even in the domain of biology, because of the decreasing influence now attributed to the selective process in the evolution of species; and we could in no sense admit, for the social organisms considered as so many antagonistic units, those immense hecatombs of vanquished and that scanty band of survivors upon which the Neo-Darwinian school is obliged to depend in defending the claims to omnipotence of natural selection. Lastly, considering the ever-increasing respect that is now being paid to the theories of Lamarck on the function which creates the organ, sociological science, less than any other science, can no longer admit that an organ may arise and be developed, unless it is preceded by some function which responds to certain effective requirements of living society, and which by its repeated exercise gradually and directly impresses on it an appropriate growth and form. ${ }^{\mathrm{I}}$

The popularity of Kidd's theories may be explained by the fact that they seemed to support indirectly the other class of argument which argues in favour of the permanent vitality of religion, and of which I shall now give a rapid summary.

It is said that religion, having left all other fields of social activity, is more than ever necessary in that of morality; that without moral principles no society

" For a more detailed examination of the debate between Neo-Lamarckians and Neo-Darwinians, vide my already mentioned work : Sur la transmissibilité des caractères acquis. Hypothèse d'une centro-epigénèse, c. v: La question de la trans. des car. acq. English edition, Chicago, The Open Court Publishing Company, IgIr. 
can persist, and that religion alone is capable of establishing, inculcating, and strengthening them. Hence, according to these writers, arises the very grave danger that society is at present running if it does not check in time its descent to irreligion.

Here we must distinguish. Even if it is not explicitly confessed, there exists a great apprehension of the daily widening and imperious movement of the claims of the proletariat. For the moment it is limited to what is called social legislation. But there is little doubt that some day or other, when they feel that they are strong enough to do so, the workers will attack and transform from top to bottom, in the direction they deem most to their own advantage, even the most fundamental of social institutions, beginning with the rights of property. This movement is a direct result of the weakening of the religious sentiment in the working classes, a sentiment which, in conformity with its own function, always predisposed them in the past to bow before the ruling powers, whatever they might be. But it is quite clear that this has nothing to do with the question of morality. It is rather an episode, perhaps the most impressive of all, in the secular struggle between classes, which, just because it is provoked by the most exploited and the most oppressed classes, can end-very probably by pacific and legal methods-only in a more equitable social transformation, i.e. in one that is more in conformity with the well-being of the majority.

As for the moral question, properly so called, it subdivides into two, one of which is concerned with the establishment of what are called "moral principles" 
as well as their evolution towards higher and higher forms, while the other refers to the difficulty of extending and strengthening these principles in the community.

Now, in all that concerns moral evolution one fact stands out clearly, and Stuart Mill has noted this in the essay in which he clearly shows the inutility of religion in the future: that it is to the progress of ideas and sentiments, which takes place in society outside the religious sentiment, that the moral improvement of religions is due, and it is not to the latter that we owe the former. And that is so, because the collective conscience has always been more ready to adapt itself to the new and higher forms of economic evolution which permitted the continuous softening and refinement of social life. But religion, from its very nature conservative in everything, has always opposed the most tenacious resistance to every change-even of the ethics it has made its own. This is precisely why Mill is of opinion that not only will future progress be possible without religion, but that the disappearance of all religion will make that progress easier. ${ }^{\mathrm{I}}$

On the other hand, as far as the propagation and strengthening of moral principles are concerned, in which in every age social circumstances or the interest of the dominant class required that the community should share, it is certain that this was one of the capital missions of all religions, or better still that, as we have seen, it was the function from which they drew their very origin, and which constituted so to speak their

- Vide Stuart Mill, Three Essays on Religion, 3rd edition, London, Longmans, Green \& Co., 1885, second essay : Utility of Religion, p. 75. 
raison d'être. But in this as in every other domain, religion is seen supplanted gradually by another organ, now marvellously developed and much more efficient, the function of which consists in the formation and manifestation of the collective conscience.

Built up by every means of communication and transmission of thought, by the most varied methods of the propagation of ideas, by all of what we call the organs of public opinion, by every kind of meeting and association adapted to elicit and to express the resultant of many individual wills, by all the representative systems in every department of social activity, this complex apparatus of the collective conscience now allows, with greater and greater facility and perfection and in an ever-increasing number of cases, of concerted agreement and action between the components of each social group or sub-group, and thus between all the members of society in general. It exercises in consequence an ever-increasing and decisive influence in all the domains of social activity, and therefore also in the domain of morality.

Thus the unanimous acquiescence of society in those fixed moral principles which are really indispensable or useful to the existence or to the well-being, not only of this or that social dominant class, but of society as a whole, imposes itself upon each individual with an authority, which is no less powerful than that which was at one time exercised by religion; and the praise and blame, the esteem and contempt of public opinion have daily acquired greater and greater importance, so that henceforth it becomes for the large majority 
of individuals the principal mainspring of all their actions. ${ }^{\text {I }}$

In every way we are certain of one fact, that the only organ actually brought into play to fight immorality is the organ of the collective conscience and not the religious organ. Associations against this or that moral danger, propaganda founded on reliable statistics in connection with the individual and social injury caused by certain vices, electoral and press campaigns against scandals, public or tacit ostracism of this or that more typical representative of antisocial morality-these are the only methods employed by society of to-day to combat antisocial tendencies, and they take the place of the celestial thunderbolts which are now and forever abandoned as useless.

And it proceeds in the same way when it is a question of promulgating or affirming directly some new moral principle, or of raising the collective morality in some direction or other which seems to be urgent: educative systems adapted to the fashioning and orientation, durably and to the desired end, of the effective faculties of youth; new and more varied ways of manifesting public approval in such a form that it will be more eagerly desired than it is at present; ever greater care and discernment in awarding public esteem, so that we no longer see moral and social positions, to which that esteem alone should constitute a claim, occupied by men unworthy of such posts; and finally, and above all, a high appreciation of the pride which each man must feel in his own "social value," and which, where the weak and base remain confined

I Cf Stuart Mill, op. cit., second essay, pp. 78-8I, 84-7 
within their narrow egoism, impels, on the contrary, a man to spend himself for others, and to furnish the greatest possible contribution to well-being and social utility.

Finally, the more the social conscience extends and improves, the more easily it discovers and lays bare the distress, the pain and the injustice, which by reason of their humble origin have hitherto remained inarticulate. Thus society daily becomes more sensitive, its emotivity becomes refined, its sense of justice is broadened, its moral level is raised to a height at all times greater than that of which religion has as yet given us even a distant glimpse.

Society, henceforth guided in its progress by principles of a' purely rational order, may now regard with tranquil serenity the definitive and not inglorious decline of one of the forms of its activity which responds no longer to its needs, but to which none the less does it owe its origin, its development, and its present civilization.

But if religion seems thus doomed to extinction as a social organ and phenomenon, we cannot judge it in the same way if we consider it as a psychic manifestation and individual fact. The projection of our own individual finalism outside ourselves into the whole universe, the last philosophico-metaphysical remnant of the grossly animistic conception of primitive man, the aspiration for the triumph of good over evil, the still more general need to believe that everything that has value for us, even when we are for the moment

"Cf. Eug. Rignano, La Morale razionale, "Riv. It. di Sociologie," January-February 1906, pp. 97 et seq. 
deprived of it, is always preserved unimpaired through all the changes and chances' of 'the real world, for a later realization: all this joined to the sweetest, most intimate, and ineffable consolations that illusion born of ardent desire is capable of giving, such are and will remain for ever the eternal sources of religious feeling for all minds with a more or less mystical tendency.

This mystical elite can thus keep alight within its heart, and transmit in the ages to come from one generation to another, the sacred torch of religion, as long as human life shall endure. ${ }^{\mathrm{I}}$

- Cf. Luigi Valli, Il fondamento psicologico dclla religione, Roma, Loescher, I894, c. viii : L'essenza della religione ; Harold Höffding, Religionsphilosophie, Leipzig, Reisland, I901, c. iii : Psychologische Religionsphilosophie, in particular Sect. D : Der Satz von der Erhaltung des Wertes; Stuart Mill, op. cit., second essay : Utility of Religion, p. I20. 


\section{VII}

\section{HISTORIC MATERIALISM}

IT may be said that historic Materialism has represented and still represents in sociological science the analogous movement of ideas which took place at the beginning of the last century in biological science, when it was applied to unfold the relative importance of the different morphological characteristics, for the purpose of a natural classification of species, and a wider knowledge of the vital phenomena of the organism.

And just as that movement had as its aim to show how much more important in this respect is the inmost and deepest structure of the organism than the external and more obvious conformation, so historic Materialism came into existence to protest against the excessive importance always awarded by historians and historical philosophers to certain external social manifestations of quite a secondary order, while they entirely neglected other more obscure and humble phenomena, which, at first of no interest at all, are, on the contrary, of the greatest value in the study of the complicated mechanism and evolution of the whole of social life.

The social phenomenon considered by historic Mate- 
rialism as the most important of all is, as we know, the economic phenomenon.

But historic Materialism $\operatorname{did}^{\text {not }}$ nop there! At the same time as it recognized by the aid of a powerful synthesis the supreme importance of the economic structure or organization with respect to all other sociological phenomena, it further and unwarrantably affirmed the irresistible nature of the course of economic phenomena, which, although successively fixing and shaping in its own image the whole social superstructure, built up of legal, political, ethical and ideological phenomena, was in its turn influenced by none of these. It was thus impossible for it ever to be inflienced by man's will, even if collective, and therefore not even by law, which is the most direct manifestation of that collective will.

Thus historic Materialism came to assert a merely one-sided rather than a completely reciprocal interdependence of the different social phenomena, and gave to the evolution of society a rigidly fatalistic colouring. Besides, the economic structure itself, on which would depend the whole social superstructure, would in its turn be fixed at each stage of its evolution by the successive modes of being of a supreme factor which, compelled by its very nature to suffer continual transformation, would thus inevitably induce and give direction to the whole of social and economic evolution.

To Marx this supreme factor would be the instrument of production in the wide sense of the word, or what he calls by the name of " material productive forces." Its action would be notable especially in the determina- 
tion of the transition from domestic to capitalistic economy and from the regime of small industry to the present regime of the factory system. To others this primordial factor would be something quite different. Thus Loria finds it in the density of population, the continual increase of which would have determined by the past the four successive fundamental states-collective, slave-holding, servile, and wage-earning-and which would still continue to determine all the secondary manifestations of the latter. To other experts the first impulse would again be something else. But in all alike the fundamental thesis remains unaltered, that the economic structure is self-evolved by its own intrinsic force, modifying gradually in a corresponding manner the whole social superstructure, without on its side in any way being influenced by this superstructure, and not even by the law which is its most important manifestation.

It cannot be denied that a whole series of facts, well established by evidence, give a strong appearance of truth to this way of looking at things. Thus we are familiar with the impotence of many laws in the presence of certain economic phenomena which they tend either to further or to check. As an example it will be sufficient to recall the mercantile laws of the seventeenth and eighteenth centuries, which aimed at making the balance of commerce as favourable as possible to the continual increase of the mass of precious metals in the country, and in our own time, the anti-trust laws of the United States. On the other hand, a number of these laws, quite powerless at the outset to struggle against given economic phenomena, have seen in the 
long run their field of application reduced little by little to nothing, because of the transformations effected by economic phenomena quite outside their influence. Such were the laws against usury in the Middle Ages, which, powerless at first to cope with the high rate of interest, continued in many cases to subsist even when the natural drop of the rate of profit, and therefore of the interest of money itself, made them completely useless. Such laws continuing to subsist for some time at least, although no longer useful-becoming obsolete as the English say-and the existence thereby revealed of a kind of force of inertia in law, seem to indicate that legal phenomena, far from outstripping economic phenomena, which they should modify, are, on the contrary, themselves dragged along at the heels of the latter, and have no choice but to follow.

The most important transformations to which an economic regime may be exposed may sometimes also be produced in the course of the natural evolution of the economic process, without law entering into the matter at all. This is demonstrated by all those cases in which the latter exists side by side with, and, so to say, is impassable to, the economic evolution, i.e. without its fundamental outlines being subjected, for any length of time at least, to any modification. Thus the above-mentioned gradual transformation of the regime of small industry into the factory system which has, may I say, completely changed the aspect of the capitalistic regime, and which Marx has so excellently described in his magnum opus, was almost entirely accomplished while the law of property remained unchanged in its fundamental conformation, and even 
before the other legal institutions more especially concerned with this side of the economic process perceived the change which had supervened.

The most profound social transformations themselves may be produced unknown to law. Thus it was that during the decline of the Roman Empire the increasing rarity and therefore the increasing price of slaves on the one hand, and on the other the progressive impoverishment of a large portion of the ever more numerous and more necessitous parasitic class, which created a proletariat of free men and of freedmen, spontaneously gave rise to the gradual replacing of slavery by servile labour in agriculture, and by wage-earning labour in the arts and trades, both being economically more convenient.

But do these, and other similar facts which might be multiplied at leisure, suffice to prove the absolute independence and immutability of economic phenomena in the presence of other social facts, and especially the impossibility of ever being modified by the collective human will, whatever may be the institutions in which that collective will is manifested? Or do they not rather merely go to show that because of the intrinsic difference in the modes of action of these two most fundamental social factors, the economic and the legal, their reciprocal influences and interferences are connected with certain well-determined conditions for which we must look?

A solemn denial, the more effective because it has been made in our own days, has already been given to this affirmation of the irresistible and inevitable nature of the social evolution by the repeated successes of the 
associations created by the working classes in selfdefence, of which the first and the most celebrated were the English trade unions, in their struggle for the increase of wages. While the natural course of the economic process must have led to a progressive impoverishment and a degradation of the working classes, the collective action of the latter ultimately modified it to its advantage.

If conscious collective action by itself alone, even before assuming the character of a real legal phenomenon, thus shows itself capable of changing in one direction rather than in another the course of economic phenomena, must it not be $d /$ priori presumed that it is all the more capable of it, at least in certain cases, when it is manifested and consolidated in law in general, which prolongs the period of its efficacy, and particularly in the law of property which encircles and dams in the whole course of economic phenomena? Now there is more than enough confirmation $a$ posteriori of this presumption.

Let us compare, for instance, the two regimes of the ownership of land in France and England. In the latter, the Norman usurpers and their descendants, having become by conquest the proprietors of the whole of the soil, and being small in number compared to the rest of the population, aimed at preserving their monopoly by instituting, as was done everywhere else at the time, the entailed estate and the trust, and these resulted in the maintenance of latifundia, or the system of very large landed property. At an interval of several centuries, in France, the expropriation of the property of the nobility and the clergy by the middle classes of 
the Revolution, the expropriating class being in this case a much larger fraction of the whole population, ended, on the contrary, in a breaking up of the land, which was favoured still more by the special testamentary and legacy laws that the middle classes themselves hastened to pass to avoid the danger of seeing the gradual reappearance of the system of large estates. It is thus that the difference between the two systems of property, between the two legal systems blocking and guiding the course of the rural economic phenomena, led to quite different economic manifestations and evolutions: in the one case, immense territorial properties, absenteeism, pasturage to the detriment of cereals, the depopulation of the land, evictions of whole rural populations, and great inequality in the distribution of wealth ; on the other, an over-division of the soil, the proprietor cultivating his own land, intensive agriculture, the spirit of thrift general and intense, and a greater equality in distribution.

But we must be careful not to conclude that in these cases the regime of property reflects and follows the economic process; for it is, on the contrary, evident that it precedes and determines it.

We could mention a great number of similar instances to prove that the law effectively possesses in given conditions a determinative efficacy in economic phenomena; but this is quite unnecessary, because historic Materialism, by its second fundamental thesis, has itself contributed a very strong and decisive argument against its first thesis, represented by the so-called "inevitable" course of the economic process. This second thesis is true, and historic Materialism has 
supported it by a very large number of facts, but it absolutely contradicts the former : I refer to the struggle between class and class.

By the sociological law of this struggle historic Materialism has, in fact, affirmed that by far the largest number of the most striking social facts which constitute the texture of history are but the more or less direct or indirect results and manifestations of the incessant struggle in every society between the different classes, each being drawn into it by its own particular economic motive. As Marx and Engels wrote in the celebrated Manifesto of the Communist Party, "the history of society so far has been the history of the struggle between class and class."

By "struggle," we must merely understand in this case the tendency of each conscious social group, economically homogeneous, to increase its economic advantages at the expense of all the other groups. "The egoism of individuals," writes Spencer in his Study of Sociology, "leads to an egoism of the class they form ; and besides the separate efforts, generates a joint effort to get an undue share of the aggregate proceeds of social activity. The aggressive tendencies thus developed in each class have to be balanced by like aggressive tendencies in other classes."

Looked at in this way, the class struggle in the midst of the social organism corresponds exactly to the struggle of the different parts, organs, tissues, and cells, revealed by Wilhelm Roux, which goes on continually in every organism. And so this class struggle appears only as one of the numerous manifestations and consequences of that universal and irresistible tendency of life towards 
self-expansion, the primordial and fundamental stimulus of the whole of organic evolution both biological and sociological.

But it is not enough to say that this struggle between classes exists. We must study and know the different ways in which it comes to be manifested, either directly in the economic field, or indirectly in all the other social fields, and it will be equally necessary to follow step by step the continual changes in the respective efficacy or "weight" of each of these classes in so far as they are sociological factors, and the effects produced in turn by these changes-changes during the periods of so-called revolutions, which eventually reach their culminating point in the alternate succession of these classes to power. It is by proceeding in this way that we can really succeed in throwing a dazzling light either on the changes which supervene in the political and legal constitution of the different States, and in all the other social internal manifestations in general, ethical and ideological included, or on the external acts themselves of society, in so far as the latter forms a distinct unit, such as wars, treaties of peace, dismemberment or fusion of States, imperialism, and the like.

Social phenomena which appeared to be utterly unlike and to be due to the most different causes have thus been reduced to a single cause, assimilated to each other, and therefore explained in the real sense of the word as used by positive philosophy. The search for the economic motive of this or that social class as the stimulus or factor of historic events which at first sight might seem to be produced by causes of quite a different kind, or of which the cause was not understood 
at all, and the search for the causes, in most cases economic, altering incessantly the respective "weights" of the different social classes, have thus come to be the corner stone of a whole series of historical reconstructions upon a scientific basis.

The most typical of the historical facts upon which the founders of historic Materialism more especially endeavour to support and sustain their doctrine of this struggle of classes are too well known for it to be worth while to dwell upon them here. In the Crusades, for instance, they point to the economic interest which the dominant classes of the flourishing Italian republics, of Venice in particular, had in making war against the Turk to secure for themselves the rich markets of the East. The reformation associated with the name of Luther appears due, not so much to the desire to get rid of dogma, as to avoid the heavy taxes levied by Rome in various ways, including the sale of indulgences. The diffusion of Christianity is shown in its origin to be a real movement of proletarian demand. The removal of the capital from Rome to Byzantium and the elevation of Christianity to the rank of the official religion are attributed by Renan himself to the displacement of the centre of gravity of the empire caused by the preponderating "weight" acquired by the wealthy commercial classes of the East, the bourgeoisie of those days, who clung to the Christian proletariat to counterbalance and to crush the old Roman parasitic aristocracy. The great French Revolution at once appeared to all as the effect of the sudden rupture of an equilibrium which had long been unstable, in consequence of the preponderance the capitalist 


\section{I98 ESSAYS IN SCIENTIFIC SYNTHESIS}

middle classes had acquired over the landed nobility. And even the numerous successive political crises in France, which as mere ideologies remain an inexplicable mystery-Bonapartist, Legitimist, Orleanist, Republican, Plebiscitist, and so on-are, on the contrary, at once understood if we look at them in the light of the multiple economic interests in play, which under these names fight for the triumph of one over the other: interests of the actual holders of lands already nationalized and of the former expropriated proprietors, of the great landed property partly restored under the Bourbons, and of the manufactures and high finance represented by the House of Orleans, of the small trades and businesses to which with the aid of the working classes we owe the Revolution of 1848 and the peasant proprietors on whom Napoleon III relied -all these political transformations thus reduce in turn to one and the same fundamental cause, to the struggle between the different economic classes, as Marx himself has shown us in the suggestive pages in which he applies and illustrates his doctrine.

Some writers, like Vilfredo Pareto in his Systemes socialistes, see in the class struggle nothing, but a struggle of elites, each trying to supplant the other. But we must distinguish between a struggle of elites each relying on its own social class, and a struggle of elites within one and the same social class. In the first case the elite represents only the necessary rallying centre for the dispersed members of the class, the organ which synthetizes and co-ordinates the collective will, which thus comes to be disengaged less confusedly from the individual wills. The struggle of elites is in this case 
only the superficial aspect under which is hidden the far deeper and far more fundamental phenomenon of the struggle of classes. In the second case, on the contrary, in which the élites all look for support from the same social class, and each tries to eject the other from power, this fact represents but a later and secondary variation of the primary and principal phenomenon. The preponderance of one elite rather than another is to the fact of the struggle maintained by this class against its antagonists what the fact of this or that accidental harmonic note accompanying the fundamental note is to the vibration of the latter. The different élites who succeed one another only change, so to speak, the timbre of the real and typical struggle which the class as a whole persists in carrying on without essential variations. Thus it was that the succession of the different elites within the revolutionary bourgeoisie class during the most critical period of the great French Revolution, and the quarrels of the different élites in the socialist party of to-day, do not sensibly alter the substance of the principal fact, which, under this sorry disguise, is all the while an imposing historic phenomenon of fundamental importance.

On the other hand, by this assertion that there is a struggle of classes in which each is guided by some economic motive, historic Materialism has not the slightest intention of denying the existence of even the noblest individual aspirations, free from any material interest, however slight; it affirms only that they cannot influence the action of a conscious collectivity with homogeneous economic interests, in the moral 
attitude of which is reflected only the average of the commonest ethical characteristics of all its members.

Historic Materialism no longer excludes certain collective ideal aspirations, nor does it deny their effect on the masses. But in cases of this kind we have to do with " social instincts," such as religious faith, racial hatred, and the like, i.e. collective tendencies with stereotyped modes of reaction, impulsive, and unthinking, in fact quite like the instincts or reflex movements of the animal organism. And the " conscious" classes, i.e. those whose members, on the contrary, have the faculty of acting in concert under the influence of reason, then utilize these collective instincts for their economic motives. Thus when Peter the Hermit incited the crowds to deliver the Holy Sepulchre, neither Peter nor the crowds were acting under the influence of any economic motive; but the conscious classes knew very well how to turn to their economic advantage this valuable unconscious force.

There are some who refuse to admit that every conscious class does act always and exclusively to its own advantage, because they see the dominant classes sometimes and even often take measures or make laws which turn to their own detriment and are to the advantage of the dominated classes. Such, for instance, is all the so-called social legislation of the present day in favour of the working classes. But in holding this view they forget that a class, however remote it may be from power, may always in spite of that have even a considerable "weight," and that in one way or other it may always make that weight prevail. It is well known that even in absolute regimes, the class in power, 
court or nobility, is always forced to rely on one or other of the other social classes which, in its political intuition, it judges to be the most powerful. Now this counts for much more in these days of representative government. Thus Loria has very well shown that the struggle between the two English political parties, Conservative and Liberal, the one representing the interests of landed property and the other those of the industries, led to a whole series of legislative acts and measures in favour of the working classes, merely because each of the two parties was forced to make one concession after another in order to buy their support.

It is just because any class in power finds it must rely on other classes, i.e. must increase its own "weight" by their " weight," that the necessity arises of dressing up its economic motive in idealistic guise, so as to represent its plans of social action as of the most general possible interest.

Moreover, it is only by a quite natural and spontaneous tendency, and often in quite good faith, that the members of one given economic class are driven to take the particular interests of their class to be identical with the interests of society in general, and consequently to consider the social institutions or sanctions which favour or protect their particular interests as so many " natural rights" or "supreme principles of justice." It is possible and easy for each of us to investigate the subject by asking in succession several persons, belonging to the most different classes, any social question whatever of general application. Each of them, while developing considerations of general utility alone, will reach a solution agreeable to the interests of his own 
class. Thus, for instance, as concerns the relation between the individual and the State, the Manchester formula of laissez-faire, revived in Spencer's philosophico-legal theory of the individual against the State, no less than the opposite doctrine of State intervention by means of normative and controlling social legislation, will each find its most convinced supporters in the classes to the economic interest of which they respectively answer.

And so by the appearance on the political scene of new classes which give new directions to social action, and by the continual change of values or relative social "weights" of the different classes, we are very often able to explain the successive rise and fall of certain economic, legal, ethical, and philosophical doctrines; a case in point is that of the Manchester school, now so discredited and yet so flourishing at the beginning of the past century.

On the other hand, when we see a people, such as the English of the seventeenth and eighteenth centuries, professing a religion eminently humanitarian, and yet introducing slavery into their American colonies, and there maintaining it, as soon as the economic advantage of the capitalist class required it, we are bound to recognize how illusory it is to count on collective idealities as effective social forces; it also shows what a mistake it would be to attribute the disappearance of slavery in the ancient Roman world to the Christian ideality of the human brotherhood.

It is only when the economic interests of the socially predominant classes happen to coincide with one of these collective idealities, always more or less present 
or latent in human beings, that this ideality, no longer attacked but encouraged by those who are interested, is developed, and expands and stirs the world, so that it appears to be itself the cause of the movement. It is the story of the fly on the wheel over again. Thus the humanitarian ideal of a universal peace, which in all times has given rise to the highest aspirations of the best minds, has begun effectively to take root only in our own days; because now for the first time the greater importance of international economic exchanges and relations in general has caused every economic crisis in one economically advanced country to be felt at once in all the rest; so that the capitalist class in every State feels itself menaced in its most vital interests by every war which may contingently break out between civilized nations, even if its own country should not take direct part in it. When, however, owing to the particular conditions of the economic development of a country, the economic interests of its dominant capitalist classes, together with its military power, are such as to hope to profit by a war, the humanitarian ideal which appeared so efficacious becomes quite powerless, as we have learned from the present terrible war upon which Germany has not hesitated to embark for merely economic motives.

To sum up what I have now rapidly and incompletely developed on the subject of the action that the different classes in conflict may take to produce the most fundamental facts of history and to determine the direction of the whole of social evolution in general, the fundamental contradiction $I$ have indicated above, into which the doctrine of historic Materialism has 
fallen, is made perfectly clear to our minds. Historic Materialism, in fact, announces on the one hand that the struggle between classes is the supreme law of history, and that it is this struggle which makes history; on the other, it denies that the action of classes can ever have, either by direct action on economic phenomena themselves or by suitable modifications in the law of property and in legal institutions in general, any determining effect on the course of the economic process, which must follow undisturbed its independent and inevitable evolution.

Can a greater contradiction be imagined? Either the struggle between the different classes, each tending to secure for itself the greatest economic advantage, exists, and it follows that economic phenomena may be modified in one direction or another according as this or that class becomes preponderant; or, the economic process, as immutable as the orbits of the planets in the heavens, follows its inevitable course apart from any human influence whatever, and then the struggle between classes, the sole object of which is to change the economic process, can no longer exist for the want of anything to fight about. Thus certain changes in the course of the sun would certainly offer great economic advantages to northern races, and disadvantages to the people of the South, but I think it would be idle to seek in the archives of history for any racial or class struggle having as its object the turning of the sun aside from its eternal path.

This fundamental error of Marxism has ended in serious damage to the socialist movement. The prediction of the near and necessary approach of 
the collectivist regime, in which none is exploited and none is exploiter, was no doubt at first of considerable value in inspiring and diffusing in the masses the socialistic gospel and creed, just as faith in the near approach of the millennium contributed to the diffusion of Christianity. But in the end it became itself, on the contrary, the principal cause of the present profound crisis in the socialist party in every country, for it had no other proposal to make than ... to await the inevitable maturity of the collectivist regime.

If, on the contrary, we admit the possibility that the economic process may raise to the rank of a preponderating or co-determining sociological factor a new class, whose interest is, for instance, to introduce into the legal institution of property certain changes which would assure it new and greater economic advantages, and that these changes when once introduced would modify the economic process in the desired and foreseen direction, then this will be the action of this conscious class, efficaciously exercised by the intermediary of suitable modifications of the law of property, and not at all a process of internal evolution, which will constitute the effective cause of the change supervening in the course of economic phenomena. Even if we admit, what is not always the case, that the growth of the power of this new class is exclusively the result of the manner in which the economic process previously developed, this would not in any way prevent the work of that class, as soon as it became the prepondering factor, from being a sociological factor effective for itself, of a nature quite different from that of the real economic phenomenon. 
Once this startling contradiction of historic Materialism has been rejected, which has seriously and deeply invalidated every scientific application of this doctrine that even its best exponents have made, then this law of the struggle of class against class is effectively shown to be one of the finest conquests of sociological science, because, with the exception of a few economic laws properly so called, it is the first which has made possible for sociology that prevision which is the supreme end of all science and the measure of the degree of perfection to which it has attained. ${ }^{\text {I }}$

In many cases it will, in fact, be sufficient to examine which social classes would see their interests favoured and which would find theirs prejudiced by a given contingent social action, such as a war, a modification in the rights of property, a law, or other measure, and to ascertain which of the two groups of classes is preponderating, i.e. which has the most "weight" as a sociological factor, to be able to see at once and with the utmost certainty if the event will or will not take place.

But to give this sociological law of class struggle an ever-increasing power of prevision, it must be completed. I have tried to do this in another volume, by looking first of all for the laws which govern the variations of the respective "weights" of the different social classes, and by then studying the laws which regulate the different possible modes of action of these classes, and the different efficiency of each of these possible

I See what I have already said on this subject in my essay : La sociologie dans le cours de philosophie positive d'Auguste Comte, Paris, Giard et Brière, 1902, pp. 41 et seq. ; Italian edition, Palermo, Sandron, 1904, pp. 1 I6 et seq. 
modes of action, which each class can follow when it has gained a markedly preponderating " weight," or acquired a new force capable of counterbalancing, in part at least, those of the other classes.

Among the elements which compete in determining the social "weight" of any particular group of individuals, the degree of perfection of the collective conscience of the group, its economic power, and the number of its components have appeared to be the most important of all. It must be noted, however, that the degree of perfection of the collective conscience -with which is connected the more or less closely harmonious action and the larger or smaller number of circumstances in which the group can work in concert -depends in its turn on other elements which are not all of an economic nature, elements which complicate considerably the phenomenon, and on which it would here be useless to dwell.r

As for the different modes of action possible to each class, they vary according to the "weight" it has relatively to the others. Thus it is only when it is not yet possible for it to direct its modifying action on legal phenomena that it turns directly to economic phenomena. This has happened, as we have seen, in the case of trade unions, and in general of all working-class organizations of resistance, from the first awakening of a collective conscience in the classes of workers. But it is only as a makeshift that any col-

"Cf. Eugenio Rignano, Di un socialismo in accordo colla dottrina economica liberale, Torino, Bocca, I90I ; French edition : Un socialisme en harmonic avec la doctrine économique libérale, Paris, Giard et Brière, I904; last chapter : La conscience collective prolćtarienne en tant que facteur sociologique. 
lectivity whatever resigns itself to adopt such a system of action, which has the minimum technical output, and which consequently is adopted only when the class is not yet strong enough to choose a better plan.

Collective action, in fact, is of an intermittent nature, because it implies for each of its manifestations a preliminary concerted agreement between an often considerable number of individuals. The economic phenomenon, on the contrary, and more than ever in these days, is continuous and is constantly changing. Acts of buying, selling, and transforming different kinds of goods go on without intermission; at each moment the prices of raw and manufactured materials change with the conditions of the market; it may be said that at every moment supply and demand in manual labour are also changing, and, in consequence, the conditions of labour. More stability in prices, it is true, is effected by combinations of buyers and sellers of the same goods, just as agreements between trade unions and associations of employers secure a greater stability in the conditions of manual labour, such as the hours in a day's work, wages, and the like. But that does not diminish the intrinsic difficulty which economic phenomena show in adapting themselves to this stability, and does not prevent them from tending to bear heavily on the rules imposed upon them by these conventions, and from withdrawing entirely from them when the term of the agreement has expired. And this occurs the more readily when on the side interested in rejecting these agreements there is the quick will of a single individual such as an employer, and on the other the will of a large collectivity, slow in expressing itself, 
and from its very nature prevented from that frequent repetition which would be nevertheless necessary for the preservation at least of the economic advantages already obtained.

To realize the slow, complicated, and costly machinery set in motion by even the best organized of the trade unions, whenever a rather important deliberation is necessary, we must read a few chapters of the classical Industrial Democracy of Sidney and Beatrice Webb, in which is told in detail the history of the wonderful system which has been gradually created by the most highly organized sections of the British working classes. And when any one of the unions, to give effect to its deliberations, is forced to enter into a struggle with its opponents, the employers, each is well aware of the immense economic sacrifice to which the conflict is bound to give rise.

It follows that the system of collective action aimed directly at the economic phenomenon, rendering necessary a frequent repetition of that action, must always be excessively costly, and therefore, as I have said above, must be technically imperfect. We thus understand how it comes about that immediately one class acquires the "weight" strictly necessary for it to be able to exert its determining influence upon the legal phenomena, it straightway turns its action on the latter, which represents a technically superior method.

In fact, the legal phenomenon crystallizing, so to speak, the desiderata of the class into a scheme of rules which are maintained by themselves-i.e. when once it is established it remains unaltered owing to the support derived from all the social organs affected to 
the maintenance and defence of law in general-it prolongs the operating efficacy of the collective will of the class, even beyond the moment of its effective activity; and, from being intermittent as it was, it makes it, with regard to its effects, as if it were continuous. Thus when a national syndicate of miners has agitated and secured by legislation an eight-hours day, however great the cost of this direct action on the legal phenomenon may be as compared with what would have been necessary if the concession had been wrung merely from the respective employers, it is always clear that the road followed is more advantageous, since for a long time to come there will be no need of a similar effort.

But of all legal phenomena the most important for its efficacy in determining or modifying the course of economic phenomena is the law of property. The legal phenomenon, in fact, in many cases meets with very great difficulties in enclosing and maintaining within its rigid framework of rules the economic phenomenon when the latter is in course of operation. The economic phenomenon, especially when the two parts between which it is produced, or even one of them alone, are formed of very small economic units, whether mere individuals or small businesses, is something fugitive and elusive, and easily slips through the meshes of the legal rules. Thus the sweating system, for example, like usury in the Middle Ages, mocks at all laws contrived to deal with it. It is in this very powerlessness to deal with the economic phenomenon which is revealed by the law in many cases that, as I have shown above, we must look 
for the origin of the exaggerated and therefore erroneous doctrine of the absolute immutability of economic phenomena relative to the human will.

But all economic actions and reactions start from given states of possession of property to produce and to arrive at other states of possession. So that, however free they may otherwise be left, or come to be in practice, to take place at will by contract between the different members of society, these economic actions and reactions cannot, however, escape the general framework of legal dispositions which regulates and establishes the different modalities of these initial and final states of possession. Thus, for instance, if a trust prevents the sale of a large landed property, the economic phenomena arising out of this state of possession would necessarily be quite different from those arising from the sale or division at will of a piece of land of equal size. If an entail requires the whole of the paternal patrimony to belong to the eldest child, the economic phenomena which on the death of the present holder must be produced by the different children, must of necessity be different from those which the children would give rise to were the patrimony to be left to be divided into equal portions among them. And so on. So that these legal rules determining the different modalities of the states of possession, and constituting what is called the law of property, operate like a system of dikes, suitable for canalizing in this or that direction, according to its conformation, the whole course of the economic phenomena. Thus there are such modifications of the law of property which, owing to the infinite forms it may 
naturally assume, present themselves as the most efficacious means of action at the disposal of any social class for the purpose of modifying to its advantage the economic process.

It is therefore natural that the action of the different classes should always turn with preference towards this means of maximum efficacy, as soon as their degree of power has made this possible to them. This condition is necessary, for just because of its efficacy in essentially modifying the respective economic conditions of the respective social classes, it is the means which meets with the most obstinate resistance on the part of the classes who would be injured by the introduction of these modifications. So much the more that, while the legal modifications of 'secondary importance, which directly concern merely certain particular categories of economic phenomena, interest only some of the numerous classes or sub-classes into which society is divided, so, on the contrary, because of the effects it has on the whole of economic life, a fundamental modification of the law of property interests them all more or less, so that they come in this way to take sides with one or other of the two principal antagonistic groups. Thus it is only when the "weight" of one of the classes or groups of classes happens to have a very marked preeminence on the previously preponderating "weight" of the other class or the other group that this means may be adopted and may succeed.

These fundamental alterations in the relative "weights" of the different social classes give rise to what are really at bottom social revolutions. But they do not always present themselves in the cata- 
strophic form of which the French Revolution is the classic instance. They may take place, especially nowadays, by perfectly peaceful and legal methods, owing to the safety valves provided by representative government. For instance, the profound modifications of the regime of landed property which England was forced some years ago to grant to Ireland, the introduction of higher and higher death duties both in England and the colonies of Australia and New Zealand, which, losing their fiscal character, gradually assume that of a genuinely hereditary sharing of the community in private patrimonies, are already approaching this type of peaceful and legal revolutions.

In all cases, whether these fundamental alterations of the relative preponderance of the different social classes take place in a catastrophic fashion or by peaceful and legal ways, they happen very rarely and at long intervals. Throughout each intervening period, the right of property remains unaltered in its fundamental lines, as they were determined in the past by the economic interest of the class still dominant; the economic process, on the contrary, changes during the period and goes on evolving. On this side again it assumes a certain aspect of independence, which in its turn has remarkably contributed to the blunder into which the founders of historic Materialism have fallen when they proclaimed the "inevitable march" of the economic process.

We have thus three principal ways in which the social action of the different classes is shown, as they are exerted directly on the economic phenomenon, or on the legal phenomenon in general, or on the law 
of property in particular. There is in addition a law which we may call the law of the three consecutive stages of collective action, which shows us that the succession of these different modes of action depends on the gradual increase of the power of the class, which makes it possible for it to pass gradually from the least to the most efficacious system. And finally-we have certain notions, although as yet quite rudimentary, on the different degrees of efficacy with respect to economic phenomena of which each of these three systems of action is capable. These three orders of facts, in combination with the laws which teach us the conditions upon which the relative "weight" of the different classes depends, represent an aggregate of data which already in itself takes us a little way towards the completion of the sociological law of the struggle between classes. This completion is just what we had in view, and it enables us to increase continually our power of prevision with reference to the sociological phenomenality.

Once this system of subsidiary laws completing the principal law is suitably increased and improved, we have in it a valuable guide capable of directing the different classes to the road which will be best for each to follow according to its circumstances and its aims. Then, and only then, the political art, in the highest sense of the word, whether of the men who direct public affairs, or of the élites at the head of the different classes, may rest, as Auguste Comte so ardently desired, on really scientific bases.

To sum up all that has been said, I may conclude by the assertion that in spite of its rather numerous 
exaggerations, and especially in spite of its glaring fundamental contradiction, historic Materialism has played a really great and important part in the progress and development of sociological science. By the fundamental law of the struggle of classes, by the relief in which it has shown the economic motive as a social impulse par excellence, by the importance among all sociological phenomena which it has rightly attributed to the economic phenomenon, which hitherto had been completely misunderstood or neglected, by the active part it attributed to economic phenomena in determining legal phenomena, from whence is derived, although in spite of the founders of the doctrine, the knowledge of the inverse action of legal phenomena upon economic phenomena, and finally by its attempted explanation, with the aid of these few fundamental principles, of the whole present and past sociological phenomenality, historic Materialism has given rise to an imposing system, capable of combining in a single whole, now really deserving of the name of sociological science, the three great disciplines, until then disconnected and independent, which developed unknown to each othereconomics, law, and history. This is enough to assure historic Materialism a distinguished place among the fruitful conceptions of the human mind. 


\section{VIII}

\section{SOCIALISM}

THE historic problem of the causes of the socialist movement of our time may now be said to be solved. Apart from this problem, everything connected with socialism seems to be divided into two fundamental and quite distinct questions - its degree of "probability" and its degree of "superiority" or "inferiority." The former concerns the fact in itself of the advent of the socialist regime, that is, if this advent must be considered as necessary, or probable, or simply possible (or impossible). The latter, which again divides into two questions, closely connected at bottom, is concerned with the less or greater "hedonistic output" and the less or greater "equity" of the future as compared with the present regime. It is clear that nothing can be more different than these two questions of relative probability and relative superiority or inferiority. And the prevalent chaos of opinion is due to the fact that even the most eminent writers on both sides, socialist and anti-socialist, have so often made no distinction between them and have, in fact, treated them as one and the same question.

However, in both questions there is no doubt that the solution will depend on the meaning attached to the 
word "socialism," for perhaps in the whole of economic and sociological science there is hardly any other term so elastic and uncertain in its significance. So I propose in the following pages to examine in their broadest outlines how these questions are presented by the various forms of socialism which now hold the field, and thus to handle the so-called "social question" in its most essential lines as synthetically as possible, with all the objective impartiality of which I am capable.

The social question assumes to-day the typical form of a division of society into two main, antagonistic classes-the wage-earning classes, without the instruments and means of production, and the capitalists. It arose, we may say, with the gradual disappearance of domestic and small industry. This was the consequence of the introduction into the field of economic production of a technical capital incessantly growing larger in proportion to the subsistence-capital, which until then had played an almost exclusive, or at least a preponderating rôle. The substitution of the "machine" for the modest "tool" of other days ultimately led to a more and more notable decrease in the normal value of the daily work of the artisan. This involved his disappearance in economic competition as an independent worker, since he had nothing but his tools and subsistence-capital, and when once his savings were exhausted he was compelled to become a wage-earner in the very manufactories which were his competitors. This disappearance of most of the independent workers, and the suppression of entire social classes (first of all-and perhaps the most important-the hand- 
weavers), this phenomenon, as is known, reached its acute stage in England at the beginning of the last century.

It is the study of the new economic regime as it was developed in Britain more than anywhere else, and the painful revelation of all the poverty of which the coming of this regime was the direct cause, that urged Marx to try to discover the deeply seated " unfairness" which seemed to be part of its very being.

Marx's theory of value implicitly admits as "equitable" only such an economic regime as will guarantee to the worker the whole product of his work. As in the case of the social division of labour no one can consume all the product of his own work, nor at the same time can he do without the labour of others, so the formula will be replaced by the following: All products must be exchanged in proportion to the number of hours of work stored up or crystallized in each of them (always taking into account the intensity and quality of the work), and each will receive in exchange for his own product as much material for consumption as represents in the aggregate the same number of hours of work. From this ideal regime of distribution, arbitrarily chosen as equitable, Marx proposes to prove the " unfairness" of the capitalist regime.

Stress must be laid on the fact that Marx's theory, instead of being a scientific doctrine, impartially seeking the laws regulating the relations between given economic phenomena, is rather an "affective evaluation" of the degree of equity in two systems, one of which is taken as the ideal and the other of which is one to be attacked. 
We know the process of reasoning followed by Marx to show the "usurpation" by the capitalist of his own "profit." The exchange of products or goods in the regime of free competition really takes place, according to Marx, in proportion to the respective quantities of work which are necessary to produce them. One kind of goods alone is not subject to this kind of exchange, and it is "labour-power." While the worker, in fact, gives to the capitalist so many hours of work-those stored up in the goods which the latter exchanges afterwards for others in proportion to this labour-he receives in exchange a living-wage only, no more and no less than is strictly necessary to keep him alive, i.e. rigorously calculated on the "cost of production" of labour-power. But such a sum of "subsistencegoods" represents a quantity of work far less than that which the worker has produced. The value of the difference constitutes a "surplus value" (Mehrwerth), which the capitalist appropriates without giving the worker anything in exchange, and which constitutes the "profit" on his capital.

This theory is based entirely on the erroneous assertion that the goods are exchanged simply in proportion to the respective quantities of labour that they represent. If that were true for goods produced solely by wages-capital, because then capital itself is proportional to the quantity of work produced, it is no longer.so, as Ricardo has clearly shown, when the technical capital (machinery, raw material, etc.) intervenes in unequal proportions with respect to the wages-capital and to the corresponding quantities of work thus put in action. In this case, which nowadays is the commonest of all, 
the profit on the technical capital, the rate of which is measured by that of wages-capital, causes, as we know, the increase of the exchange-values or respective prices of the goods. If Marx himself, in the third and posthumous volume of his Capital, recognized this disturbing action of exchange-value on the fact of technical capital, he attempted to conceal his admission as far as possible in the ambiguous formula according to which goods which have demanded different proportions of technical capital are no longer sold at their value.

Why did Marx fear to recognize openly the truth of facts, i.e. that the profit of the technical capital contributes to the exchange-value of the goods? Why does he attach so much importance to the denial that raising of prices is caused by the profit on the technical capital ? Certainly it is not on this that the equity or non-equity of the profit can depend. The whole difference consists in this: According to Marx, the profit on both capitals -wages-capital and technical capital-is taken from the worker in his quality as producer. According to the contrary theory, if the worker as producer is compelled to surrender only the profit on the wages-capital, it is later as consumer, on account of the rise in price of goods produced by a technical capital, that he has to pay the profit on the technical capital. As each workman is at once producer and consumer, Marx's theory of value in proving the equity or the non-equity of profit has by no means the importance attributed to it by socialists in general and by collectivists in particular.

Even if Marx's theory of value be accepted as true, it would give us no "proof " of the unfairness of profit; 
for a Senior could always object that the surplus value constituting the profit is nothing but the "reward of abstinence" which in equity comes to the capitalist for his function of thrift and accumulation. It little matters that Marx, anticipating this objection, tries to show that the origin of capital, far from being found in labour and abstinence, goes back to the violent usurpation of lands which were already the property of the community. This impure origin-which in part is true-does not prevent capital in its course of continual transformation and increase from arising nowadays, in the normal way, from thrift and accumulation.

The importance attached by Marx and his school to the most rigorous proportionality between the exchangevalue of commodities and the quantity of labour necessary for their production, would be justified if the fact that capital does not contribute to the increase of the exchange-value of commodities signified that capital is of no value to the community. But evidently there is no correlation between the two orders of ideas. It cannot, however, be denied that this was the real reason why Marx's value theory in the eyes of most people seemed to contain a "proof" of the unfairness of profit.

The question from the point of view of "equity" does not consist then in ascertaining in what particular way capital succeeded in levying its profit on the total sum of social production. This concerns the scientific point of view of the analysis of the process of the production and division of wealth, but has nothing in common with the problem of finding out if profit, thus levied 
in one way or another on the annual social fund, is equitable or not.

To solve this question the first step would be to examine if capital is or is not useful. Two cases might be presented, which, although strongly contrasted, would have both led Marx to deny the equity of profit independently of any theory of value. After having established the fact that capital is useless, or even baneful (as, for instance, many economists did not hesitate to maintain during the painful crisis referred to above, in which the whole body of handicraftsmen was thrust into the proletariat), he would have been able ipso facto to infer the unfairness of profit. But even if he had explicitly recognized the utility of capital, and therefore the " equity " of a certain " reward for abstinence," he would still have been able to object that this did not necessarily imply the equity of "profit" in general. For he would still have had to ascertain if such a profit-it being given that it does not concern the person, but the thing in itself as long as the latter lasts and even if this thing is found in other hands than those that originally accumulated it-if this profit, I say, would not eventually exceed that amount strictly necessary and sufficient to give the maximum impulse to thrift and accumulation, or, worse still, if it would not eventually degenerate at last into a mere right of levy on the annual social product conceded to a few privileged individuals, with no reciprocity on their part for any real contribution of service. But Marx, as we know, satisfied by his "proof" of the unfairness of profit based on his theory of value, never dreamed of making an inquiry of this kind. 
At any rate, after having shown in his characteristic way the unfairness of the capitalist regime, Marx does not set himself to sketch, as his predecessors did, those fantastic projects of social reconstruction, which they hope to realize by this or that measure insignificant in itself, but possessing the magical virtues of regeneration; he preferred an extra-judicial inquiry into the direction which by the force of things and not by the will of man the economic process itself inevitably follows.

Hence arises the great distinction drawn by collectivists between the earlier "utopian" socialism and the "scientific" socialism of Marx.

Here then was abandoned the question of the evaluation of the comparative equity of one given regime with respect to another, and was attacked, or rather ought to have been attacked, the purely scientific question of the disinterested examination of the natural laws which regulate the dynamics of economic relations.

But in this connection, in spite of all the appearances in his favour, Marx does not really escape from the utopian socialism which preceded him. For once the equity of a given regime is admitted, he flatters himself that he can compel facts to prove that the present regime, by its simple and more and more unfair development, tends to the ideal regime. From the thesis springs the antithesis, of which will be made the synthesis, in the Hegelian sense.

We all know in what consists the process of capitalist accumulation and concentration, by means of which Marx, by the predominance of the ever larger undertakings which survive their small competitors, has transported into the economic domain that struggle for 
existence and that natural selection of the fittest which Darwin about" the same time was applying to biology. Very laborious, in fact, must have been the growth of modern capitalism in its beginnings, and very deep the impression that the fierce competition by which capitalism strengthened its position must have made upon contemporaries, if the conception of a merciless struggle and an incessant hecatomb of victims could of itself penetrate, simultaneously and independently, the two great theories of the middle of the last century-the one directly and the other, thanks to the work of Malthus, indirectly - and that, too, in such a way as to seem to be the pivot of the whole of biological and economic evolution!

Capitalist concentration carried to its furthest limits will lead, as Marx prophesied, to a concentration of the whole of production into the hands of a very few capitalist magnates. At that point, it will suffice to burst, by way of revolutionary expropriation on the part of the proletariat, the fragile capitalist wrappings, in order to obtain and to install immediately the new and already matured collectivist regime.

Although, with the exception of the catastrophic conception which brings it to a close, this is the most masterly part of the work of Marx, and although, as in the case of the trusts of later days, some of his predictions have come true, it cannot however be said that on the whole his predictions resist the objective examination of facts, and in particular of such facts as have been developed since his time.

The numerous data placed at our disposal by more and more improved systems of economic statistics, 
their elaboration by the two opposed camps and the polemics they have provoked in dissidents even of the socialist camp, such as Kautsky and Bernstein, now enable us to make two definite statements. In the first place, if one cannot deny a certain tendency on the part of the great productive enterprises to increase still further, and to be concentrated in more and more gigantic trusts, it is not however universal, and, on the contrary, in many spheres of industry small and ordinary sized businesses still successfully resist the encroachment of their powerful competitors. In the second place, it must be recognized that to this concentration of "enterprises" there is not always a parallel correspondence in a concentration of " property," for partnership makes a certain division of the latter compatible with the former. At any rate, the concentration of productive enterprises and of the property of capital does not take place equally everywhere, as it must if at the right moment the capitalist mould is to be broken at one blow, and the collectivist regime to be at once installed in its entirety. On the other hand, we cannot conceive of revolutionary expropriation repeated more than once, first of all of the more "concentrated" enterprises, in the serene expectation that the others also will reach the requisite degree of concentration before being in their turn expropriated without compensation. And finally, the relative powers of the capitalist class which is to be expropriated and of the wage-earning class which would expropriate it do not, in fact, as we shall later see, tend to become such as to allow of a revolutionary act of this nature and of such gravity. 
Of the collectivist theory there remains, from the practical point of view, nothing but the concept and the tendency to entrust to the community (State, province, commune) the carrying on of certain industries which are at once monopolies and public services. But it would be a great illusion to suppose that we can see in this even the minutest beginning of realization for the catastrophe predicted by Marx. There is here no trace of revolutionary expropriation, but a gradual transformation proceeding by way of expropriation with complete compensation. This compensation and the capital necessary for the carrying on of the enterprise can be procured nowadays only by means of credit. It is enough to show that such a process must be widely limited in its action, that it must entirely lose its political character and become a purely technical question regarding the administrative capacity of the public authorities and the economic advantage of the whole community, a question to which different answers will be received in each particular case.

It would therefore be useless to waste time in dealing even briefly with the question of the "hedonistic output " of the collectivist regime, as presented in Schäfle's classic exposition. The collectivists adopted certain arguments to establish the superiority of a unitary organization of the whole of production, in comparison with the present anarchy of individualistic production and free competition (for which, moreover, the cartels and trusts of to-day have tried to find a partial remedy). To these arguments the partisans of liberty replied, with Paul Leroy-Beaulieu at the head, by first denying 
the very possibility of such a regime, and by setting forth in each case the beneficent effects of the private initiative and competition which stimulates as compared with the inertia and dilatory measures which have made bureaucracy proverbial, and, in general, by insisting on the incapacity shown by the State and public authorities in carrying on direct production.

The collectivists replied that in the question of " hedonistic output" is included, not only the question of economic productivity in the absolute sense, but the other question which looks to a better division of wealth, seeing that by equality of economic production the "hedonistic output" increases for the whole of society in proportion as the division of wealth is less unequal.

The liberals were nevertheless justified in retorting, here also with Paul Leroy-Beaulieu, and especially with Spencer, that a limitation of each individual liberty-the menace of which was necessarily implied in a regime in which the State imperiously disposed of all the human forces of labour, and became the producer of all the goods of consumption, both material and intellectual-must be counted so serious a hedonistic loss that no material advantage can make up for it.

But it would be idle, as I have said, to dwell at length on these controversies, in spite of the great echo they awakened in the past, for the very good reason that the pure and genuine collectivist regime is itself relegated henceforth by the socialists themselves to the limbo of utopias.

It will be more to the point to give a very rapid 
summary of the other socialisms before and after Marx, seeing that all, it may be said-just as it has been the case with collectivism in regard to the socialization of the public services above mentioned-have left in their wreckage some vital residue, and that it is of all these vital residues that the complex socialism of to-day is to a large extent composed.

Thus, for instance, in "co-operative socialism" the illusion of Buchez and Louis Blanc as to the irresistible force of self-expansion which they attributed to co-operation of production quickly vanished, and the economic blunder of Proudhon and Lassalle, as to the supposed capacity attributed to credit of creating capital, was easily unmasked. But there yet remained the fruitful and living idea of co-operation of production, agricultural and industrial, and advances of capital by which the State can come to its aid and give an impulse-by rural banks, banks for co-operatives, labour banks - which the different States are already tending more and more to create and support.

The same is true of the "agrarian" or "landed" socialism of Wallace and George.

The proposal of Wallace, Darwin's illustrious rival, of nationalizing the land, was based, as we know, on the Ricardo theory of rent. This indeed enabled Wallace to affirm that the differential rents should belong to the community alone, being the exclusive product of the unequal generosity with which Nature had endowed the various types of land with her "indestructible forces." But it was easy to object that, at bottom, there was no reason to give to land 
a place apart and privileged among all the other instruments and means of production.

If land, in fact, still perhaps represents the most important class of instruments of production as compared with any other single class, it henceforth represents, in the countries most advanced from the economic point of view, but a very small and daily decreasing fraction of the total value of the instruments of production and of capital in general.

If, on the other hand, it is true that the untilled surface of cultivable land was made by no one, the same is true of the land on which a factory stands; but the land as well as the factory had to absorb very notable quantities of human labour and capital before reaching its present productive capacity.

And if the different types of land represent different degrees of fertility, these are now, just as in manufactories, which in the same industry have a variable technical efficiency, " acquired" qualitative differences which are much more important now than the primordial natural differences.

But even though the land, unlike other instruments of production, always owed its productive capacity and its qualitative differences to Nature rather than to human labour, it is right to remark that the present proprietors of the soil, if not in England at any rate on the Continent, have become so by purchase, and that therefore, from the positive legal point of view as well as that of abstract equity, they do not differ from the proprietors of capital. It would not be " equitable," therefore, even from the socialist point of view, to subject the former to some form of expropriation 
without compensation, if it were not thought that the same treatment should be meted out to the rest.

George, on the contrary, as we also know, turned his attention rather to the rent of the surface or site, which was a differential rent by the same title as Ricardo's, but which was produced, in fact, independently of all labour or assistance on the part of the occupant, and which, in rapidly growing large towns for instance, is continually increasing and often attains fabulous dimensions.

The vital part of Wallace's socialism is the principle of retaining as collective property not only all forests and cultivable land already belonging to the State, the province, or the commune, or capable of becoming such, and letting them out on lease to private contractors or to rural co-operative societies, but also all new mines, all waterfalls utilizable as sources of powerin fact, all the new natural forces capable of producing in any manner a Ricardian rent. Of George's socialism, in an attenuated form there remains the principle of devolution to the community of all " unearned increment " of urban areas due to the growth of population, the analogous principle of the "betterment tax" for all surplus value of urban estates due to public work undertaken by the communes, and the tendency to preserve as collective property the ground obtained by pulling down old parts of towns, and the new urban estates built on this ground, so as to compensate the whole community, in short, in some way or other, for the injury that each of its non-property-holding members suffers individually from the fact of all these increased values of the urban area. 
On the contrary, it does not seem to me that we can preserve any vital remainder or draw any practical applications from the agrarian "integral" socialism advocated by Loria, in opposition to the agrarian "partial" socialism of Wallace and George, which, in his opinion, would " for ever eliminate not only the rent of the land but also the profit on the capital, i.e. would destroy once for all the whole structure of the capitalist economy."

In his studies of the English colonies in America and Australia, Loria was greatly struck by the fact that the capitalists who emigrated thither could not, even by the offer of the highest wages, succeed in retaining the services of the workers they required, because the latter went off to the still virgin and unoccupied lands of these new and fertile countries, where they were attracted by the possibility of becoming independent cultivators of the soil.

The British economists had already observed and commented on this phenomenon, but they had implicitly held that it was peculiar to that part of the world and to that moment, corresponding to the beginning of modern colonies. It was Loria's great and unchallenged merit to have widened the reach of this phenomenon in space and time.

Here, in fact, he has seen the principal cause of slavery in ancient and modern times (with the negroes in the American colonies and the deported convicts from the mother country in Australia) because, as long as portions of land remain unoccupied and free, coercion is the only way by which capital can obtain workers and make its profit. On the other hand, in the increas- 
ing density of population, and in the consequent and ever-increasing difficulty of the labourer to reach the free land, and there to obtain by his work alone his means of livelihood, he recognized the cause of the gradual mitigation of slavery, itself replaced, first by serfdom and then by the wage system. That is the best and the really scientific part of Loria's work.

But he thought he saw in a return to free land the solution of the social question. Let the capitalists, said he, accumulate and keep their capital ; if you give the worker the "right to the land" it will be impossible for them to draw the slightest profit from their capital. In fact, between the worker who has the virtual right to betake himself at his free will to the free land on which he can work for his own advantage, and the capitalist who supplies all the capital required, there can be established, to prevent the worker from enjoying his virtual right to the soil, only the "mixed association" on absolutely equal terms, i.e. capitalist and labourer, both alike working, share the produce in proportion to the quantity of work that each has furnished.

I need not dwell on the "unfairness in the other direction" of a similar system in which the capitalist, even if he were to accumulate fresh capital, could no longer receive the smallest reward for abstinence. I shall no longer insist on the absolute impossibility of conceiving how the State could in our old and densely peopled countries guarantee to each his "imprescriptible right to the soil," i.e. his claim to plant himself, according to his pleasure and when he felt the need, upon a morsel of land, or "land unit," as our author calls it, sufficient to maintain him by his own work, 
even if he have no other capital. I will rather dwell for a moment on Loria's statement that the present regime tends inevitably to restore such a regime of free land.

He foresees, in fact, that antagonistic interests, developing in the midst of the present economic regime, will lead to a complicated system of reciprocal productive limitation for the different categories of the production of wealth, and therefore to a general economic depression, and to a permanent land crisis which will "launch upon the market a continual supply of parcels of depreciated land." So that "free land" will reappear and the State will only have to sanction, by its "prescriptible right to the land," a state of things already established in fact and of itself inevitable.

This is Marx over again. Seduced by the mirage of a regime of equity, which in his opinion must be established spontaneously at the beginning of all society, when most of the land is still free and fertile, Loria has also flattered himself that he can compel the facts to prove that the present regime, by its very iniquities, must lead us anew to a regime of equity, like that of the original State. But it must be recognized that, while for the catastrophe conceived by Marx a whole series of facts, the tendency to capitalist accumulation and concentration, could really be presented in support, no fact, on the contrary, seems to me to support a return to a regime of free land. This appears to me the least successful and the most unsound part of the whole of Loria's work.

While all these more or less theoretical socialisms 
were being elaborated, the fact on which even the purest materialist fatalists had counted, beginning with Marx, namely, the continuous increase of relative class power recognized in the proletariat, seemed to tend to be realized.

The proletarization of the whole body of handicraftsmen on the first invasion of modern capitalism had made the interests of the immense mass of workers economically homogeneous, all being equally reduced henceforth to wage-earning, and all being deprived of every instrument and of the other indispensable means of labour. At the same time, the crowding together of more and more considerable masses of working men in the factories led to common understanding and agreement, and to their rapid awakening to a collective class conscience. To this a little later was added, on the one hand, a raising of their intellectual level owing to compulsory elementary education, and to technical instruction, both demanded by the capitalist class itself as a condition necessary for the introduction of ever more complex and delicate productive-technical improvements, and, on the other hand, the increase of the economic power of the wage-earning class. In fact, given the great number of its members, the even modest increase of individual wages, at least of certain groups among them, obtained by the first unions which sprung spontaneously from the massing together of the men, had for its result a notable increase of the economic power of the class as a whole. So that we see that the proletariat has now the means of subsidizing a complete staff of its own employés, whose sole function is to organize and direct the movemen 
to the advantage of the common demands. Finally. in our own time the wonderful development of every means of transmission of thought has favoured, for purposes of collective understanding and concerted action, the poor and numerous classes more than the others.

Such were the multiple and simultaneous causes which, together with the weakening of the religious sentiment predisposing from all antiquity to obedience, had thus contributed to foment the spirit of demand in the working classes and to give them, as a social class, greater and greater weight.

That is why the postulates of the other socialisms, of which I have yet to give a very short account, and which we can classify in the two great categories of " reformist" and "legal" socialism, have more or less partially found, or can find, their practical realization.

Many reforms, in fact, recommended by Christian socialism, both evangelical and catholic, by "professorial " socialism, by State socialism, have already received, and will continue more and more rapidly to receive, legislative sanction. That sanction is the only means of imposing upon all employers, without prejudicing them individually, certain measures which, if taken only by some of these employers, would leave each of them, on the contrary, in an unfair position with respect to his competitors. Thus the laws forbidding night work, or limiting the hours of day work for women and children, and even for adult men in certain industries and in certain countries, compulsory holidays, measures taken to cope with the unhealthi- 
ness of certain industries, measures of prevention of accidents, insurance against accidents and professional diseases and against all diseases in general, old-age pensions, regulations for the internal discipline of factories, and the institution of arbitration tending to secure the peaceful settlement of disputes and to guarantee greater equity in the relations between the workmen and their employers, etc.-these, it may be said, are at present the sole form of socialism in the way of practical realization.

But a question arises whether this pressure on the part of the proletariat can go on for long within the limits of these reforms, all of which are undoubtedly useful (although sometimes exposed to countervailing economic checks which may turn them to the disadvantage of the class they are to benefit), but which are very modest measures compared with the " complete emancipation" with which the working man was dazzled at the dawn of the socialist movement; or rather if the very power of the proletariat, ever increasing, will not urge it to adopt in place of the present "reformist" socialism that " legal " socialism which aims at securing, by legislative means, profound modifications in the present form of the rights of property.

The complex right of property may be considered from both the legal and economic aspect-according to Sumner Maine and Adolphe Wagner respectivelyas a "bundle" or a "sum" of particular rights or powers, distinct from each other, and such that each may be separately enjoyed. And of all these rights, those in particular attacked by the different kinds of "legal" socialism, from the most radical to the most 
moderate, have always been the right of inheriting and the right of disposing of property by testament.

They come into conflict especially with the concept of equity, in the form it has gradually assumed in our time, which is summed up by the formula so dear to orthodox liberal economists, "to each according to his work and deserts." And the more so, add the "legal" socialists, because, thanks to the transformation into profit-bearing capital of all goods of consumption or products in general from the first moment of their accumulation, the rights of inheriting and leaving property by will no longer invest the heir with the free disposal of a limited quantity of commodities, previously produced and not consumed by his own father, but rather with a right of levying every year and for an infinite time, with no real personal service in return, a portion of the commodities of consumption incessantly renewed and due to the work of others. At the same time, the rights of inheriting and of disposing by testament appear to "legal" socialists as the greatest obstacle to that socialization of capitals which they consider indispensable to guarantee to the worker the free and gratuitous disposal of the instruments and means necessary for his work.

On the other hand, it is an undeniable fact that the rights of inheriting and of disposing by testament constitute in these days the most powerful if not the only stimulus to work, thrift, and the indispensable and profitable accumulation of ever fresh capital. And it is just such a consideration as this that has always caused the failure, even from the theoretical point of 
view, of every proposal, as, for instance, that of the school of Saint-Simon, of a pure and simple abolition of these rights.

"Legal " socialism, therefore, is always seen compelled to defend intermediary transformations. Thus De Laveleye and Wagner are content with simple death duties, proportional or progressive according to the size of the patrimony, to be applied to the gradual nationalization of the land or the gradual municipalization of urban estates. John Stuart Mill, who in certain ways may be considered as a "legal" socialist, preferred to retain the right of disposing by will of the whole of the patrimony, but to suppress the right of inheriting a patrimony beyond a certain restricted limit of size. He thus had in view a greater equalization of private fortunes, and he desired to prevent great hereditary estates from encouraging idleness, and, may I add, from dissuading from that later accumulation and capitalization of the respective revenues, which, because of the very size of the patrimony inherited, in most cases becomes quite useless and is therefore completely neglected. Huet would allow the man who accumulated wealth a complete and absolute right to leave it by will, but he would not allow the heir to dispose of his inheritance, which came back of right to the State; but the State should afterwards, according to this writer, lease out as private property these thus nationalized patrimonies, by distributing them in accordance with certain equitable principles. In his land nationalization schemes Wallace proposed that the annuities paid by the State to each landlord for the redemption of the natural Ricardian rent (quit-rent), which, as Wallace said, he had always 
unfairly enjoyed, should still be paid to such heirs as were born at the date of the passing of the law, so that no person should be disappointed of such hopes as had hitherto been legitimatized by the State: but that they would cease immediately on the death of those heirs.

Here I may be permitted to recall my proposal of a levy "progressive in time" made by the State on successions. It took the form of a moderate levy on patrimonies arising from labour and personal thrift, but would increase rapidly for the different portions of patrimony hereditarily acquired by the dead, by the fact that for each of these portions the tax would be heavier in proportion to the number of hereditary transmissions through which each patrimonial portion had already passed. Naturally the different patrimonial portions would be considered only from the quantitative point of view of the total sum of their value, and not distinguished according to the nature of their employment, which might at every moment undergo the most various transformations. I have called these taxes "progressive in time" because they would increase no longer in proportion to the size of the estate, but, on the average, according to the time which had respectively elapsed since the beginning of the accumulation of each of these different patrimonial shares.

The object in view in such a modification of the law of property was that of constituting a gradual and continuously operative process of reduction into collective property of private capitals, not only of those already accumulated in the past, but of those also continually being formed, and of further securing, accord- 
ing to the rate of progression adopted, a more or less considerable rapidity of that process of socialization which the complex circumstances of the moment, political or economic, rendered the most appropriate. Besides, this would be a greater stimulus to thrift and the incessant accumulation of new capitals than the present unlimited testamentary right, by this very faculty left to the testator of disposing much more freely of the property amassed by his own labour and deserts than of the property that he had merely inherited. In this way the law of property thus modified would constitute what may be called (from analogy with patents which assure property in inventions for a certain period of time) a " patent of accumulation and capitalization," limited to the period of time rigorously necessary and sufficient to constitute the greatest stimulus to labour and thrift. ${ }^{\mathrm{I}}$

As we have seen, there are plenty of transformations of the law of property-and here I have mentioned only some of the most characteristic-adaptable to the realization on a vast scale of that nationalization of private capital which socialism in general, more or less explicitly or implicitly, has always deemed indispensable to the effective emancipation of a great part at least of the present proletariat. More than a socialism in itself, "legal" socialism is therefore presented as the system capable of furnishing to the various

× Vide E. Rignano, Un socialisme en harmonie avec la doctrine écono. mique libérale, Paris, Giard et Brière, I904 ; Italian edition, Torino, Bocca, IgoI, ch. $\mathrm{ii}$ and $\mathrm{iii}$; and the two little propaganda pamphlets, by the same author, La question de l'héritage, Paris, Soc. Nouv. de. libr. et d'édit, I905, and Generationenfolge und Pragression in der Erbschaftssteuer, and edition, Berlin, Wigand, rgog. 
systems of socialism mentioned above the means of practical realization of such of their elements as, under the test of facts, have shown some vitality. Credit for productive co-operation, agricultural or industrial, by means of suitable "Labour Banks"; the nationalization or municipalization of undertakings which are public services and have the nature of monopolies; the passing into the domain of the State of cultivable land to be let on lease to private employers or rural co-operative societies; the transformation into common property of urban estates; the redemption of the public debts of the States, of provinces, and of communes, and the substitution of revenues for our present taxes-the two last items being the most important desiderata of orthodox economy itself: not one of these reforms can have a ghost of a possible chance of development on broad and solid foundations if the State is not first of all provided with the means of carrying them into effect.

"Legal" socialism is, however, presented as a complete antithesis to "collectivist" socialism, thanks to its "liberal" aspect. For it would invest the State with no coercive function, but only with that of providing, by appropriate independent organs, an increasing number of workers with the means indispensable to their work, thus freeing them from their present dependence on the private possessors of capital. So that by thus facilitating as far as possible the spontaneous association and co-operation of labour, it would result in a still greater development of the "free-contract" system of to-day.

Finally, "legal" socialism clearly is presented not 
as a new regime to which we are led by the irresistible development of the present economic process, but as a radical reform of the law of property, of which the realization depends only on the conscious action of that social class which more than any other will gain thereby an economic advantage.

Hence the whole question reduces to discovering, as I have said above, if the proletariat is really increasing its class power with respect to the opposing class, and continuing to have greater and more weight as a social factor, and, such being the case, if it will then be able in the future as at present to be content with that pressure exercised on what we call social legislation, or if it will not rather turn and converge its efforts on " legal" socialism itself.

To the second question we can but reply that historic Materialism teaches us how each social class, once it has attained to power or to a decisive and preponderating superiority over all the other classes hitherto alone the dominating classes, has always shown a tendency to modify in its own favour the law of property, as the most efficacious and the best adapted means of satisfying promptly its own economic interests. And so there remains only the first question, that is, if the proletariat is really increasing incessantly its own class-power relative to that of the capitalist class.

Marx saw in the "economic homogeneity" of the wage-earning class, at present without means of production, and also in their continual numerical increase, the great power of the proletariat. But he attributed the whole of the weakness of the 
capitalist class to the constant diminution in the number of its members, finally to be reduced to a few magnates, the sole people in whose hands all capital will remain.

Now it is not at all true, in fact, that the ranks of the capitalist class have been thinned, or that they show any more and more marked tendency to become so. Statistics rather show us that the number of capitalists, in so far as they are individuals enjoying any revenue from capital, is increasing not only absolutely but more than relatively to the population. The base of the capitalist pyramid is broadening instead of narrowing.

What has contributed and is contributing sensibly to this phenomenon is the new intermediate class of small, average, and large "employés" which capitalism itself, by the development given to great private undertakings and to the action of public bodies, has substituted in part for that of the old independent artisans who have now almost disappeared, and partly to the other class of small and average capitalist-employers whose number and importance have really diminished, at least relatively. This "bureaucratic" class has largely profited, for its thrift, from the above-mentioned division of the capitalist property made compatible, thanks to the joint-stock companies, with the greater and greater concentration of undertakings. In its turn, the considerable development of State loans, together with provincial and communal loans, in consequence of the increased action of these public bodies, has likewise greatly favoured this diffusion of small and moderate savings among the "bureaucratic" class. 
Of this new middle class; whose members, in addition to the wages received for their own work, enjoy the income arising from the investment of their savings, as well as of that of the "free professions," which from this point of view is analogous, the socialist party must take account in its "maximum programme," if it is not to find in it an implacable adversary instead of a valuable and powerful ally.

Now, not only is the basis of the capitalist class broadening, but there is a notable, almost hypertrophic, increase of its mass of wealth, especially in the higher strata. It is impossible that this fact should not increase and go on increasing the classpower. On the contrary, as an intrinsic and deeply seated cause of great weakness, itself alone perhaps more powerful than all the other favourable causes put together, one may point to its " economic heterogeneity," which brings it about that instead of finding ourselves in the presence of a single class, we meet with a multitude of sub-classes of the most varied and more or less antagonistic interests : landed property on the one hand and industrial commercial property on the other; protectionist manufacturers whose interests are opposed to those of tradesmen who advocate free-trade; high finance of speculation in conflict with productive industry; capitalist employers and capitalist holders of stock; manufacturers of one class against those of another; stockholders deriving their incomes respectively from different sources; small capitalists against average, and average against great capitalists, etc. We know how the proletariat has not lost its opportunity of 
profiting by this intra-capitalist antagonism, and how it makes one conquest after another by utilizing the aid of one or other of these sub-classes.

At the same time, the proletariat, which has already outstripped in number all the other social classes put together, has not yet ceased also to grow, as we have seen, in its economic class power. The rapid progress of social legislation which goes on under the steady pressure of an organized proletariat shows clearly enough that for the latter a continuous increase of power is a fact.

A new cause of weakness, however, is now arising for the proletariat, exactly analogous to that which we have now seen to be so menacing to the capitalist class, that is, the loss of its own "economic homogeneity." Side by side with certain categories of workmen who have of late years received considerable increases of wages, are other categories who continue to receive the old famine rates of pay; and between these two extremes are all possible degrees; and in the same way there exist all possible degrees in the hours and other conditions of work. Similarly, side by side with the "skilled" labourers in certain of the great industries, men of increasingly high level of professional education, there are others who have remained quite "unskilled" in other sorts of production. So that never perhaps more than now are the technical heterogeneity and the diversity of the surrounding conditions of the different industries more reflected in the economic and intellectual conditions of the respective workmen. At the same time, owing to the fact that wages nowadays follow closely, under the pressure 
of the working masses, the favourable conditions of their industries, it already sometimes happens that in the field of economic antagonisms the interests of the wage-earners and of their capitalist employers are often so bound together that sometimes the working masses are dragged into an economic conflict between different undertakings in the same industry or between different industries. Further, to the interests of the workers or employés of the State and all public bodies, whose increase of wages may be covered only by the taxes, are opposed those of the workers in private enterprises, which, wholly or partly, directly or indirectly, have to bear these taxes. Even more notable is the fact that from the great mass of 'wage-earners has already more than once been detached on certain questions the small fraction of workers labouring in co-operative societies. Side by side with labourers who are producing commodities of prime necessity there is a daily increase in the number of workers producing commodities which are luxuries, and of men who are serving the rich classes directly, and both the latter categories would find a decrease in the demand for their work were there too sudden a drop in the economic power of the capitalist class. Finally, the modest savings of certain classes of workmen, cleverly encouraged by the capitalist class by the facilities offered for small savings, already form a bond of union between the proletarian élite and the class of small capitalists. Let us remember in this connection the biting satire of Richter on the victorious counter-revolution on the very morrow of the expropriation and socialization of all the private capital that a triumphant 
socialism had carried out, a counter-revolution arising from the protest of the small depositors in the savings banks.

This " heterogeneity" has already had as one effect that we have often to deal with many proletarian parties rather than with a single socialist party. It may even be said that it is permanently reflected in the fundamental split between the revolutionary syndicalists and the reformist socialists. The former, for the most part consisting of the working masses who have profited less than their brethren by " social legislation," reproach the others that their " minimum programme" does not represent the slightest step forward towards the "maximum programme" of socialization of the instruments and means of production, the sole reform necessary, they say, which at the same time and appreciably will profit the whole of the proletariat without distinction. But they still cling to the old discredited doctrine of the Marxian catastrophe, that a revolutionary tempest can install the new regime in twenty-four hours.

It seems, therefore, that if the possibility still exists of blending the whole proletariat into one party, this can only happen if a " medium programme," serving as a point of departure for the maximum, should build up again in the desideratum common to the whole proletariat the old and now threatened "homogeneity." I

If I have dwelt at such length on these considera-

- Eugenio Rignano, Partito socialista unico o partiti proletari molteplici? "Riforma Sociale," Torino, year XII, fasc. 8; ditto, Per un programma medio, "Critica Sociale," Milano, year XIV, n. I0. 
tions-a longer development of which will be found in my previously quoted volume-it is for the purpose of showing more clearly that the question as to the coming or non-coming of socialism and its eventual form, that question so interesting even from the purely scientific point of view, must be regarded with respect to the equilibrium and the resultant of various social. forces, according to their respective "weights" and economic interests, and not from the "fatalistic" aspect of the irresistible tendency of the mechanical process of economic evolution.

This "fatalistic" conception breaks down when facts are impartially examined. In the preceding essay I have already had occasion to remark the fundamental contradiction in which the historic Materialism of Marx and his disciples is struggling, which announces on the one hand that the class struggle is the arbiter and the maker of history, while at the same time it bases the whole of social evolution on the blind play of purely economic phenomena.

One great merit of the fatalistic socialism of Marx has undoubtedly been that it has so powerfully aided the historical school to modify radically the views of the classic economics on the immutability of economic laws and relations, and that it has furthered the most, ardent study of the succession of the different social regimes by going back to the remotest antiquity or to the beginnings of new modern colonies.

On the other hand, a great merit of the "legal" socialism has been that it also contributed to the radical modification of the metaphysical concept of a " natural law," absolute and immutable, from which Spencer 
himself in his Justice could not get free. It is sufficient here to recall the works of Sumner Maine and De Laveleye, the most suggestive perhaps of all in the presentation of the great variety of the past forms of law, and therefore in proving the great variability of which all law in general and that of property in particular is susceptible. Nor must we forget the applications which from John Stuart Mill to Adolphe Wagner have been made of the utilitarianism of Bentham even to the law of property, according to which the greatest social utility of this law, and of one or other of its particular forms, may alone constitute, according to the time and the circumstances, its justification and its relative "equity."

But, I repeat, neither the simple evolutionism of the " fatalist" economist nor the simple legal evolutionism (which claims to predict the tendency of future transformations of law from those of the past) can by themselves, and without the detailed analysis of present society in the different social classes, suffice to indicate to us even vaguely the future of that society.

In every case, whatever may be this more or less unknown future, we can at least, as a conclusion from all that I have said, affirm one fact which is of good omen. It is that the awakening of a collective conscience in the class less favoured by fate, a class which constitutes so large and hitherto so disparaged a portion of our fellow-creatures, has in itself enlarged and improved the whole of the social conscience; while the increased power of that class has already rendered less unequal the different social forces in conflict. The result is a 
greater social sensitiveness to the pain and suffering under which innumerable human beings are still groaning, and the formation of a new and supreme ideal of greater equity. So that we may now hope that whatever be the final issue of the shock of future antagonisms, humanity may cast away its dread of foundering in still deeper abysms, and that in all confidence and security it may ascend to loftier heights and happier destinies. 


\section{INDEX OF AUTHORS CITED}

Abercrombie, $136 n$.

Allen, Grant, 162 n.

Allonnes, R. d', ro7 n., $123 n$.

Azam, 149

Bain, II7n., II9, I20 n., I $33 n$.

Baldwin, 129

Bentham, 249

Bernard, Claude, 22, 72, 85, 104

Bernstein, 225

Binet, 134 n.

Blanc, Louis, 228

Born, 68, 69

Buchez, 228

Buckle, 167

Butler, S., 50, ro5

Carpenter, $\times 37 n$.

Castle, v. Davenport

Channing, I77n.

Ciamician, 78, 88

Comte, 175, $21_{4}$

Cope, 50

Cuvier, 29

Dallinger, ror

Darwin, C., 30, 69

Darwin, F., 2x, 63, 105

Davenport, 102 n., ro3 $n$.

De Vries, 33, 46, 66

Duhem, 176

Durkheim, 25

Eimer, 47
Engelmann, 85

Engels, 195

Espinas, 157

Flechsig, 8r, 106

Foucart, $152 n ., 154 n$.

Frazer, $162 n$.

Galton, 32, 34, 4I, 66, II 5,157

Garten, 6I, 62

Gennep, Van, 16r

George, 228

Giard, I09, I I $n$., I I I $n$.

Goblet d'Alviella, $162 n$.

Guyau, r69 $n$.

Haberlandt, 2 I

Haeckel, 50

Hering, 50, 7I, 72, 81, 105

Hertwig, 72, 83

Hertz, 85

Höffding, 25, $187 n$.

Hubert, 162

Hume, 152

James, 123, 129, x30 $n$.

Janet, $\mathbf{I}_{4} 8$

Jennings, 91, 99, I31

Kautsky, 225

Kidd, 38, 167 n., 178,179

Lamarck, 28, 29, 37 et seq., 97, 156 
Lange, 123

Lassalle, 228

Laveleye, De, 238, 249

Lécaillon, I Io $n$.

Lehmann, 113

Leroy-Beaulieu, 226, 227

Letourneau, I66 n., $169 n$.

Loeb, 40

Loria, 190, 201, 231

Lubbock, $167 \mathrm{n}$.

Luther, 197

Macario, 149

Mach, 72, 86, 89, $131 \mathrm{n}$.

Maine, Sumner, 160, 236, 249

Malthus; 224

Marx, 38, 189, 218 et seq.

Maudsley, 73, 124, $133 n$.

Maupas, 86

Maury, 138

Mauss, I62

Maxwell, Clerk, Io

Mendel, 4I, 66

Mesnel, 149

Meumann, $123 n$.

Mill, J. S., 183,185 n., 187 n., 238,249

Morgan, Lloyd, $107 n$., I I I $n$.

Müller, F., 50

Müller, G. E., II 3

Müller, J., 7x, 72

Nägeli, 47

Neal, $102 n$.

Orr, 50

Ostwald, 86 et seq., $127 n$.

Pareto, 198

Pfeffer, 60

Piéron, 93 n., $103 n$.
Pillon, 112, I13n.

Proudhon, 228

Quinton, 99

Reinach, S., 159 n., I60

Renan, 167 n., 177 n., 197

Rendal, 125

Ribot, 95, 97, 107 n., 112, 116 , $118 n$., I19n., I20 n., 122, 125 , 126 n., $127 n$., $133,134 n$, 136 n., 137

Ricardo, 228

Roux, 38, 68, 69, 94 n., 195

Schāffle, 226

Schiff, 9I

Schneider, $94 n$.

Schopenhauer, 96

Semon, 50, 105

Senior, 221

Sergi, 123

Sherrington, 106, 107n., 122 n., I 29

Spencer, H., 46, 86, II $4 n$., 118 n., 120 n., 152, $165 n$., $167 n ., 195,202,227,248$

Stahl, $102 n$.

Stout, 122

Taine, 147,176

Tylor, 25

Valli, $187 n$.

Verworn, 77

Wagner, A., 236, 238, 248

Wallace, A. R., 228

Webb, S. and B., 209

Weismann, 33, 34, 46, 66, 180, $18 \mathrm{I}$ Wundt, 73 


\section{INDEX OF SUBJECTS}

Adaptations, Ior

Assimilation, 22, 82

Association, limitation of, $8 \mathrm{I}$

"Behaviour" of organisms, 90

Biogenesis, 50

Calendar, functions of, 162

Capacity factor, 74

Capital, Marx on, 218

Catalysis, 86

Centro - epigenetic hypothesis, 54

Consciousness, c. v,

Continuity, of germ plasm, 34

Double personality, 152

Emotions, 12I

Energy, mnemic property of nervous, 70

Evolution, c. ii

Experiment, ro

Finalism, 22, 130

Germ-plasm, continuity of, 34

Indecision, 125

Land, 229: ownership of, 193
Levy, progression in time, 239

Love, maternal, 109

Manchester School, 202

Materialism, historic, c. vii

Mathematics, I1, 12

Maturation, 42, 69

Memory, c. iii

Neo-Darwinism, 31, 181

Neo-Lamarckism, $3^{1}$

Nervions, 75

Pain, 12I

Particulate inheritance, 32

Physiologists and psychologists,

24

Pleasure, 121

Property, law of, 210

Psychologists and physiologists, 24

Recapitulation, 50

Religion, c. vi

Reproduction, sexual, 40

Selection, natural, 32, 46

Self-preservation, 119

Sexual instinct, 94

Sin, 160

Socialism, c. viii

"Sweating," 210 


\section{ESSAYS IN SCIENTIFIC SYNTHESIS}

Symbiosis, 109

Synapsis, $6 \dot{9}$

Synthesis, and Evolution Theory, c. ii

Taboo, 160

Tendencies, the affective, c. iv Theory, in science, c. i
Transference, of affective tendencies, 97

Vitalism, 17

War, I7I

"Weights" of classes, 196

"Will," the potential factor in vital energy, 78,121 

This book is DUE on the last date stamped below

JAN 201938

FEB 241954

For'm L-9-35m-8, 28 
AA 0000208363

$$
\begin{gathered}
B 3 \\
3636 \\
\text { R4E7 }
\end{gathered}
$$


